The use and experience of an audit \& feedback cycle when implementing a clinical practice guideline in specialist mental health care in Norway.

A qualitative case study

\author{
Monica Stolt Pedersen \\ Norwegian National Advisory Unit on Concurrent Substance \\ Abuse and Mental Health Disorders \\ Innlandet Hospital Trust \\ (O) Innlandet Hospital Trust
}

Dissertation for the degree of Philosophiae Doctor (PhD)

Faculty of Medicine

University of Oslo

Oslo 2021

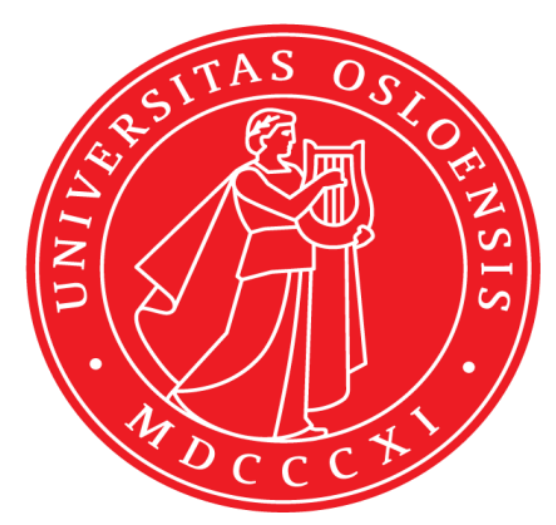


(C) Monica Stolt Pedersen, 2021

Series of dissertations submitted to the Faculty of Medicine, University of Oslo

ISBN 978-82-8377-909-7

All rights reserved. No part of this publication may be reproduced or transmitted, in any form or by any means, without permission.

Cover: Hanne Baadsgaard Utigard.

Print production: Reprosentralen, University of Oslo. 


\section{Meningen}

Meningen

er ikke for én og én av oss,

ikke for deg eller meg.

Det faller mye rå mørtel

på steinene i grunnmuren,

mye sulk og søppel,

før katedralens idé

syner seg i pilastre og strebebuer.

Hans Børli

(gjengitt med tillatelse fra Beathe Børli Karterud) 



\section{Acknowledgements}

To indulge oneself to a Phd-project and doctoral thesis is by no means a one-woman's job! Without the knowledge, patience, helpfulness, understanding, intellect and kindness of people around me, this would not have been possible.

First, and foremost I would like to express my sincere gratitude to my two supervisors, Professor Lars Lien and Professor Anne Landheim at the Norwegian National Advisory Unit on Concurrent Substance Abuse and Mental Health Disorders at Innlandet Hospital Trust. Lars, always a marvelous project leader, calm, encouraging, humorous and pushing the work forward. Anne, always kind, seeing the bigger picture, making sure that everything is connected and the details are in place. Without the encouragement, endurance, resourcefulness, cleverness, knowledge and not least, the patience and kindness you both have shown - this would not have been achievable. You persevered when the road was bumpy. You believed in the project and me when I lost sight. I will forever hold you in my heart with deep appreciation.

I am sincerely grateful to the collaborators in the project; to the hospital and the DPC in particular for letting me learn about the everyday life in the clinic. You welcomed me with openness, information, thoughts and reflections. You are the gold of this thesis! A particular appreciation to Merete Møller, who organised the A\&F and paved the way to data gathering, and contributing when needed. Always cheerful, knowledgeable, and helpful. Kari Kjønsberg, thank you for bringing experience and sensitivity into the focus group interviews. As a comoderator you were indispensable, and as a co-traveler you brought joy to the journey.

Thank you to University of Oslo, Faculty of Medicine, Institute for clinical medicine for enrolling me to the doctoral program. I have learned a lot and had the privilege to take excellent courses.

I am grateful for the opportunity to be a $\mathrm{PhD}$-fellow and most grateful to Innlandet Hospital Trust for financing this $\mathrm{PhD}$-project. In addition to finances, there has been amounts of practical and human support, and in particular, I would like to express my gratitude to alwayshelpful Kari Lillehaug at the research department. My colleges at the Research department, with Director Ingeborg Hartz in front, thank you for always showing the bigger picture of research and for good companionship. 
Fellow PhD students, Hanne, Bjørn, Helge, Henning, Arne Jan, Anne, Eva and Susmita without you, life as a $\mathrm{PhD}$ student would be much gloomier. Thank you for listening, for sharing, for wise discussions and comments, and for all the wonderful talks and laughter. In particular, I would like to express my appreciation to Hanne Kilen Stuen and Bjørn Stensrud for giving me valuable insight into qualitative research methods and philosophy.

A huge thank you goes to all my inspiring, competent, supporting and wonderful colleagues at Innlandet Hospital Trust. Norwegian National Advisory Unit on Concurrent Substance Abuse and Mental Health Disorders, thank you for nice lunches, enlightening conversations and lots of help and support. Center for Psychology of Religion, my home away from home, has been the starting point and ending place for this PhD. Thank you in particular to Professor Lars Danbolt for initiating the mere thought of a PhD and the birth of the project. Without you, I would not ever have thought of the possibility. To my colleagues Sigrid Helene, Knut and Tor Arne for inspiring and insightful conversations, joyful lunches, and cheering. A special appreciation to Sigrid Helene Kjørven Haug for insightful conversations on practice and qualitative methods, and for encouragement and assistance. And to the librarians, Liv-Elin Hansen, Hanne Rustlie, Lina Melketiene, Elin Undeli and Urd Hertzberg: Thank you for being my excellent librarians these years. You always inspire me to be a better medical librarian!

Thank you to my mother Sigrund Stolt, my father Harald Pedersen who sadly passed in July 2021, and to my sister and brother, Nina Stolt Larsen and Bjarne Christian Pedersen, for your support and always believing in me. Thank you to Cecilie Nilsen and Elin Opheim, for support, laughter, vacations, discussions and friendship that far surpasses a thesis. Thank you BTC for get-togethers, exercise and champagne. I am a rich woman! For that, I owe a thank you to everyone who contributes to this wealth; my dear friends and family. This thesis has left me less social than usual - I can only say; I will be back!

To Øystein, the footing and platform in my life, and Øyvor and Idunn, our marvelous and beloved daughters; without your support and encouragement, this would not have been possible. Moreover not worth it. You did not necessarily make the journey easier, but you placed the perspectives. For that, I love you to the moon and back - thank you!

Hamar, 27. September 2021 


\section{Contents}

Acknowledgements..................................................................................................................................... i

Summary of the thesis................................................................................................................ vi

Sammendrag ................................................................................................................. ix

Abbreviations.................................................................................................................................... xii

Tables and figures .............................................................................................................................. xiii

List of publications .............................................................................................................................. xiv

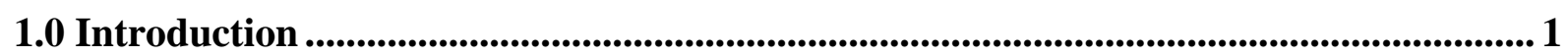

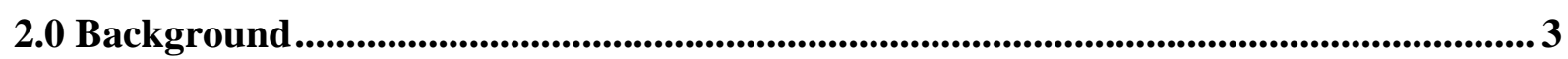

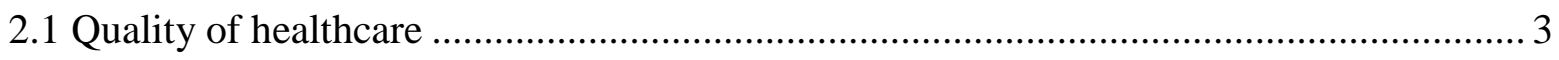

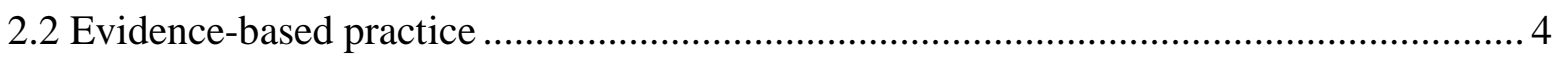

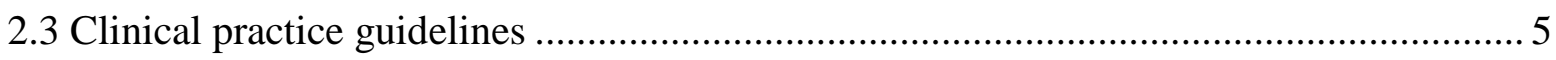

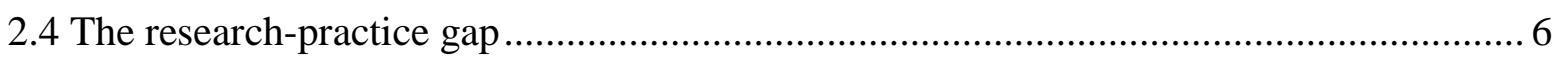

2.5 Implementation and implementation research........................................................ 7

2.5.1 The role of leadership in implementation ............................................................

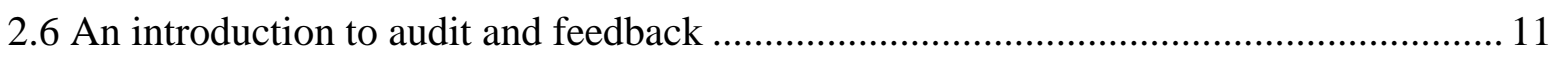

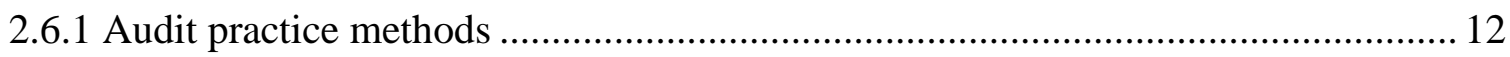

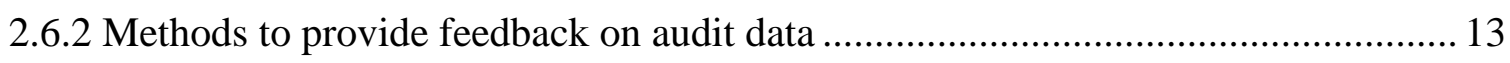

2.6.3 Audit and feedback as a cyclic process............................................................... 14

2.6.4 The effect of audit and feedback as an implementation strategy ............................ 15

3.0 Literature review ............................................................................................................. 16

3.1 Searching for qualitative studies on audit and feedback ............................................... 16

3.2 Knowledge status of qualitative research on audit and feedback .................................... 18

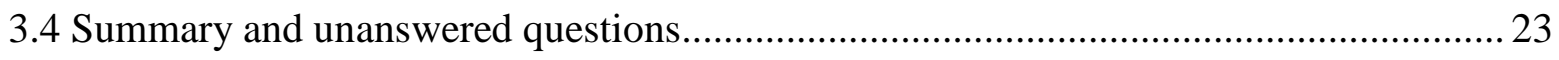

4.0 Aims and research questions ............................................................................................... 25

5.0 Materials and methods................................................................................................................ 26

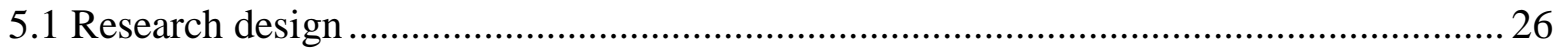

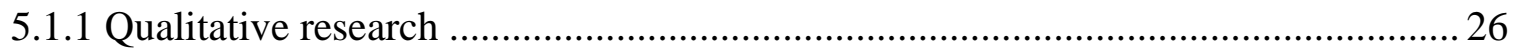

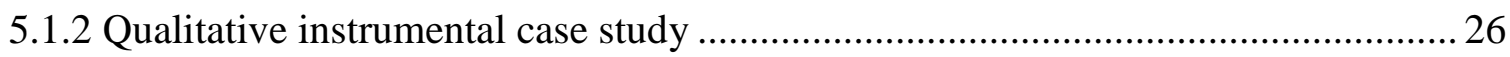

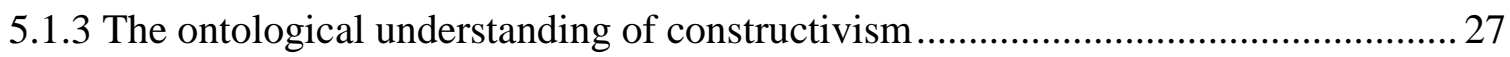

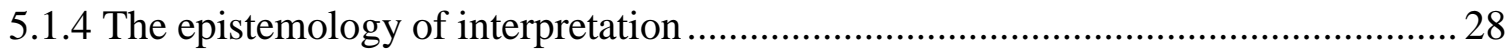

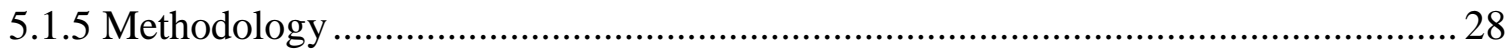

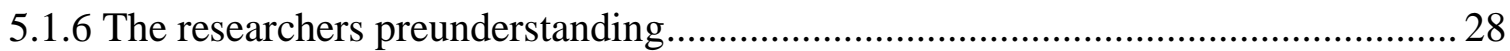


5.2 The outer context and object of implementation

5.2.1 Persons with concurrent substance use disorders and mental disorders and the mental health care system they relate to in Norway ....

5.2.2 The National Guideline for the assessment, treatment and social rehabilitation of persons with concurrent substance use disorders and mental disorders ......................... 32

5.2.3 Tools developed to ease the implementation of the National Guideline ................. 33

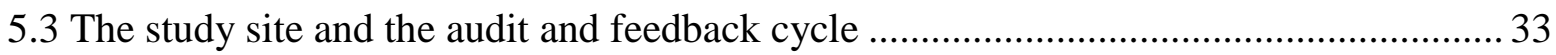

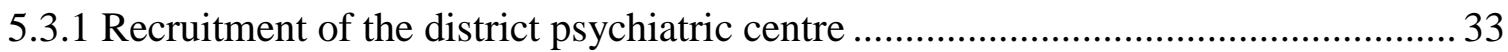

5.3.2 Description of the district psychiatric centre (the study site) .................................. 34

5.3.3 Description of the A\&F cycle conducted at the district psychiatric centre .............. 35

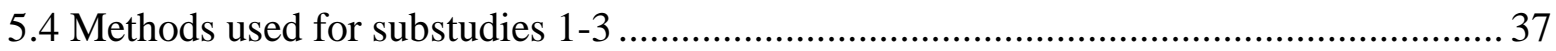

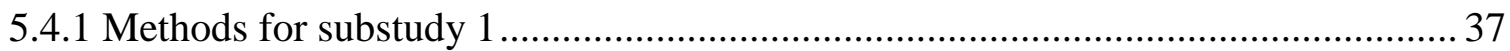

5.4.1.1 Recruitment and description of the participants ............................................. 37

5.4.1.2 Observations of the quality improvement team meetings ................................ 38

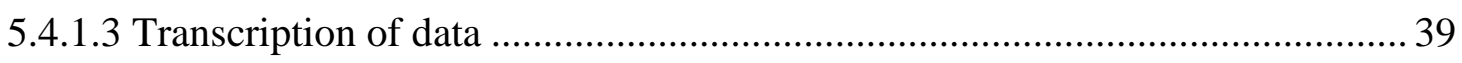

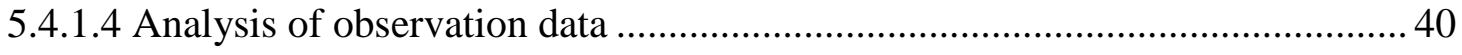

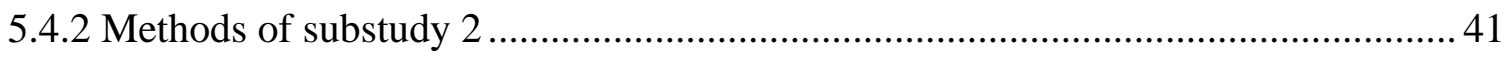

5.4.2.1 Recruitment and description of the participants ........................................... 41

5.4.2.2 Developing an interview guide for the focus group interviews ...................... 42

5.4.2.3 Focus group interviews of staff members .................................................. 43

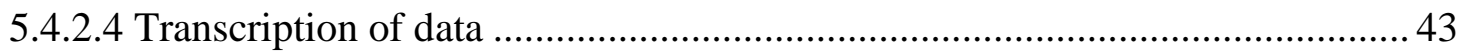

5.4.2.5 Analysis of focus group interview data ...................................................... 44

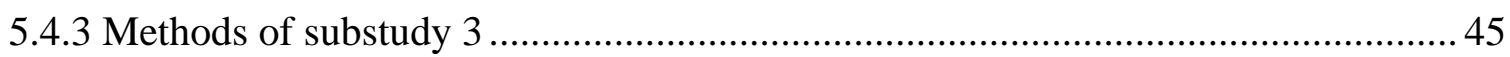

5.4.3.1 Recruitment and description of participants............................................... 45

5.4.3.2 Developing an interview guide for the individual interviews ......................... 45

5.4.3.3 Individual interviews of the first-line managers ........................................... 46

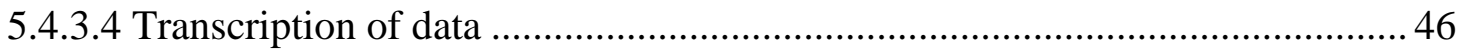

5.4.3.5 Analysis of the individual interview data..................................................... 47

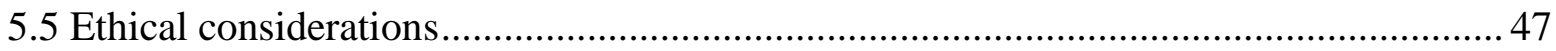

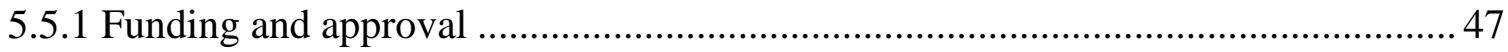

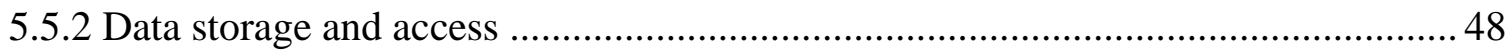

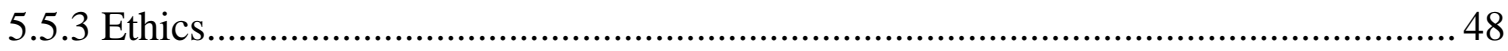

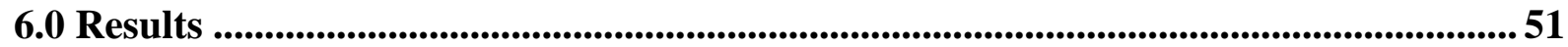


6.1 Paper 1: Acting on audit and feedback: A qualitative instrumental case study on mental

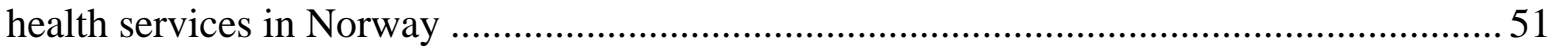

6.2 Paper 2: Audit and feedback in mental healthcare: Staff experiences ........................... 52

6.3 Paper 3: First-line managers' experience of the use of an audit and feedback cycle in specialist mental health care: A qualitative case study ....................................................... 53

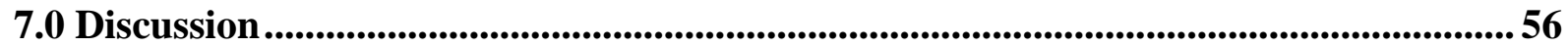

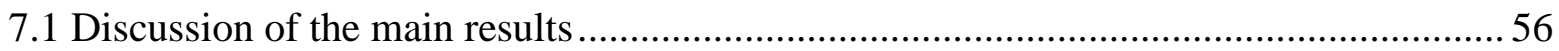

7.1.1 An A\&F cycle creates an opportunity for open and sharing practice ......................56

7.1.2 Attitudes to and knowledge of EBP and information competency as barriers to A\&F

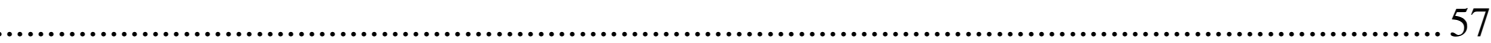

7.1.3 Disclaiming responsibility and limited leadership throughout the A\&F cycle........ 59

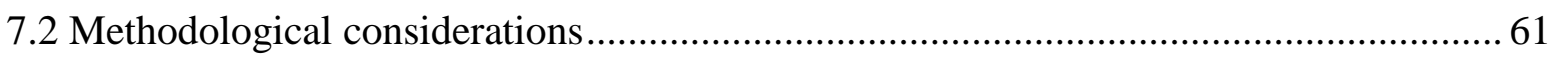

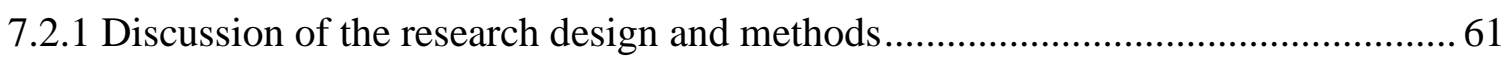

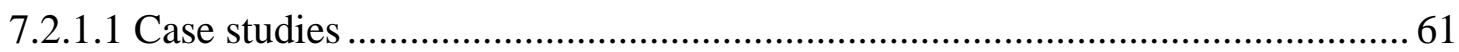

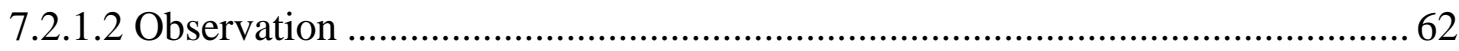

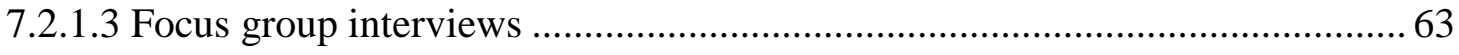

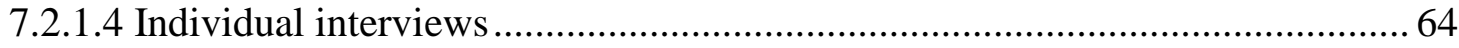

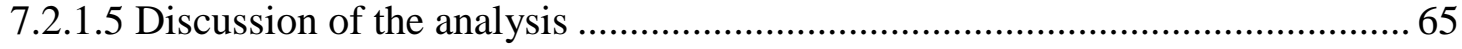

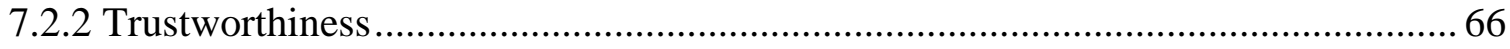

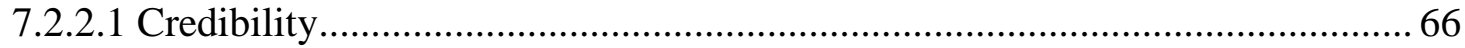

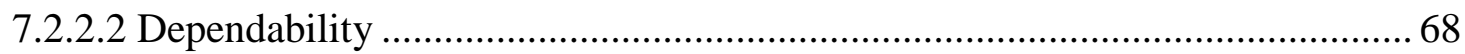

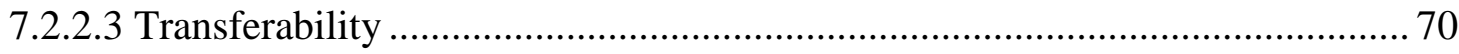

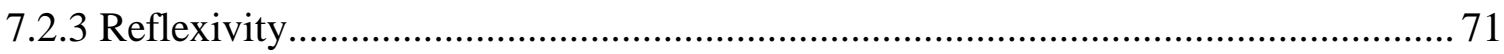

8.0 Conclusions and implications for practice ............................................................. 73

9.0 Implications for further research .......................................................................................... 75

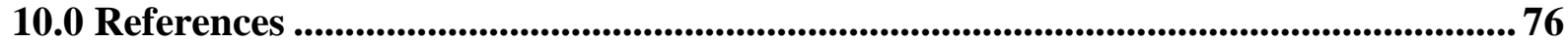

\section{Paper 1-3}

\section{Appendix}




\section{Summary of the thesis}

Clinical practice guidelines (CPGs) specify a desired clinical practice. To use CPGs may achieve high quality services and evidence-based practice (EBP). CPGs are not necessarily easily adopted. Implementation research are needed to optimise the use of CPGs. A widely used implementation strategy is audit and feedback (A\&F). It involves developing clinical performance summaries (audit) and providing those summaries (feedback) to practitioners, teams or organisations. A\&F can be a circular process were reflecting on results, agreeing on improvement and developing improvement plans are essential components. A\&F gives "small but potentially important improvements in professional practice", although its effects on practice and quality of care vary. We therefore need more knowledge on why and when it works best. The aim of this study was to add to the knowledge of the use and experience of an A\&F cycle in a District psychiatric center (DPC) in Norway in order to help optimise its design and use.

"The National Guideline for Assessment, Treatment and Social Rehabilitation of Persons with Concurrent Substance Use Disorders and Mental Disorders" was launched in 2012 together with A\&F tools to assist its implementation. This thesis has a qualitative design where the implementation of this particular CPG in one DPC in Norway employing an A\&F cycle was used as a case. Observation of QI team meetings, focus group interviews of staffs and individual interviews of first-line managers were conducted to describe and explore their experience and use of the $A \& F$ cycle.

The main findings from observations of QI team meetings was that they contributed to awareness of the CPG and to discussions of best practice. When CPGs arrives, self-reported audits seem valuable as an implementation strategy. Completing action forms resulted in new tasks and responsibilities and forced reconsiderations. It also brought forth discussions on lack of knowledge, sources of knowledge and where to seek new knowledge. The A\&F thus contributed to the recognition of lack of information competence. The observations uncovered that registered nurses and social educators turned to the consultants regarding all kinds of questions concerning clinical knowledge. A CPG alone is not enough to solve researchpractice gaps in the treatment of persons with concurrent substance use disorders and mental disorders. The A\&F raised the awareness of these patients, the complexity of the illness and the system of care. The A\&F turned out to be important to clarify the patients' needs in a local context and at a micro level as it illuminated the consequences for each unit, for individuals' 
everyday work and in relation to the broader health care system with which the staff must cooperate.

The main finding from focus group interview was that staffs viewed $A \& F$ as valuable to reveal areas requiring improvements. It also confirmed good practice and highlighted competencies hidden in everyday practice. The staff experienced increased awareness and a greater sense of responsibility towards the particular CPG and patients addressed, but agreed that an $A \& F$ had to be part of a larger process, an A\&F cycle, to be valuable. However, they felt being alone in the process; no one took full responsibility for following up on decided actions. An initial enthusiasm fizzled out and led to a lack of attention to the A\&F cycle. Reminder functions and a process facilitator were among the suggested improvements. The staff felt that there was a never-ending flow of guidelines, procedures and projects from organisational and national bodies. They felt a lack of prioritisation and not being given enough time to become good at something. These deficiencies caused a sense of nonownership of the A\&F cycle despite the fact that staff were invited to participate through QI team meetings.

Interviews with the first-line managers found a positive attitude towards $A \& F$ and they saw it as their responsibility to ensure that the cycle was completed and facilitated. Nonetheless, administrative daily tasks left little room for the A\&F cycle and focus slowly faded. They experienced lack of support from the upper management and requested stronger organisational focus and more involvement from the Research and development (R\&D) nurses and the staff. However, they gave the R\&D nurses little responsibility and made little use of the QI teams after the initial phase. The first-line managers considered the A\&F cycle to be a top-down process, despite invitation to participate and engagement in several introductory meetings. They also felt being flooded with initiatives (such as CPGs and organisational procedures) from superior authorities and saw them more as directives than as decision aids for QI. They perceived that upper-level management or issuing bodies did not understand the daily life in a busy clinic. Additionally, the roles of the first-line managers and the psychiatrist could be complex with different view on how to run the units and decisions taken. The first-line managers seemed to define themselves as part of the staff rather than as unit managers.

A key message from this case study is that $A \& F$ is experienced as useful. Limited organisational support and capacity to respond effectively to A\&F partly limited its accomplishment and impact. Stronger links between EBP, information competency and A\&F 
could lead to greater understanding and autonomy amongst staffs and enhance ownership of the whole A\&F cycle, and thus its effect as an implementation strategy to enhance the use of CPGs in mental health care. This suggests a stronger focus on implementation leadership focusing on communicating why A\&F is important, how it works with EBP, and QI skills. Conducting research in naturally occurring processes is challenging, but important, to learn more about the use and experiences of $A \& F$. A\&F is only one strategy of many, and can never be detached from its context and the broader field of QI. However, the importance of seeing the whole must never diminish the value of learning from the parts. 


\section{Sammendrag}

Nasjonale retningslinjer gir råd og anbefalinger til heletjenesten og befolkningen. Å bruke retningslinjer kan bidra til tjenester av høy kvalitet og kunnskapsbasert praksis (KBP). Retningslinjer er ikke nødvendigvis enkel å ta i bruk i praksis og implementeringsforskning er nødvendig for å optimalisere bruken. En mye brukt implementeringsstrategi er audit og feedback, eller gap-undersøkelser. De måler praksis med utgangspunkt i en standard (f.eks. en retningslinje) og gir tilbakemelding om resultatene til individer, team eller organisasjoner. Gap-undersøkelser kan være en sirkulær prosess der man reflekterer over resultatene, blir enige om forbedringer og utvikler handlingsplaner. Gap-undersøkelser gir "små, men potensielt viktige forbedringer i profesjonell praksis", selv om effekten på praksis og tjenestekvalitet varierer. Vi trenger derfor mer kunnskap om hvorfor og når gap-undersøkelser fungerer best. Målet med denne studien var å øke kunnskapen om bruk og erfaring av en gapundersøkelsessyklus i et distriktspsykiatrisk senter (DPS) i Norge. Det er for å bidra til å optimalisere design og bruk av gap-undersøkelser.

"Nasjonal faglig retningslinje for utredning, behandling og oppfølging av personer med samtidig ruslidelse og psykisk lidelse - ROP-lidelser" ble lansert i 2012 sammen med gapundersøkelses-verktøy for bidra til implementering. Denne studien har et kvalitativt design der implementering av denne spesifikke retningslinja i et DPS i Norge som bruker en gapundersøkelses-syklus ble brukt som et case. Observasjon av forbedringsmøter, fokusgruppeintervjuer med personalet og individuelle intervjuer av førstelinjeledere ble gjennomført for å beskrive og utforske deres erfaring med og bruk av verktøyet.

Hovedfunnene fra observasjoner av forbedringsmøtene var at de bidro til bevissthet om retningslinjer og til diskusjon om god praksis. Når retningslinjer lanseres, er gapundersøkelser verdifullt som implementeringsstrategi. Utfylling av forbedringsskjemaer resulterte i nye oppgaver og ansvar og nye vurdering måtte gjøres. Det førte også til diskusjoner om mangel på kunnskap, kunnskapskilder og hvor man kan søke ny kunnskap. Gap-unders økelser bidro dermed til kunnskap om mangel på informasjonskompetanse. Observasjonene avdekket at sykepleiere og vernepleiere henvendte seg til legene om alle slags spørsmål vedrørende praksis. En retningslinje er ikke nok alene til å tette gapet mellom forskning og praksis når det gjelder behandling av personer med ROP-lidelser. Gapundersøkelser $\varnothing k$ te bevisstheten omkring pasientgruppen, kompleksiteten i sykdommen og helsetjenesten. Gap-undersøkelser viste seg å være viktig for å klargjøre pasientenes behov i 
en lokal kontekst og på et mikronivå ettersom det belyste konsekvensene for hver enhet, for enkeltpersoners daglige arbeid og i forhold til det bredere helsevesenet som personalet må samarbeide med.

Hovedfunnet fra fokusgruppeintervjuet var at personalet så på gap-undersøkelser som verdifullt for å avdekke områder som krever forbedringer. Det bekreftet også god praksis og fremhevet kompetanser som kunne være skjult i daglig praksis. Personalet opplevde $\varnothing \mathrm{kt}$ bevissthet og større ansvarsfølelse overfor denne retningslinja og pasientgruppa, men var enige om at en gap-undersøkelse måtte være en del av en større prosess, en gapundersøkelses-syklus, for å være verdifull. Imidlertid følte de seg alene i prosessen der ingen tok det fulle ansvaret for å følge opp besluttede tiltak. Entusiasmen som ble vist i begynnelsen av prosessen ebbet ut som følge av mangel på oppmerksomhet om gap-undersøkelsen i organisasjonen. Påminnere og en prosessleder var blant de foreslåtte forbedringene. Personalet følte at det var en uendelig strøm av retningslinjer, prosedyrer og prosjekter fra organisasjonen og nasjonale organer. De følte på manglende prioriteringer og at de aldri fikk nok tid til å bli gode på noe. Disse tingen førte til mangel på eierskap til gap-undersøkelsen til tross for at personalet ble invitert til å delta gjennom forbedringsmøtene.

Intervjuer med førstelinjeledere fant en positiv holdning til gap-undersøkelser, og de så det som sitt ansvar å sikre at prosessen ble tilrettelagt og fullført. Imidlertid etterlot administrative daglige oppgaver lite rom for gap-undersøkelser og fokuset forsvant. De opplevde mangel på støtte fra den $\emptyset$ verste ledelsen og ba om sterkere organisasjonsfokus og mer engasjement fra fagutviklingssykepleierne og personalet. Imidlertid ga de fagutviklingssykepleierne lite ansvar og brukte forbedringsteamene lite etter den første fasen. Førstelinjeledere anså etter hvert gapundersøkelses-syklusen for å være en top-down-prosess, til tross for invitasjon til å delta og deltakelse i flere innledende møter. De følte også at de ble oversvømt av tiltak og krav (som retningslinjer og prosedyrer) fra overordnede myndigheter og så på disse mer som direktiver enn som hjelpemidler for kvalitetsforbedring. De oppfattet at ledelsen på høyere nivåer eller utstedende organer ikke forsto dagliglivet i en travel klinikk. Førstelinjeledere kunne synes å definere seg selv som en del av personalet i stedet for som enhetsledere. I tillegg kan rollene mellom førstelinjeledere og fagledelsen være komplekse med ulike syn på hvordan enhetene skal drives og beslutninger som tas.

Et viktig funn fra denne casestudien er at gap-undersøkelser oppleves som nyttige og verdifulle. Begrenset organisatorisk støtte og gjennomføring av gap-undersøkelses-syklusen begrenset delvis resultatene og effekten. Sterkere koblinger mellom KBP, 
informasjonskompetanse og gap-unders $\varnothing$ kelser kan føre til større forståelse og autonomi blant ansatte og $\varnothing$ ke eierskapet til hele syklusen, og dermed $\emptyset \mathrm{ke}$ effekten som en implementeringsstrategi for å forbedre bruken av retningslinjer i psykisk helsevern. Dette peker mot sterkere implementeringsledelse med fokus på å kommunisere hvorfor gapundersøkelser er viktig, hvordan det fungerer sammen med KBP og kvalitetsforbedringsferdigheter.

Å drive forskning i naturlig prosesser er utfordrende, men viktig, for å lære mer om bruk av og erfaringer med A\&F. A\&F er bare en strategi av mange. Den kan ikke skilles ut fra sin kontekst og det bredere feltet kvalitetsforbedring. Imidlertid må viktigheten av å se helheten aldri redusere verdien av å lære av delene. 
Abbreviations

$\begin{array}{ll}\text { A\&F } & \text { Audit and Feedback } \\ \text { CPG } & \text { Clinical Practice Guideline } \\ \text { CRT } & \text { Crisis Resolution Team (an outpatient emergency team) } \\ \text { DPC } & \begin{array}{l}\text { District Psychiatric Centre (in international literature sometimes } \\ \text { called CMHC - Community Mental Health Centre) }\end{array} \\ \text { EBP } & \text { Evidence-Based Practice } \\ \text { GP } & \text { General Practitioner } \\ \text { QI } & \text { Quality Improvement } \\ \text { R\&D (personnel/nurses) } & \begin{array}{l}\text { Research and Development personnel/nurses } \\ \text { TA }\end{array} \\ \text { The Advisory Unit } & \begin{array}{l}\text { National Advisory Unit on Concurrent Substance Abuse and } \\ \text { Mental Health Disorders }\end{array} \\ \text { The National Guideline } & \begin{array}{l}\text { Re National Guideline for Assessment, Treatment and Social } \\ \text { Disorders and Mental Disorders }\end{array} \\ \text { TSB } & \begin{array}{l}\text { Interdisciplinary specialised substance abuse treatment } \\ \text { departments }\end{array}\end{array}$




\section{Tables and figures}

Table 1: $\quad$ Participants in the QI team meetings with number of teams and meetings per unit

Table 2: $\quad$ QI teams and focus groups: (a) QI teams and total members from each unit, (b) focus groups participants and how many participated in the QI teams one year earlier, and (c) educational background

Figure 1: An illustration of the Boolean literature search

Figure 2: An illustration of the A\&F cycle (the case) with study description 


\section{List of publications}

\section{Paper 1}

Pedersen, M. S., Landheim, A., Møller, M., \& Lien, L. (2018). Acting on audit \& feedback: A qualitative instrumental case study in mental health services in Norway. BMC Health Services Research, 18, 1-11. doi:10.1186/s12913-018-2862-y

\section{Paper 2}

Pedersen, M. S., Landheim, A., Møller, M., \& Lien, L. (2018). Audit and feedback in mental healthcare: staff experiences. International Journal of Health Care Quality Assurance, 31(7), 822-833. doi:10.1108/IJHCQA-08-2017-0142

\section{Paper 3}

Pedersen, M. S., Landheim, A., Møller, M., \& Lien, L. (2019). First-line managers' experience of the use of audit and feedback cycle in specialist mental health care: A qualitative case study. Archives of Psychiatric Nursing, 33(6), 103-109.

doi:10.1016/j.apnu.2019.10.009 


\subsection{Introduction}

The overall aim of this study is to add to the knowledge of the use and experience of an audit and feedback (A\&F) cycle in a district psychiatric centre (DPC) in Norway using a qualitative instrumental case study within the field of implementation research. A naturally occurring quality improvement (QI) process in a DPC was used as the case. Different phases of the A\&F cycle are described and explored as part of the process of implementing a clinical practice guideline $(\mathrm{CPG})$.

One of several ways to contribute to high quality services and evidence-based practice (EBP) in health care is to follow CPGs. CPGs summarise clinical evidence applicable to health care practices, supplemented by expert consensus, to specify a desired clinical practice. They may offer clinical recommendations, decision aids and QI and implementation plans (Brownson, Colditz, \& Proctor, 2017, p. 387). Despite broad agreement on their importance, CPGs are not necessarily easily accepted or adopted in clinical practice (Sheldon, Cullum, Dawson, Lankshear, Lowson, Watt, West, Wright, \& Wright, 2004). Implementation strategies are needed to facilitate the use of CPGs. One of several implementation strategies are A\&F, which is aimed at health care professionals and used for a variety of interventions. It involves developing clinical performance summaries (audit) over a specific period, and subsequently providing those summaries (feedback) to individual practitioners, teams or health care organisations (Brehaut \& Eva, 2012). A\&F is commonly the basis for QI or implementation projects, and can be described as a circular process, an audit cycle or an A\&F cycle (Burgess, 2011; Dixon \& Pearce, 2011; Potter, Fuller, \& Ferris, 2010). Reflecting on results, agreeing on where improvement is needed and producing an improvement plan are essential components of the process. It is popular as an implementation strategy and gives "small but potentially important improvements in professional practice" (Ivers, Grimshaw, Jamtvedt, Flottorp, O'Brien, French, Young, \& Odgaard-Jensen, 2014), although its effects vary (Ivers, Jamtvedt, Flottorp, Young, Odgaard-Jensen, French, O'Brien, Johansen, Grimshaw, \& Oxman, 2012; Ivers, Sales, Colquhoun, Michie, Foy, Francis, \& Grimshaw, 2014).

The CPG implemented in this study was "The National Guideline for Assessment, Treatment and Social Rehabilitation of Persons with Concurrent Substance Use Disorders and Mental Disorders" (the researcher's translation from Norwegian Directorate of Health, 2012) (hereafter the National Guideline). The National Advisory Unit on Concurrent Substance Abuse and Mental Health Disorders (hereafter the Advisory Unit) developed implementation 
tools to assist in implementing the National Guideline. The main strategy aimed at DPCs involves the use of standard electronic audit questionnaires mirroring the recommendations in the National Guideline (Advisory Unit, 2013) in combination with action forms to structure the implementation process and provide instructions on how to proceed, forming an A\&F cycle.

In this thesis, the implementation of the National Guideline in one DPC is used as an instrumental case. This is done to gain knowledge of how an A\&F cycle is used and experienced by professionals in specialist mental health services in Norway. The process is examined from different angles and at different times. This thesis seeks to contribute to the knowledge of A\&F cycles in general and in specialist mental health care in particular. 


\subsection{Background}

This section places the overall aim of the thesis in a broader context and provides conceptual clarifications and a theoretical framework. These clarifications and frameworks are considered essential to understand the results of the thesis, representing its points of departure. Malterud (2016) described using theory as a background and an inspiration, which is the ambition in this thesis.

\subsection{Quality of healthcare}

Providing high quality care is the ultimate goal of Norwegian national health care services (Meld. St. 11 (2020-2021), 2020). Consequently, there is a need to explore the concept of health care quality. There are several definitions of the quality of healthcare, as described by Busse and colleagues (2019), spanning the last few decades from Donabedian in 1980 to the World Health Organization (WHO) in 2018. In 2000, Campbell and colleagues (2000) defined quality of health care on the basis of access and effectiveness, separating definitions pertaining to an individual patient and a population. For populations they defined quality as "the ability to access effective care on an efficient and equitable basis for the optimisation of health benefit/well-being for the whole population". About a decade later, the European Commission stated that "[good quality care is] health care that is effective, safe and responds to the needs and preference of patients" (Busse et al., 2019). In 2018, the WHO said that "[quality] health services across the world should be Effective: providing evidence-based health care services to those who need them, Safe: avoiding harm to people for whom the care is intended, People-centred: providing care that responds to individual preferences, needs and values" (Busse et al., 2019, p. 7). The latter two definitions focus on three main dimensions of quality: effectiveness, safety and responsiveness (or patient-centeredness). Quality health care is widely defined, not easily obtained or measured and calls for continuous work to improve quality when health care is not functioning optimally.

QI has been defined as "the combined and unceasing efforts of everyone--healthcare professionals, patients and their families, researchers, payers, planners and educators-to make the changes that will lead to better patient outcomes (health), better system performance (care) and better professional development”, involving testing and learning in a dynamic, wide-ranging and ongoing process (Banerjee, Stanton, Lemer, \& Marshall, 2012). While QI seeks to obtain measurable changes in processes of care and outcomes, implementation science studies the incorporation of evidence to practice and the use of specific tools, 
methods, frameworks, and study designs to achieve their goals within a local setting (Kao, 2014). The next section examines EBP as a way of thinking about incorporating research to practice to ensure good quality health care.

\subsection{Evidence-based practice}

The term "Evidence-based Medicine" was established in the 1990-s by researcher at MacMaster University and was introduced as a new paradigm (Evidence-Based Medicine Working Group, 1992). This term, and (partly) this way of thinking are based on the work of Archie Cochrane in the 1970, the establishing of the Cochrane Collaboration and rigorous research summaries based on randomised controlled trials (Cochrane Collaboration, 2013). In 1996, the paper "Evidence based medicine: What it is and what it isn't" defined evidencebased medicine as "the conscientious, explicit, and judicious use of current best evidence in making decisions about the care of individual patients" (Sackett, Rosenberg, Gray, Haynes, \& Richardson, 1996). The definitions has since evolved, particularly to include patient preferences and values, and to be more specific about the use of research. Further, the use of evidence-based medicine expanded to include other health disciplines; the term EBP is now used to embrace both medicine and a wider range of health care practices (Albarqouni, Hoffmann, Straus, Olsen, Young, Ilic, Shaneyfelt, Haynes, Guyatt, \& Glasziou, 2018). One definition of EBP is "to make professional decisions based on systematically acquired research-based knowledge, experience-based knowledge and the patient's wishes and needs in a given situation" (Nortvedt, 2007). This definition is widely accepted and also used by the Norwegian Electronic Health Library (2016) and is therefore used in this thesis.

EBP can be understood as a method of working, learning to reflect on one's practice, asking good questions, searching for relevant literature, critically assessing the literature found and applying this knowledge to practice and by evaluating practice (McHugh \& Barlow, 2012; Nortvedt, 2007; Norwegian Electronic Health Library, 2016). The underlying idea is that by using summarised knowledge, patient knowledge and preferences and clinical experience from the field of practice, we may improve the quality of health care. This means ensuring that the best knowledge forms the basis for decisions on patient treatment and care, ensuring trustworthy evidence for health care personnel and patients, and aiming for the same basis for decisions to be used by all clinicians. The incorporation of EBP is an essential element for improving patient safety, quality of care, and disease outcomes (Melnyk \& Fineout-Overholt, 2015). 
One of several ways to ensure EBP is to summarise research and clinical expert consensus regarding recommendations in CPGs. This is outlined in the next section.

\subsection{Clinical practice guidelines}

For a given condition or treatment, CPGs synthesise scientific evidence to inform health care policy, planning, delivery, evaluation, and QI (Shekelle, Woolf, Grimshaw, Schünemann, \& Eccles, 2012). Many different terms are used for these guidelines, such as clinical guideline, practice guideline, CPG, clinical pathway, protocol and national guideline (Kredo, Bernhardsson, Machingaidze, Young, Louw, Ochodo, \& Grimmer, 2016). This may lead to confusion and difficulties when describing QI interventions, for example in research.

Different definitions emphasise various elements of CPGs and their purpose and use. The Institute of Medicine (US) (2011) defined CPGs as "statements that include recommendations intended to optimise patient care that are informed by a systematic review of evidence and an assessment of the benefits and harms of alternative care options". This definition identifies essential attributes for a CPG to be considered trustworthy, but does not consider context and applicability. Later, Brownson and colleagues stated that CPGs summarise clinical evidence applicable to health care practices (usually in a given (national) context), supplemented by expert consensus, in order to specify a desired clinical practice. They may offer clinical recommendations, decision aids and suggestions for QI and implementation (Brownson et al., 2017, p. 387). This is a broader definition, but one that takes into account context, different types of knowledge (i.e. expert consensus) and implementation.

The Norwegian Directorate of Health has a statutory mandate to issue CPGs in Norway. Recommendations in national CPGs are not legally binding (unless tied to a legal act), but normative by indicating recommended courses of action (Norwegian Directorate of Health, 2019). It is stated that CPGs should help to ensure that health care services are of good quality, have the right priorities, do not have undesirable variety in the services offered, solve health care interaction challenges and provide comprehensive patient pathways (Norwegian Directorate of Health, 2019). CPGs may be important tools when several therapies are available, or where uncertainty exists regarding treatment options. CPGs are considered a foundation for health care policy, planning, delivery, evaluation and QI by clinicians, managers and policymakers. They aim to improve care for clients, patients and service users and are produced at a fast pace (Barbui, Girlanda, Ay, Cipriani, Becker, \& Koesters, 2014; Shekelle et al., 2012). 
Many CPGs cover topics that involve several professional disciplines, as does the National Guideline. In this sense, they may also serve as a basis for interdisciplinary collaboration and coordination of clinical practice (Grol, Wensing, Eccles, \& Davis, 2013). Another purpose of CPGs is that they may be used as benchmarks for measuring health care quality and progress towards improvement (Burgers, Smolders, Van der Weijden, Davis, \& Grol, 2013; Grol et al., 2013, p. 93; Turner, Misso, Harris, \& Green, 2008), which is an important premise for A\&F and thus this thesis.

According to the principles of EBP as described above, CPGs are important tools in health care. However, despite a small number of studies showing that the implementation of CPGs may achieve changes in mental health care, most results showed little effect and uncertainty remains as to whether CPGs have any impact on provider performance and patient outcomes (Barbui et al., 2014; Bighelli, Ostuzzi, Girlanda, Cipriani, Becker, Koesters, \& Barbui, 2016; Weinmann, Koesters, \& Becker, 2007). A recent systematic review on medication prescribing rates in mental health care showed that few studies have evaluated the effect of guidelines on prescription rates (Nguyen, Seiler, Brown, \& O'Donoghue, 2019). Seven of eighteen CPG evaluations showed no impact, while the rest showed that CPGs were successful in generating change, but quite often to a minimal extent (Nguyen et al., 2019). A paramount question is how implementation should be carried out to maximise the benefit of CPGs (Bighelli et al., 2016). The existence of CPGs is often inadequate for bringing evidence into clinical practice (this is explored further in the next sections). CPGs are not indisputable notes of scientific evidence, nor do they intend to override the experience of health care practitioners. However, they are important as means to achieve actions that increases the likelihood of good quality healthcare.

\subsection{The research-practice gap}

A "research-practice gap" is a disparity between what is known to be best practice (i.e. as stated in a CPG) and what is actually done in clinical practice. Despite efforts made through CPGs, international research shows that a research-practice gap exists across all types of health care and disease (Bet, Hugtenburg, Penninx, Balkom, Nolen, \& Hoogendijk, 2013; Claudi, Ingskog, Cooper, Jenum, \& Hausken, 2008; Girlanda, Fiedler, Becker, Barbui, \& Koesters, 2017; Grol, 2008; Grol, Wensing, \& Eccles, 2005; Haddock, Eisner, Boone, Davies, Coogan, \& Barrowclough, 2014; Henrotin, 2009; McGlynn, Asch, Adams, Keesey, Hicks, DeCristofaro, \& Kerr, 2003; Proctor, Landsverk, Aarons, Chambers, Glisson, \& Mittman, 2009; Prytys, Garety, Jolley, Onwumere, \& Craig, 2011; Sederer, 2009; Sheldon et al., 2004; 
von Ranson, Wallace, \& Stevenson, 2013). The gap between ideal and actual care was described by the Institute of Medicine (2001) as a "quality chasm". Schuster, McGlynn and Brook (2005) reported that US patients received 55\% of recommended treatment and that the quality varied according to the medical condition from $79 \%$ of recommended care for senile cataracts to $11 \%$ of recommended treatment for alcohol dependence. The WHO (2013) estimated that between $35 \%$ and $50 \%$ of people with severe mental disorders receive no treatment for their disorder in high income countries, and care is often of poor quality for those receiving treatment. Barriers to adopting recommendations from CPGs to practice are widely known from a variety of areas of health care (Cabana, Rand, Powe, Wu, Wilson, Abboud, \& Rubin, 1999; Fischer, Lange, Klose, Greiner, \& Kraemer, 2016; Flottorp, Oxman, Krause, Musila, Wensing, Godycki-Cwirko, Baker, \& Eccles, 2013; Francke, Smit, de Veer, \& Mistiaen, 2008). These barriers may be tied to the CPG itself (e.g. not easily implemented), the health care practitioner (e.g. lack of skills or knowledge), the system (e.g. characteristics of the organisation), among others (Kredo et al., 2016; Lau, Stevenson, Ong, Dziedzic, Treweek, Eldridge, Everitt, Kennedy, Qureshi, Rogers, Peacock, \& Murray, 2016; Prior, Guerin, \& Grimmer-Somers, 2008).

People with mental or substance use problems do not necessarily get the treatment they need, and the situation seems even worse for people with concurrent substance use disorders and mental disorders (Havassy, Alvidrez, \& Mericle, 2009). The complexity of the illness may lead to difficulties in care and treatment (Morisano, Babor, \& Robaina, 2014). A Norwegian inspection revealed a general failure in assessing persons with concurrent substance use disorders and mental disorders. The inspection found an unclear division of responsibilities and task allocation between the various service providers in the municipality and in the specialist health service and between the organisational levels, risking patients not receiving a comprehensive service that meets their complex needs. In the inspection of the specialist health service, particular emphasis was placed on the inadequate assessment of patients' substance abuse problems at DPCs (Meld. St. 7 (2019-2020), 2019).

This thesis is based on this underlying assumption of the existence of a research-practice gap and the need to provide knowledge on how to bridge this gap.

\subsection{Implementation and implementation research}

We now have quite sophisticated methods of producing CPGs by synthesising and grading the quality of the evidence and translating this into practice recommendations, but we are still not sophisticated enough to have all the knowledge needed to translate CPGs into practice 
(Barbui et al., 2014). The past 10-15 years have seen an increasing interest in guideline implementation strategies (Grimshaw, Eccles, Lavis, Hill, \& Squires, 2012). The success of CPGs is not only tied to their content and quality, but also to the effectiveness of the dissemination and implementation strategies chosen to maximise the benefit of the CPG (Bighelli et al., 2016; Gagliardi, 2012; Prytys et al., 2011).

Implementation is defined as a specified set of activities designed to put into practice a programme (Barbui, 2017). "Implere" is derived from Latin and means "to finish". It is implicit in the term that it must be an active process to apply a knowledge-based intervention within a context, contrary to the term "diffusion", which is a passive, unplanned spread of an intervention (Rabin \& Brownson, 2012). As with CPGs, many terms are used to describe "implementation", sometimes differently in various countries. For example, the terms "implementation science" or "research utilisation" are commonly used in the UK and Europe, while in the US, the terms "dissemination" and "diffusion", "research use" and "knowledge transfer and uptake" are widely used. Canada more frequently uses "knowledge transfer and exchange" and "knowledge translation" (Eccles, Armstrong, Baker, Cleary, Davies, Davies, Glasziou, Ilott, Kinmonth, Leng, Logan, Marteau, Michie, Rogers, Rycroft-Malone, \& Sibbald, 2009; Straus, Tetroe, \& Graham, 2009). A definition of knowledge translation stemming from the Canadian Institutes of Health Research is "the exchange, synthesis and ethically-sound application of knowledge - within a complex system of interactions among researchers and users - to accelerate the capture of the benefits of research for [patients] through improved health, more effective services and products, and a strengthened healthcare system” (Edwards, Bureau, Prichard, Barer, McInnes, Frank, Estabrooks, \& Forest, 2004). This definition clarifies the importance of implementation to benefit patients and health care systems and acknowledges the complexity of these systems. This definition of implementation science was given in the inaugural issue of the Journal of Implementation Science:

Implementation research is the scientific study of methods to promote the systematic uptake of research findings and other evidence-based practices into routine practice, and, hence to improve the quality and effectiveness of health services. It includes the study of influences on healthcare professional and organisational behaviour. (Eccles \& Mittman, 2006)

Since the terminology is so inconsistently used, studying the field can be challenging (Damschroder, Aron, Keith, Kirsh, Alexander, \& Lowery, 2009; Michie, Fixsen, Grimshaw, 
\& Eccles, 2009). The terminology in the field is pointed out to address the importance of being explicit and thorough when describing what is actually done.

Implementation is seldom a straightforward process. Various implementation strategies have been developed over the year to improve the uptake of recommendations in CPGs or other evidence-based tools to improve health care services (EPOC, 2015; Grimshaw, Thomas, MacLennan, Fraser, Ramsay, Vale, Whitty, Eccles, Matowe, Shirran, Wensing, Dijkstra, \& Donaldson, 2004), with varying effects. Before 2010, it was uncommon to include guideline implementation strategies or recommendations in a CPG (Liang, Abi Safi, \& Gagliardi, 2017). The National Guideline was the first CPG in Norway to include a section on implementation, and offer guideline implementation strategies simultaneously (Norwegian Directorate of Health, 2019). The Effective Practice and Organisation of Care (EPOC) Group is a Cochrane review group whose tasks include systematically reviewing various strategies designed to improve health professional practice and the organisation of health care services. An implementation strategy may be defined as "a purposeful procedure to achieve clinical practice compliance with a guideline recommendation" (Mazza, Bairstow, Buchan, Chakraborty, Van Hecke, Grech, \& Kunnamo, 2013). The EPOC strategies are organised into four main topics: delivery of health care services, financial arrangements, governance arrangements, and implementation strategies, all of them with subtopics. One intervention is $\mathrm{A} \& \mathrm{~F}$, an implementation strategy targeting health care professionals (Cochrane Collaboration, 2020). As the main strategy studied in this thesis, A\&F is discussed in detail in Section 2.7 and 3.0.

It is sometimes a slow process to translate CPGs into routine clinical practice (Morris, Wooding, \& Grant, 2011). Implementation research aims to decrease this time lag by using systematic approaches to enhance the uptake of EBPs (such as CPGs). In 2017, Girlanda and colleagues found no impact of guideline implementation on provider performance in specialist mental health care, which implied the lack of any effect of guideline implementation on guideline adherence (Girlanda et al., 2017). There is still a lack of research on the pathway from CPGs to EBP (Girlanda et al., 2017). This justifies further research at multiple levels to ensure that users of mental health care receive the best available treatment and care. The ultimate goal of any implementation activity is continuous QI.

\subsubsection{The role of leadership in implementation}

Leadership is tied to QI and implementation efforts, where it is considered an important contextual factor and contributor to implementation success (Damschroder et al., 2009; 
Egeland, Hauge, Ruud, Ogden, \& Heiervang, 2019; Gifford, Davies, Edwards, Griffin, \& Lybanon, 2007; Guerrero, Aarons, Grella, Garner, Cook, \& Vega, 2016; Reichenpfader, Carlfjord, \& Nilsen, 2015; Saeed, Bloch, \& Silver, 2015; Sandström, Borglin, Nilsson, \& Willman, 2011; Taylor, Dy, Foy, Hempel, McDonald, Øvretveit, Pronovost, Rubenstein, Wachter, \& Shekelle, 2011; Versteeg, Laurant, Franx, Jacobs, \& Wensing, 2012; Aarons, Ehrhart, Farahnak, \& Sklar, 2014). Gifford et al. define leadership as a "multidimensional process of influence ... that includes behaviors and activities of managers that exert direct and indirect influence on individuals, their environment, and organisational infrastructure" (Gifford et al., 2007). Both transformational leadership, focusing on inspiring and motivating followers for a particular course of action, and transactional leadership, focusing on managing incentives and rewards and meeting quality standards, are important for managing and supporting organisational change (Aarons, Ehrhart, Farahnak, \& Hurlburt, 2015). There is a difference between management and leadership. Whereas managers are the ones who budget, staff, organise and identify and solve problems, leaders are supposed to have a vision and a mission and direct, inspire and motivate (Kotterman, 2006). However, leadership is an essential part of the role of a manager (Burke \& Friedman, 2011). These two distinct roles can be difficult to combine in one person. There is also a tendency to set leadership skills aside in favour of managing the workplace, particularly in large, complex organisations. In the implementation literature, as in the organisations themselves, the two concepts are not always distinct (Kotterman, 2006).

Hospital management is often organised in three levels: senior, middle and frontline management (Parand, Dopson, Renz, \& Vincent, 2014). Senior management is responsible for health trust-wide or high-level functions. Middle managers usually have several subordinate managers reporting to them and are placed in the middle of an organisational hierarchy. Frontline managers, or first-line managers as they are termed in this thesis, are those who have frontline staff reporting to them, and have the role of supervision of individuals providing direct services (Priestland \& Hanig, 2005). Although we know that senior or upperlevel management usually makes the strategic decisions regarding implementing EBP, it is the first-line personnel who effectively carry out implementation, preferably led by the first-line managers (Aarons et al., 2015; Aarons et al., 2014).

To sum up the background so far, providing quality health care is an ultimate goal, and EBP may be considered a foundation for health care services. CPGs provide recommendations on how health and social care personnel should work to prevent undesired variation in the 
context of specific disorders on the route to EBP. However, the complexity of health care services, the large number of CPGs and several other barriers reduce the use of CPGs, forming a research-practice gap. Implementation research aims to reduce this gap by finding better ways to implement CPGs. Leadership is an important factor of the successful implementation of CPGs.

As mentioned, one broadly used implementation strategy is A\&F. Research has explored ways to collect data and give feedback and how to carry out an A\&F cycle which is outlined in the following sections.

\subsection{An introduction to audit and feedback}

A Cochrane review on A\&F defined it as a "summary of the clinical performance of healthcare provider(s) over a specified period of time" (Ivers et al., 2012). This definition is broad, and are not specific on various part of the process or the feedback. The term A\&F is used for a variety of interventions that involves developing clinical performance summaries (audit) over a specific period and subsequently providing those summaries (feedback) to individual practitioners, teams or health care organisations (Brehaut \& Eva, 2012). Numerous terms and definitions are used to describe this process, including clinical audit, medical audit, nursing audit, management audit, benchmarking, utilisation review, concurrent review, peer review in health care, review of records, chart review, practice data, hospital data, audits or auditing and A\&F. This thesis uses the term A\&F for a broad definition of what the intervention involves, as in the Cochrane review (Ivers et al., 2012) and as further detailed by Brehaut and Eva (2012).

An A\&F strategy is a well-established intervention used in different health care settings to improve quality in health care (Burgess, 2011; Foy, Eccles, Jamtvedt, Young, Grimshaw, \& Baker, 2005; Hysong, Best, \& Pugh, 2006; Ivers, Grimshaw, et al., 2014; Ivers et al., 2012). $\mathrm{A} \& \mathrm{~F}$ is commonly designed to be a part of a multifaceted improvement strategy, where it is theorised to promote health professionals' motivation to improve practice (Burgess, 2011; Foy et al., 2005; Grimshaw et al., 2004; Ivers et al., 2012). Several models that give advice on how to implement new practices recommend beginning by identifying whether there is a discrepancy between the EBP to be implemented and current practice (Graham, Straus, \& Tetroe, 2009; Grol et al., 2013).

A key function of $\mathrm{A} \& \mathrm{~F}$ is to identify suboptimal performance and recognise the need for change (Burgess, 2011; Foy \& Eccles, 2009; Ivers, Sales, et al., 2014). This is assumed to 
prompt a wish to optimise practice if an audit shows suboptimal practice when measured against a standard, such as CPG (Ivers et al., 2012). This assumption is based on a range of theories, of which three psychological theories have been the most popular: control theory, goal setting theory and feedback intervention theory (Brown, Gude, Blakeman, van der Veer, Ivers, Francis, Lorencatto, Presseau, Peek, \& Daker-White, 2019). Control theory (Carver \& Scheier, 1982) starts with sensing a present condition (called an input function). This perception is then compared against a standard or point of reference (called a comparator). The idea is that if someone perceives a discrepancy between the present condition and the standard, they will act (output function) with the ultimate goal of reducing the discrepancy. Goal setting theory (Locke \& Latham, 2002) focuses on the core properties of an effective goal. These properties are tied to the specificity and level of difficulty of the goal. The goal might affect different levels, such as the individual, group or organisational levels. There is a difference between a learning goal and a performance goal, and these different goals should be properly used. There are mediators and moderators of goal effects, including the source of the goal, in other words, whether the goal is assigned, self-set or participatively set. Goalsetting theory acknowledges the importance of conscious goals and self-efficacy and focuses primarily on motivation in work settings. Feedback intervention theory (Kluger \& DeNisi, 1996) examines the assumption that feedback on performance improves performance, finding that around 1/3 of feedback interventions have no, or even a negative, effect. A definition of a feedback intervention is "actions taken by (an) external agent(s) to provide information regarding some aspect(s) of one's task performance". Feedback intervention theory aims to integrate existing theory and explain the negative effect of feedback intervention on performance (moderators). The effect increases if the feedback is provided for a familiar task. The effect is also greater if it can support learning and if the discrepancies regarding the standard are at a task level (velocity feedback intervention and goal setting). Finally, if the feedback intervention is devoid of cues at the metatask level (cues that direct attention to the self), it may lead to considerably enhanced performance (Kluger \& DeNisi, 1996).

However, all of these theories, particularly the three most popular ones explained here, address only part of the feedback process. Potentially important factors specific to health care may be missed (Brown et al., 2019).

\subsubsection{Audit practice methods}

Donabedian (1988) explained that the quality of care can be classified under three categories: structure, process and outcome. The two most common foci of measures in an audit are 
process and outcome (Flottorp, Jamtvedt, Gibis, \& McKee, 2010). Data may be collected (manually or electronically) from various sources, such as patient information systems or from ad hoc data collection exercises. Patient records, discharge records, prescription data, direct observations, interviews, surveys and questionnaires are some examples (Burgess, 2011, p. 63). Clinical charts are typically part of the patient documentation system, sometimes, as in Norway, divided into nursing charts and doctors' charts. Outcome measures may include patients' health status, physiological measures or mortality (Flottorp et al., 2010). To answer questions about the process of care, it is relevant to know what care is appropriate for whom. This information may be found in a CPG. This thesis focuses on A\&F used to evaluate the care process and capture recent performance for some operations. The audited data may be compared against a consensus benchmark, a summary of peer performance or the historical data of the recipient (Wagner, Durbin, Barnsley, \& Ivers, 2019). It is important that the data come from a trusted source (Brown et al., 2019).

\subsubsection{Methods to provide feedback on audit data}

A fair amount of the A\&F research concerns how, when and to whom feedback is given. The idea is that when performance and care are measured against evidence-based standards, feeding back results can motivate service providers to improve (Hysong, Kell, Petersen, Campbell, \& Trautner, 2017). In 2014, Ivers, Grimshaw and colleagues (2014) reviewed the feedback reported in the Cochrane 2012 review (Ivers et al., 2012) and found that the feedback was sensitive to how, when and by whom it was delivered. The feedback was most effective when it was presented on a number of occasions. It was also important that it was delivered by a trusted person, a supervisor or a respected colleague. It was more likely to succeed if it aimed to decrease the targeted behaviour and when the baseline performance was low. Importantly, it was also essential that the A\&F was followed by action plans to reach specific goals. If the recipients of the feedback were non-physicians, it was also easier to achieve greater improvements.

Brehaut, Colquhoun, Eva, Carroll, Sales, Michie, Ivers, \& Grimshaw, (2016) proposed 15 suggestions to improve the effectiveness of $A \& F$, summarised around four main themes: the nature of the desired action, the nature of the data available for feedback, the feedback display and the delivering of the feedback intervention. The final suggestion was to construct feedback through social interaction, for example through discussions in QI groups; the recipients of the feedback should actively work with the material they have received and establish their own learning based on the data. After reviewing the literature on feedback, 
Brehaut and colleagues called for more research on the topic in several areas, including further studies on social interactions when working with feedback.

\subsubsection{Audit and feedback as a cyclic process}

$\mathrm{A} \& \mathrm{~F}$ is commonly designed to be part of a multifaceted improvement strategy (Burgess, 2011; Foy et al., 2005; Grimshaw et al., 2004; Ivers et al., 2012). Some claim that an audit should never be only about measuring practice; it should be seen and executed as a circular process with stages (Burgess, 2011; Dixon \& Pearce, 2011; Potter et al., 2010). The Healthcare Quality Improvement Partnership in the UK provided an explicit definition of A\&F (using the term clinical audit):

Clinical audit is a quality improvement process that seeks to improve patient care and outcomes through systematic review of care against explicit criteria and the implementation of change. Aspects of the structure, process and outcomes of care are selected and systematically evaluated against explicit criteria. Where indicated, changes are implemented at an individual, team, or service level and further monitoring is used to confirm improvement in healthcare delivery. (Potter et al., 2010)

The last part of this definition indicates that A\&F is a cyclic process. The stages are not necessarily linear, but may include an iterative process. The stages are definition of standards, measurement (audit), analysis of feedback reports and planning of actions, implementation of the improvement plan and re-measurement; together, these form an integrated process (Burgess, 2011, p. 6) or an A\&F cycle as the term is used in this thesis. Reflecting on results, agreeing on where improvement is needed and producing an improvement plan are essential components of the process (Ivers, Grimshaw, et al., 2014; Ivers et al., 2012; Ivers, Sales, et al., 2014). An A\&F cycle involves reflecting on a repeating a self-regulating QI process. In this way, it may serve as the mechanism of action for A\&F interventions (Brown et al., 2019). The most important outcome from this systematic review from Brown and colleagues of qualitative studies on $\mathrm{A} \& \mathrm{~F}$ was a theory called clinical performance feedback intervention theory (2019). This theory states that feedback is a cyclical and sequential process that loses its effectiveness if any of the individual processes fail, halting progress round the cycle. In terms of explanatory mechanisms, they summarise these in three propositions. The first is a limited capacity to engage with feedback both in the organisation and among health care professionals. The second is that those interacting with the feedback are influenced by strong beliefs regarding how patient care should be provided. The last proposition is that feedback is most effective if it directly supports clinical behaviours (Brown et al., 2019). 


\subsubsection{The effect of audit and feedback as an implementation strategy}

In 2012, an important Cochrane review was published, measuring the effect of A\&F in 140 studies (Ivers et al., 2012). This is the most recent Cochrane review on A\&F. It found that compliance with the desired practice showed a $4.3 \%$ absolute improvement ( $16 \%$ absolute improvement in health professionals' compliance with the desired behaviour considering a $75^{\text {th }}$ percentile effect size). It showed highly variable A\&F results, ranging from substantial positive effects to null and even negative effects on providers' behaviour. The authors' conclusion was that $\mathrm{A} \& \mathrm{~F}$ leads to small but important improvements when the goal is to improve professional practice.

This 2012 Cochrane review was a re-review of a 2006 Cochrane review (Jamtvedt, Young, Kristoffersen, O'Brien, \& Oxman, 2006). One of the significant findings from the most recent Cochrane review (Ivers et al., 2012) was that A\&F shows higher efficiency when the performance of health professionals is poor to begin with. It has a better effect when a supervisor or colleague is responsible for the $\mathrm{A} \& \mathrm{~F}$, when the $\mathrm{A} \& \mathrm{~F}$ is provided more than once, when feedback is given both orally and in writing and when the process includes clear targets and an action plan. An article called "No more 'business as usual' with audit and feedback interventions" (Ivers, Sales, et al., 2014) concluded that A\&F is potentially vital to improve the quality of care, but that there are still knowledge gaps related to when and how A\&F will work best in different settings and with different groups of health professionals, for example. The answer is not to conduct more trials where A\&F is compared to usual care, as the effect size of A\&F became stable around 2003 (Ivers, Grimshaw, et al., 2014). A variety of studies have been successful in determining how to optimise $A \& F$ as an intervention (Brehaut et al., 2016). However, a recent systematic review on the effect of A\&F in primary health care confirmed the stagnation in A\&F research and showed that there is insufficient research on A\&F and a need to build on existing knowledge (Van Den Bulck, Spitaels, Vaes, Goderis, Hermens, \& Vankrunkelsven, 2020).

Qualitative research on A\&F may contribute to a more nuanced picture and increase the understanding of the variable effect of the strategy in mental health care settings. In particular, there is a gap in terms of exploring the implementation of an entire A\&F cycle.

This section introduced A\&F and some important findings on the subject. The following section examines the knowledge status using literature searches of qualitative research on A\&F. 


\subsection{Literature review}

This section first presents the literature search process conducted for the thesis. Thereafter a status of knowledge of qualitative research on the view on A\&F is presented. The section ends with a summary of unanswered questions that are the basis for the aims and research questions.

At the outset of this study, an extensive literature search was conducted to gain an understanding of the field in 2014. The researcher needed to be informed about key research on implementation science in general and on $\mathrm{A} \& \mathrm{~F}$ in particular, especially in relation to mental health care. A large body of literature was searched and reviewed, but without following the principles of a systematic review (Moher, Liberati, Tetzlaff, Altman, \& Group, 2009). The terms used when identifying literature on implementation were selected from a list of terms collected by McKibbon and Lokker (2009). Literature searches were then conducted for each of the three papers that form part of this thesis, and then again at the start of writing the thesis.

\subsection{Searching for qualitative studies on audit and feedback}

The literature search for writing the thesis is the ones reported on here, using the report strategy STARLITE as recommended for qualitative literature searches (Booth, 2006). The sampling strategy was selective, with attempts to identify all relevant studies within the limits explained below.

Conceptual limitations were literature on A\&F, literature on mental health care/substance related disorders, and qualitative research.

Figure 1: An illustration of the Boolean literature search (figure made by MSP, 2021).

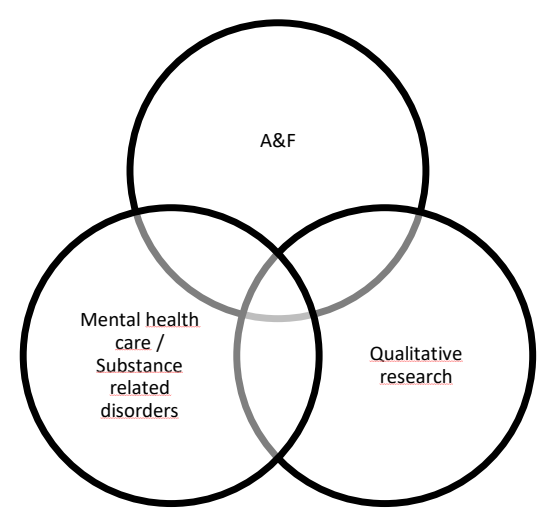

No geographical or other inclusion/exclusion criteria were set. Functional limits were put on language; only literature in English or the Scandinavian languages was included. 
The main search approach was protocol driven (search strategy defined at the outset of the study, and for each substudy) with systematic searches, added with hand searching, and citation snowballing from the most relevant articles (Choong, Galgani, Dunn, \& Tsafnat, 2014). The range of years was 2000-2021; the initial searches were conducted in 2015. New searches were conducted repeatedly, using varying search strategies. The main reason for this was the difficulty retrieving qualitative research on $A \& F$ in mental health care. A new literature search was carried out in 2021 during the final phases of the thesis being written.

A search strategy combining subject headings and text words was used, which is supposed to give the best retrieval results (Jenuwine \& Floyd, 2004). Literature in the field of implementation research is difficult to find due to the largely non-standardised terminology in the field (McKibbon, Lokker, Wilczynski, Haynes, Ciliska, Dobbins, Davis, \& Straus, 2012). This was demonstrated throughout the Background section of the thesis. This justifies the combined use of text words and standardised subject headings. Search strategies for each database used terms to define $\mathrm{A} \& \mathrm{~F}$ and terms to define mental health care/substance related disorders. For A\&F, subject headings such as clinical audit, medical audit, nursing audit, benchmarking, utilisation review were used along with text words such as audit, auditing, record review, chart review, practice data and hospital data, all used with the Boolean operator OR. For mental health care/substance related disorders, subject headings such as mental disorders, mental health, mental health services, psychiatric hospitals and psychiatry were used combined with the Boolean operator OR. In addition, terms such as substance related disorders and text words such as ((drug or alcohol) adj (abuse or misuse or depend*)) were used. A search strategy on PsycINFO uses the APA Thesaurus of Psychological Index Terms, while a search strategy on MEDLINE uses MeSH (medical subject headings). There are differences in the thesauruses used in the various databases regarding which terms are included as subject headings, and which need to be included as text words. This was taken into account for each database. On MEDLINE the search strategy yielded far too many irrelevant references. A search strategy using the adjacent operator seemed to give adequate results (audit adj4 feedback) where the adj4 operator finds terms in any order with three words (or fewer) between them.

Study types under the umbrella term "qualitative studies" were searched for, using either the search limitation function qualitative (best balance) in clinical queries or qualitative research as a subject heading (MeSH / The APA Thesaurus of Psychological Index Terms) or text words such as qualitative, experience, interview and focus group. The reason for this was that 
search filters are not sensitive enough to retrieve qualitative research (Booth, 2016; McKibbon, Wilczynski, \& Haynes, 2006).

For all literature searches, the most common databases for health services available from the Norwegian Electronic Health Library [Helsebiblioteket] were used: MEDLINE, PsycINFO, CINAHL, EMBASE and SveMed+. Web of Science was used at only one point, in 2015 (access through the Oslo University Library). ProQuest Dissertations \& Theses was search in April 2021.

Initially, almost 2000 studies were found through the literature searches. Once duplicates were removed, around two-thirds of the articles were immediately discarded for obviously not pertaining to the subject of interest. 670 studies remained to be further scrutinised. The vast majority of the studies on mental health or substance use care were about the AUDIT (Alcohol Use Disorders Identification Test) or Patient Reported outcome Measures. Studies were excluded if they were on a different subject (for example, the auditory field), reviewed patient experiences, explored views on particular technological interventions, were not qualitative studies or were in languages other than English or the Scandinavian languages. In total, 31 studies were found and these are reported in the following section (and thus are not cited in this section). Two theses were found, but both of them were mixed methods studies; therefore, only the articles published in the qualitative part of these theses are described. The majority of the studies were conducted on somatic hospitals, followed by primary care. One study was on specialist mental health care and three on nursing homes. 13 studies were conducted in European countries (England, Ireland, the Netherlands, Denmark and Sweden), 10 in Canada, five in the USA, two in Australia and one in South-Africa. The most recent literature search conducted in April 2021 revealed a large increase (given the few studies before 2019) in the number of studies (2010-11: 1 study, 2012-13: 1 study, 2014-15: 5 studies, 2016-17: 5 studies, 2018-19: 8 studies, 2020-April 2021: 11 studies). This might indicate a rising interest in qualitative methods in research to inform A\&F.

\subsection{Knowledge status of qualitative research on audit and feedback}

Only one qualitative study on A\&F in mental health care was found (Shepherd, Meehan, Davidson, \& Stedman, 2010). An external team delivered this study in Australia, targeted nurse managers and the $A \& F$. In general, the $A \& F$ was well received. The results show that A\&F provided a different perspective on individual services, particularly strengths and weaknesses. Support from the A\&F team and from upper management were seen as useful. 
A\&F had a potential use as a tool for organisational gain, for example by providing an argument for resources. Engaging staff in all stages of the process was considered useful in converting benchmarking data into knowledge that could be applied at the local service level. The A\&F gave the nurse managers an occasion to provide positive feedback to the staff when service was aligned with the desired service level, and thus an opportunity to celebrate success. When provided with feedback, the staff saw it as an opportunity to learn from similar services (Shepherd et al., 2010).

Studies from outside mental health care were included since the literature on qualitative studies on A\&F in mental health care is sparse, and because the views from other areas may be generic, enabling learning and the harvesting of knowledge.

Three studies were on nursing homes (Harvey, Kitson, \& Munn, 2012; Laur, Sribaskaran, Simeoni, Desveaux, Daneman, Mulhall, Lam, \& Ivers, 2021; McCleary, Desveaux, Reis, Linklater, Witteman, Taljaard, Thavorn, Grimshaw, Ivers, \& Presseau, 2020). None of these was purely qualitative study addressing the $\mathrm{A} \& \mathrm{~F}$ experience alone, but each had a qualitative section as part of a mixed methods study or focused on the feedback reports. Two studies targeted physicians (Laur et al., 2021; McCleary et al., 2020). In general, physicians viewed their role as important for high quality care and as change drivers. A\&F, as a stand-alone intervention, was not reported to be a main force in QI work in any of the three studies. Competing A\&Fs, that is, a range of quality indicators from multiple stakeholders addressing a variety of aspects of practice, could easily reduce the priority of a particular A\&F (McCleary et al., 2020). A large study targeted A\&F facilitators in different European countries (Harvey et al., 2012). The facilitators experienced difficulties with A\&F and needed to develop both QI and A\&F skills. The most valued experience was the opportunity to compare data across sites and share learning and insight into best practice. This was perceived as important, and something the physicians in the Canadian study missed as they were often the only physician in a nursing home (Laur et al., 2021).

It is common for participants in A\&F projects to report that the feedback increased their awareness of gaps between ideal and actual performance, as intended. Several studies show that participating in A\&F may be perceived as a useful, welcome and necessary opportunity to discuss practice (Ivers, Barnsley, Upshur, Tu, Shah, Grimshaw, \& Zwarenstein, 2014; Kristensen \& Hounsgaard, 2014; Sinuff, Muscedere, Rozmovits, Dale, \& Scales, 2015; Taylor, Neuburger, Walker, Cromwell, \& Groene, 2016; van Braak, Visser, Holtrop, Statius Muller, Bont, \& van Dijk, 2019; Webster, Patel, Rice, Baxter, Paszat, Rabeneck, \& Tinmouth, 
2016). This is important given the knowledge of A\&F's effect as a popular strategy for implementation. However, most of the literature focuses on barriers to a successful A\&F intervention.

The level of trust, or doubts, in relation to data is a recurring theme in the studies on primary health care. The majority of the studies explain that the data collected needs to be meaningful to clinical practice (Arvidsson, Dahlin, \& Anell, 2021; Desveaux, Ivers, Devotta, Ramji, Weyman, \& Kiran, 2021; Glenngård \& Anell, 2021; Hysong, Smitham, SoRelle, Amspoker, Hughes, \& Haidet, 2018; Ivers, Barnsley, et al., 2014; Payne \& Hysong, 2016; Trietsch, van Steenkiste, Hobma, Frericks, Grol, Metsemakers, \& van der Weijden, 2014; van Braak et al., 2019; Wagner, Durbin, Barnsley, \& Ivers, 2017; Wagner et al., 2019). The same theme is present in several of the studies on general hospitals (Dawson, 2015; Livorsi, Goedken, Sauder, Vander Weg, Perencevich, \& Reisinger, 2018; Sykes, Thomson, Kolehmainen, Allan, \& Finch, 2020, 2021; Taylor et al., 2016). This is about the source of delivery of the data, how data are collected or perceived lack of data validity, due to poor documentation. A low level of trust in the source may generate negative emotions towards A\&F and thus the motivation to act on the data (Hysong et al., 2018).

Two very recent studies from Sweden examined different kinds of A\&F (Arvidsson et al., 2021; Glenngård \& Anell, 2021). Both studies reported that A\&F from regulators or owners targeting contractual obligations are viewed negatively and do not lead to QI for patients. In contrast, $A \& F$ that are specific and target clinical goals are perceived as meaningful and motivational.

Several studies found a discordance between population-level data and patient-centred care, that is, how to take action on data from a population level to the single patient on an everyday basis (Desveaux et al., 2021; Ivers, Barnsley, et al., 2014; Sykes et al., 2020). Data are at risk of being misinterpreted (Livorsi et al., 2018; Sykes et al., 2021) or staff not understanding what they are doing wrong (Cloney, Vinluan, Chen, Retegan, \& McCahy, 2021; Smiddy, Murphy, Savage, \& Browne, 2019), particularly if feedback reports are cumulative and interdisciplinary. This is about the difficulty of interpreting feedback-reports; feedback needs to be simple, actionable and relevant (Dawson, 2015; Gude, Roos-Blom, van der Veer, Dongelmans, de Jonge, Peek, \& de Keizer, 2019; Keizer, Beerlage-De Jong, Al Naiemi, \& van Gemert-Pijnen, 2020; Payne \& Hysong, 2016; Smiddy et al., 2019; Springer, Sales, Islam, McBride, Landis-Lewis, Tupper, Corches, Robles, \& Skolarus, 2021; Sykes et al., 2020; Trietsch et al., 2014; Wagner et al., 2017). Among nurses in acute hospital care, 
Christina and colleagues found that the response to A\&F is usually better when it is perceived as relevant and the process fits providers' preferences and values (Christina, Baldwin, Biron, Emed, \& Lepage, 2016). This is quite similar to findings among occupational therapist in stroke rehabilitation in Denmark (Kristensen \& Hounsgaard, 2014). In Australia views on A\&F suggests that feedback has to be relevant to rural or highly specialised organisations, that is locally applicable (Cloney et al., 2021).

The feedback part of the A\&F cycle is vulnerable to being experienced as punitive (Lumadi, 2017; Sykes et al., 2021). This might jeopardise the interpretation of the data or how staff interact with data collection if this is carried out with input from staff. Several studies report that feedback is given to upper level management or QI personnel without necessarily reaching clinical personnel, those who are targeted for behaviour change (Livorsi et al., 2018; Springer et al., 2021; Sykes et al., 2020). In the latter case, health care personnel might feel that an audit is just about measuring and has no impact on the quality of care (Christina et al., 2016; Livorsi et al., 2018; Sinuff et al., 2015).

Cooke and colleagues outline group feedback as a means to interpret and contextualise data and plan for change (Cooke, Duncan, Rivera, Dowling, Symonds, \& Armson, 2018). Some studies emphasise QI team meetings as a valuable place to discuss audit data and feedback reports (Rattray, Damush, Miech, Homoya, Myers, Penney, Ferguson, Giacherio, Kumar, \& Bravata, 2020; van Braak et al., 2019). These meetings are used to interpret data, evaluate feedback reports and to discuss practice and possible actions to change, providing an arena for understanding, accepting, learning and planning. However, there are difficulties with QI teams stemming from tension between physicians and other team members (Wagner et al., 2019); there is a perception that getting the buy-in of physicians for A\&F or QI projects is difficult.

A lack of QI competence and the need for QI infrastructure are addressed in several studies (Glenngård \& Anell, 2021; Ivers, Barnsley, et al., 2014; Trietsch et al., 2014; Wagner et al., 2017, 2019). This is seen as essential to be able to undertake an A\&F and act on the results to achieve a change in practice. A desire for stronger support from management or senior staff members is a recurring theme (Glenngård \& Anell, 2021; Sinuff et al., 2015). In a Canadian study, the participants reported depending on such facilitators, and the reminder function was emphasised (Wagner et al., 2019). In this study, the facilitators were part of the audit and the feedback, but were not involved in completing the cycle in the implementation phase. Another study observed physicians in the phase of having received feedback (Cooke et al., 
2018). It found that despite the presence of a facilitator in the team meeting, it was the interaction between team members that, in the majority of cases, led to discussions of EBPs and action planning, indicating that having colleagues present is as important as having a facilitator present.

A study from Denmark found an expressed need for somebody to be in charge of providing new knowledge and enabling the experience of using it in daily practice (Kristensen \& Hounsgaard, 2014). This may imply insecurity about putting new knowledge into practice, but also on how to find it.

Competing goals in an organisation are also reported as a perceived barrier (Ivers, Barnsley, et al., 2014; Payne \& Hysong, 2016). There are other barriers such as under-resourcing, project design inexperience, the lack of an overall plan for the audit and perceptions of a process that is run top-down or lacks the necessary transparency (Sinuff et al., 2015). In intensive care units in Canada, clinicians felt that A\&F was fragmented and variable in its effectiveness, while staff felt disconnected from the process (Sinuff et al., 2015). They particularly called for better information on the whole process and its rationale, along with an opportunity to act on the audit results, such as through colleagues discussions and greater engagement by senior management, leading to less of a top-down approach. This is in line with findings where family physicians report having electronic medical records, but lack QI infrastructure in their practices (Ivers, Barnsley, et al., 2014).

The full A\&F cycle is rarely the subject of qualitative research. An exception is the study by Wagner and colleagues (2019) aiming to evaluate the full A\&F cycle in primary care and presenting insight to understand the inconsistent performance of $A \& F$ - the incomplete feedback loop. External resource were used to facilitate the audit. Several barriers addressed the feedback, data validity, the feedback reports, resource constraints, team relationship and lack a of QI capacity, concluding that moving from measurement to action can be complex. Payne and Hysong (2016) observed that the assessment process itself generates emotions in physicians, which affect the actions they take. Physicians may feel proud if the feedback reveals that there is no need for improvements, or that steps can be taken to maintain practice. Feedback which reveals practice that deviates from desired practice can cause negative emotions. This can spur the physician to improve future practice or to explain why practice deviated from the desired practice. Studies have found that physicians in particular view 
themselves as high performers and competitive (Smiddy et al., 2019; Webster et al., 2016), which may motivate them to change undesired practices.

\subsection{Summary and unanswered questions}

Health care personnel may easily have negative views on $\mathrm{A} \& \mathrm{~F}$, having experienced it as recurring measurements and results not followed up. The source of the data, and how it is collected and analysed must be experienced as valid and reliable. A\&F must be perceived as having an impact on the quality of care for patients to be meaningful. That is, the data must be interpreted and translated to local context. This can best be done in teams of colleagues at a local level. To achieve a reliable and valid A\&F, a process facilitator is considered important, alongside support and engagement from managers. If some of these factors are present, health care personnel quite often experience A\&F as useful, meaningful and necessary to improve the quality of care. Competing work demands, time constraints, role confusion and access to computers and skills came up as barriers. There are frustration at not having senior medical staff on board and a perceived lack of prioritisation by senior managers. On the positive side, staff may see an A\&F as an opportunity to learn from colleagues. Barriers on how feedback is given and to the structures to act on the difference between desired and actual practice is persistent. This is related to individual patients or to whether clinicians agree with the changes or to whether it fits in with a patient-centred approach. Another group of barriers is linked to organisational frameworks, such as management support and the ability to be part of a change process.

In response to the 2012 Cochrane review on A\&F (Ivers et al., 2012), implementation researches has advocated for a shift in the research efforts (Foy et al., 2005; Ivers, Sales, et al., 2014). Research has attempted to understand $A \& F$ and there are many studies on the effects of A\&F (Brehaut et al., 2016; Ivers, Grimshaw, et al., 2014; Ivers et al., 2012; Ivers, Sales, et al., 2014). In 2016 an article was published on how to optimise the impact of A\&F, including 15 suggestions (Brehaut et al., 2016). Outcome studies are necessary to understand the A\&F cycle, but there remains a need to fully understand various parts of the intervention (Colquhoun, Michie, Sales, Ivers, Grimshaw, Carroll, Chalifoux, Eva, \& Brehaut, 2016).

With the exception of Wagner and colleagues study (2019), few qualitative studies has taken the full A\&F cycle into account, and there is sparse literature on the social interactions when working with the feedback, a theme also addressed as a gap by Brehaut (Brehaut et al., 2016). There is a need for qualitative studies to understand participants' experience of whether an A\&F cycle is acceptable to them (Grimshaw, Ivers, Linklater, Foy, Francis, Gude, \& Hysong, 
2019). Researchers often facilitate implementation and QI projects; therefore, there is a need to explore these processes as they naturally occur in clinical settings among local groups (Brownson et al., 2017; Dogherty, Harrison, Graham, \& Keeping-Burke, 2014; Kessler \& Glasgow, 2011). Such an exploration may contribute to a deeper understanding of A\&F and thus hopefully leading to better designed and executed A\&F cycles affecting the uptake of CPGs to improve practice.

Gaps persists on studies exploring the full A\&F cycle, and A\&F cycles executed locally with no external facilitator or research team, and in the context of specialist mental health care. This could contribute to uncover additional opportunities to optimize the effectiveness of A\&F. 


\subsection{Aims and research questions}

The overall aim of this study was to add to the knowledge of the use and experience of an A\&F cycle in a DPC in Norway. The aim was to explore an A\&F cycle over a year from different angles: by observing QI team meetings at the outset of the cycle and interviewing groups of personnel, including first-line managers, at the end of the cycle.

\section{Substudy 1}

The aim of this study was to describe and investigate what is discussed and thematised when QI teams in a DPC work to complete an action form as part of an A\&F cycle.

Research question 1: What is discussed and thematised when QI teams in a DPC work to complete an action form as part of an A\&F cycle?

\section{Substudy 2}

The aim of this study was to describe and explore how specialist mental health services staff experience working with an A\&F cycle as a basis for implementation to gain real-life process knowledge.

Research question 2: How do specialist mental health services staff experience working with an $A \& F$ cycle as a basis for implementation to gain real-life process knowledge?

\section{Substudy 3}

The aim of this study was to describe and explore how first-line managers in a DPC experience using an A\&F cycle as a basis for QI in specialist mental health care.

Research question 3: How do first-line managers in a DPC experience using an A\&F cycle as a basis for QI in specialist mental health care? 


\subsection{Materials and methods}

This section presents the research design of the thesis, along with the philosophical underpinnings and understanding of the design, including the researcher's preunderstanding. The methods used for all three papers which form the basis of this thesis are also described.

\subsection{Research design}

The research design is the framework of research methods and techniques chosen by a researcher. In order to achieve the overall aim, this study was designed as a qualitative instrumental case study, as described by Stake (1995). Case study research involves studying a case in a real-life, contemporary context or setting (Yin, 2014) and is suitable for exploring a process (Creswell, 2014). For this reason, an A\&F cycle that continued for a whole year was investigated.

\subsubsection{Qualitative research}

A qualitative research approach is used to understand and interpret the meaning of a social phenomenon as it is experienced by individuals or groups of people (Creswell \& Creswell, 2018). It is mainly inspired by phenomenology/hermeneutics and social constructivism (Thornquist, 2018). This contrasts with quantitative research strategies based on the natural sciences and mainly inspired by positivism and critical rationalism (Thornquist, 2018). The broad field of health scholarship has a strong tradition of qualitative research offering compelling insights into the real worlds, experiences, and perspectives of patients and health care professionals (Braun \& Clarke, 2014).

\subsubsection{Qualitative instrumental case study}

Modern social science case studies can be historically traced through anthropology and sociology, and are widely used in an array of disciplines (Creswell, 2013, p. 97; Harrison, Birks, Franklin, \& Mills, 2017). There is a history of their use as a qualitative research approach in the health and social sciences (Stake, 1995). Case studies are useful for gaining an in-depth understanding of an issue and answering the "how" questions when the behaviour of those involved cannot be manipulated or such manipulation is not desired (Baxter \& Jack, 2008; Creswell \& Creswell, 2018). Two of the three central research questions in this thesis start with the word "how". The research question of substudy 2 and 3 include open-ended words such as experience, focusing on different aspects of an A\&F cycle. 
An instrumental case is used to illuminate the "problem"; the case itself is not the most important part (Baxter \& Jack, 2008). The case is instrumental to the issue and enhances the probing of the issue (Stake, 1994). This study uses a case to understand the use and experience of an A\&F cycle in a DPC in Norway in a naturally occurring QI process during the implementation of a CPG. The case is thus instrumental to achieving this understanding. Defining a case as bounded by certain parameters, such as time and place is a feature of a case study (Creswell, 2013, p. 98). The process of implementing the National Guideline with the use of an A\&F cycle as a strategy in one DPC over one year (described in Section 5.3.3) is the bounded system used to illuminate the problem.

This thesis takes the approach that EBP is a foundation for high-quality health care and that implementation strategies such as $\mathrm{A} \& \mathrm{~F}$ are needed to help translate guidelines into practice, but with the clear understanding that this is a complex process. Therefore, while EBP and implementation research underpin the project at an axiological level, the aim of this thesis is descriptive and exploratory.

\subsubsection{The ontological understanding of constructivism}

Ontology is the sciences of reality, or what there is that can be known. The ontological presumption of this thesis is that reality is relative to the individuals involved and specifically constructed in their particular local context, in line with a social constructivist paradigm (Lincoln \& Guba, 2013). Case studies can be placed in either the positivist/post-positivist or interpretive/constructivist paradigms (Harrison et al., 2017). This thesis falls within the constructivist paradigm, where the ontological belief is that reality is local and specifically constructed and the subjectivist stance of researchers is acknowledged (Thomassen, 2006, p. 180). Similarities can exist between people and groups of people, but different organisations, cultures and experiences can create multiple social realities, since a reality in this paradigm is created if someone gives it status (Lincoln \& Guba, 2013, p. 39).

The choice of a qualitative case study is based on the assumption that in order to gain an understanding of the experience and use of an $A \& F$ cycle in practice, there is a need to examine it from the perspective of and in close cooperation with those who are the active participants in that world. Entities are a matter of definition and have ontological status if someone gives them status. A constructivist lens is appropriate for the promotion of the knowledge and skills necessary for implementation (Greenhalgh \& Russell, 2006). 


\subsubsection{The epistemology of interpretation}

In contrast to positivistic science, reality is not objective or unchangeable, but pluralistic and subjective; it differs and changes between people and groups. Epistemology concerns the relationship between the knower and what can be known, in other words, what we can acquire knowledge about and how (Lincoln \& Guba, 2013). It is impossible to answer this question detached from the answer to the ontological question "what is reality?". A constructivist understanding would imply that the product of the research is co-constructed by the researcher and the participants in their context (Mills \& Birks, 2014, p. 91). Common to postempirical philosophy is the recognition that unconditional observations and theoryindependent data are an impossibility, whether or not we are aware of it (Creswell, 2013; Thornquist, 2018, p. 229). A researcher is part of various processes by being present in these processes. This recognition of being involved in and actively interpreting experiences is consistent with a constructivist approach. This approach acknowledge and welcomes the fact that a researcher plays an active part in constructing the data gathered and the interpretation of the data, making the research value-laden (Lincoln \& Guba, 2013). The researcher preunderstanding is essential in this co-construction, and is described in Section 5.1.6.

\subsubsection{Methodology}

The methodological question must be seen in relation to the ontological belief of relativism and the epistemological belief of transactional subjectivism (Lincoln \& Guba, 2013). Two processes are necessary to explore the sense-making and meaning-making activities of the knowers involved in the research project. First, the constructions need to be revealed and their meanings found through co-construction and cooperation with the participants. This involves finding what is important to the parties and pursuing those topics. This is done by participating in the context and construction and deconstruction of meaning in this context together with the research participants. In this study, this is done by observing and interviewing participants in their context, as described in Section 5.4. Second, the various constructions must be confronted by making sense of and discussing it. The researcher in this study have taken an reflexive stance as described in Section 7.2.3, analysed the data material as described in Section 5.5 and discussed the findings in Section 7.1.

\subsubsection{The researchers preunderstanding}

A researcher's preunderstanding is quite often an important premise of and motivation for research on a subject, and the researcher influences the research process, regardless of methodology or methods used (Malterud, 2017). In the constructivist paradigm research is 
value-laden, and values must be uncovered and made transparent (Lincoln \& Guba, 2013). To clarify the researcher's preunderstanding is a step in that direction.

The researcher is an information scientist (medical librarian) with particular experience in specialist mental health care. One field of interest is EBP. In the mid-2000s, a national project on EBP was initiated at Innlandet Hospital Trust (Vandvik \& Eiring, 2011), promoting a different way of working, with greater opportunities to learn, change practice and become more involved in hospital projects. The researcher's master's degree is in the field of organisational learning and complexity theory concerning barriers to using clinical procedures in clinical practice. The results of the study suggested that clinical procedures are rarely used, regardless of profession, but their use increases with knowledge of their existence and content and a system to easily obtain them. An increased interest in QI and implementation science followed the master's degree, with the researcher teaching EBP and engaging in many valuable professional discussions. The background as an information scientist with an interest in and knowledge of EBP may be an advantage in terms of familiarity with decision aid products such as CPGs. Extencive experience in working with health personnel, particularly in the field of mental health care, has given the researcher valuable insight into this particular field of health services. It is also important to note that this background has generated a generally positive view on CPGs. This may have affected the knowledge production shared with the participants in the study. Based on the researcher's prior research and experience, EBP and A\&F is understood to be complex, context-specific phenomena that has different meanings for those involved.

Before the methods used in this study are explained, a thorough description of the outer context, the study site and the A\&F cycle is given.

\subsection{The outer context and object of implementation}

\subsubsection{Persons with concurrent substance use disorders and mental disorders and the mental health care system they relate to in Norway}

This section describes the group of patients addressed in the National Guideline and the national health care system in which the intervention took place. This is to provide an understanding of the complexity of the patient group, the need for a CPG and the complexity of its implementation in clinical practice.

The combination of substance abuse and mental illness is often referred to using terms such as comorbidity and dual diagnosis (WHO, n.d.). Comorbidity is a general term for the 
simultaneous presence of two or more disorders. Both comorbidity and dual diagnosis are imprecise concepts because they do not say anything about which diseases are discussed. The National Guideline uses the term "Persons with Concurrent Substance Use Disorders and Mental Disorders". Since it resonates with the Norwegian context of this thesis and acknowledges both disorders as appearing simultaneously, this term is used in this thesis. Many studies show high a co-occurrence of substance use disorders and mental disorders, well documented through clinical and epidemiological studies (Gråwe \& Ruud, 2006; Hartz, Pato, Medeiros, Cavazos-Rehg, Sobell, Knowles, Bierut, Pato, \& Genomic Psychiatry Cohort, 2014; Helseth, Lykke-Enger, Johnsen, \& Waal, 2009; Lai, Cleary, Sitharthan, \& Hunt, 2015; Saban \& Flisher, 2010). Persons with concurrent substance use disorders and mental disorders often derive little benefit from traditional treatment, particularly if the mental disorder is severe (Buckley, 2006; Khokhar, Dwiel, Henricks, Doucette, \& Green, 2018).

The 2011 white paper "Norwegian National Health plan” (Meld. St. 16 (2011-2015), 2011) stated that EBP is an explicit goal in Norwegian health policy and that health care systems must be developed to enable an evidence-based way of working. The white paper stated that persons with concurrent substance use disorders and mental disorders often need services over a long period, and frequently require coordinated services from the municipal and specialist health services. The national health plan from 2015 (Meld. St. 11 (2015-2016), 2015) specified the need for EBP in specialist services for people with concurrent substance use disorders and mental disorders. The white paper also referred to patient organisations calling for more EBP and a change in attitude towards these patients. EBP was part of several chapters in the most recent national health plan from 2019, which focused on implementation and particularly mentioned A\&F as an important strategy to implement CPGs (Meld. St. 7 (2019-2020), 2019).

The Norwegian health care system is divided into two levels. Primary care consist of general practitioners (GPs), emergency services, health clinics, home-based services, addiction services and nursing homes, all of which are mostly under municipalities. The second level is specialist health care with hospitals, consultants, rehabilitation centres, addiction centres, ambulance services and DPCs. Hospitals offer specialised treatment and are legally obliged to conduct research and educational activities, including training patients and their relatives (Act of Specialised Health Services, 1999). The Ministry of Health and Care Services has overall responsibility for all hospitals in Norway, and the state owns the public hospitals. The 
hospitals are organised into four regional health authorities: Health South-East, Health West, Health Central Norway and Health North.

DPCs are specialist centres (sometimes within a hospital) providing mental health care to people over the age of 18 . There are around 70 DPCs spread around the country, organised under specialised health care (Norwegian Directorate of Health \& Pedersen, 2016). GPs or other health care providers may refer patients to DPCs. They offer diagnostic assessment, outpatient and inpatient treatment and emergency assistance to people with mental and substance use disorders. The DPC system is similar to developments in other Western countries. Such decentralised specialised services are sometimes referred to as community psychiatry/community mental health care in the international literature. DPCs may be explained as community mental health centres adapted to Norwegian conditions (Larsen \& Bjørneboe, 2009). They may be organised in three management levels: senior management, middle (department) management and first-line (unit) management. Since 2001, there has been unitary management in Norwegian hospitals, replacing the traditional dual management structure based on a head nurse and a head consultant. However, the Health Personnel Act (1999) states that when cooperating with other health care professionals, the physician should make the decisions on medical questions regarding the examination and treatment of an individual patient.

Health care services have expanded and regionalised, with substance abuse treatment as one of the tasks of the health authorities. Interdisciplinary specialised substance abuse treatment departments (TSBs) include inpatient and outpatient services and are subject to the Specialist Health Services Act (1999).

The vast majority of employees of specialist mental health care are nurses, registered nurses and specialist nurses (psychiatric nurses), followed by psychologists and physicians or consulting psychiatrists (Statistics Norway, 2020). In addition, there are auxiliary nurses, social educators, child welfare officers and social workers. Registered nurses have a minimum of three years of nursing education (bachelor's degree), while psychiatric nurses have a minimum of one year of specialist education in addition to that. All health personnel in Norway need authorisation to practise as health personnel (Act of Health Personnel, 1999). Mental health care regulations require institutions to have sufficient interdisciplinary competence (Norwegian Directorate of Health, 2017). This could enable integrated treatment and interdisciplinary collaboration as recommended for persons with complex needs (Norwegian Directorate of Health, 2012). Interdisciplinary collaboration is then important and 
recommended, but it seems various professional groups have diverging views on EBP and CPGs. Nurses, managers and politicians' perceptions of the use of EBP and CPGs show that, although many value the evidence in CPGs, they seem to rely on clinical experience in everyday clinical practice (Renolen \& Hjalmhult, 2015; Sandström, Willman, Svensson, \& Borglin, 2015). The views on EBP and CPGs are diverse spanning from high importance to not applicable to clinical practice. A literature review concluded that Google is still a preferred source of information in relation to EBP among nurses, and the use of bibliographic sources is low (Alving, Christensen, \& Thrysøe, 2018). The review also documented that nurses prefer consulting and asking colleagues to searching bibliographic databases.

When the National Guideline was launched in 2012, the patient group and responsibilities were familiar, but the guideline clarified and reinforced the responsibilities and courses of action recommended for this group of patients. The next section provides a brief introduction to and overview of the National Guideline as the object of implementation in this thesis.

\subsubsection{The National Guideline for the assessment, treatment and social rehabilitation of persons with concurrent substance use disorders and mental disorders}

To ensure better services for persons with concurrent substance use disorders and mental disorders, the National Guideline was launched in 2012 (Norwegian Directorate of Health). A working group consisting of health professionals from primary and specialist services in mental health and addiction services and representatives from patient organisations developed the National Guideline. The guideline has two parts: Part 1 contains general information on persons with concurrent substance use disorders and mental disorders and Part 2 contains 93 recommendations in all. The recommendations are in the areas of service user participation, screening, diagnosis, treatment, roles and responsibility. The research evidence was graded using the SIGN classification (Scottish Intercollegiate Guidelines Network, 2019), which measured the strength of the evidence and the recommendation. The guideline is primarily designed for service providers working with people with both substance use disorders and mental disorders, especially municipal health care providers, employees of the Norwegian Labour and Welfare Administration, health and social care personnel in TSBs, health and social care personnel in mental health care and health personnel and prison staff in prison care. 


\subsubsection{Tools developed to ease the implementation of the National Guideline}

The implementation strategies developed to assist in the implementation of the National Guideline will be introduced hereafter. This is an important premise for a better understanding of the implementation strategy and process studied in this thesis, and to better understand the results in context.

The Norwegian Directorate of Health commissioned the Advisory Unit to create a guideline and tools to support the implementation of the National Guideline. According to the Advisory Unit, the main source used to develop the implementation programme was the model of Grol, Wensing and Eccles (2005).

One of the most important strategies was the development of a standard audit, an electronic questionnaire mirroring the recommendations in the National Guideline (Advisory Unit, 2013). This was a self-report questionnaire aimed at DPCs, containing 46 questions about screening practices, assessment of the target group, integrated treatment, collaboration, use of evidence-based methods and competence requirements. A group of staff members and managers from various DPCs around the country developed the audit. The questions were discussed, piloted and revised several times before the final version was made available on the Advisory Units website (https://rop.no/verktoy/gap-undersokelser/). Individual staff members of a chosen unit may answer the questionnaire. The results are aggregated at a unit level and may be shown as numbers, percentages, and/or by using charts. An action form was developed to be used together with the audit. The action form contained sections for areas for improvement, goals, actions, progress plan, main responsibility, economic assessment and evaluation. The implementation plan included brief instructions on how to use the feedback from the audit, how to use the action form and a recommendation to conduct a second audit after one year.

\subsection{The study site and the audit and feedback cycle}

\subsubsection{Recruitment of the district psychiatric centre}

An important aim of this thesis was to follow a natural implementation process entirely decided on and conducted by a DPC, independently of this research project. This meant finding a DPC ready to start an implementation process within a suitable time frame for the $\mathrm{PhD}$. Before starting the project, the author attended several meetings of the "national A\&F group", an ad hoc group led by the Advisory Unit. The purpose of the group was to develop an audit questionnaire, to test it in various settings and to discuss revisions based on 
experience. According to Creswell (2013, p. 148), gaining access to a site via gatekeepers may be vital. Thus, the reason for attending the meeting was two-fold: 1) to become familiar with $\mathrm{A} \& \mathrm{~F}$ and discussions arising in the meetings and 2) to learn about and gain access to possible sites for a case study. The choice of DPC was based on inquiries to several health authorities and DPCs and communication with staff of the Advisory Unit with knowledge of the field and the A\&F group. The choice was made in cooperation with the researcher's supervisors. No characteristics of DPCs were used to make the choice, other than the assumption that it was a "normal" or "average" DPC, thus matching a typical case within purposeful sampling (Suri, 2011).

The researcher spent several days with the staff and managers to become familiar with the chosen DPC. This is considered essential to build trust with the participants and learn the culture (Creswell, 2013, p. 250). The researcher attended several DPC meetings with the DPC manager, the first-line managers and the administrative staff, including informal conversations with these individuals. In addition, one meeting was attended with the staff from each unit, allowing for discussions to be observed before the A\&F started. The DPC administration provided documents containing formal information, such as organisational charts and minutes of meetings. The purpose of the researcher's presence was to become familiar with the field; thus, these observations were not considered as data (i.e. they were not analysed or reported on). Nevertheless, the time spent at the site increased the contextual understanding of the field.

\subsubsection{Description of the district psychiatric centre (the study site)}

The DPC where the study took place was under the Health South-East regional health authority and was located in the centre of a medium-sized city. It was a department within a hospital trust, organised under the division of mental health. The DPC was responsible for providing specialist mental health services to adults in an area with a population of 72,000 . It consisted of four units: one general outpatient unit, one crisis resolution team (CRT) and two inpatient units.

This DPC had one department manager and each of the units had a unit manager.

The inpatient units were quite similar in terms of size and staff; inpatient units 1 and 2 had 18 and 15 employees respectively who were eligible to complete the audit questionnaire, (i.e. not administrative or temporary staff). The staff were mainly registered nurses, assistant nurses and social educators, and there was one psychologist and one psychiatrist. Unit 1 focused on 
patients with psychotic disorders, while unit 2 focused on general psychiatry and patients with personality disorders. In these inpatient units, nurses, social educators (minimum three-year bachelor's degree) and assistant nurses are commonly referred to as milieu therapists or milieu personnel, while psychologists and psychiatrists (consultants) are often referred to as therapists.

The general outpatient clinic had 18 non-administrative staff eligible to complete the audit questionnaire. The staff were mainly psychologists, specialist psychologists, specialist registered nurses and consultants. The unit included a broad range of patient groups and operated as a general psychiatric outpatient clinic with regular hours and booked appointments.

The CRT had 12 full-time, non-administrative employees eligible to complete the audit questionnaire. They were mainly registered nurses and social educators, and one psychiatrist. The unit had an outreach service mainly focusing on preventing the development of serious mental health crises, preventing unnecessary hospital admissions and providing advice and guidance in emergency mental health crises.

It should be noted that the DPC was undergoing organisational and physical changes in the year between the first and the second audit. The outpatient clinic got a new first-line manager, and moved from a location outside the hospital to join the rest of the DPC at the hospital site. The health trust itself was in a rather turbulent period with many of its departments reorganising and moving. DPCs are under great pressure to conduct evidence-based work. This and the proliferation of CPGs from national bodies increased demands to document practice (as part of new public management), while regular organisational changes are contextual factors for QI projects in general and for this QI project.

\subsubsection{Description of the A\&F cycle conducted at the district psychiatric centre}

A supervisor (nurse specialist) employed by the health authority held an introductory educational meeting at the DPC in spring 2013. Later the same year, she presented the National Guideline and the tools for implementation, including the A\&F at a management meeting at the division of mental health. A decision was made to start the implementation process. The DPC manager informed the first-line managers of the decision. They all committed to the implementation process in their respective units as a unitary project for the whole DPC. 
An audit of existing practice was carried out in March 2014 with the supervisor's assistance. All four units were included, and all staff as described above were eligible to complete the audit questionnaire. Feedback was given verbally at the unit level, together with graphs presented by the supervisor and in writing (results were handed out to everyone at the meeting) about four weeks after the audit. Each unit held separate meetings where all staff were invited to sessions on EBP, a summary of the most important recommendations in the National Guideline and how to conduct an implementation process informed by an A\&F cycle. The unit managers summoned the meetings, and were present and involved. QI teams were formed to follow up on the feedback. An administrative advisor in the management team of the DPC organised all of the team meetings. Partly, this was to give the researcher an opportunity to be present at all the meetings. The QI teams met three to four weeks after feedback to reflect on the results and to complete the action forms for the following year. A final decision on the areas for improvement and the action plans was made in a DPC management meeting in June 2014. The following areas were chosen: alcohol and drug use screening, treatment of persons with concurrent substance use disorders and mental disorders and improving collaboration between the DPC, TSBs in the health authority and local authorities.

The actions (the implementation phase) were initiated the following year, with unit managers responsible for their completion. Among the actions were educational meetings aimed at all personnel and inter-professional meetings to enhance knowledge and possible role expansion. Some of the implementation strategies (including some educational meetings) were organised for the entire DPC and not at the unit level. A re-audit led by the same supervisor as for the first audit was conducted in June 2015, and all units participated. The process is illustrated in Figure 2. Feedback was given verbally to the DPC manager and the unit managers in June 2015 by the supervisor. It was assisted by graphical presentations handed out to each manager to be forwarded to the staff immediately afterwards by the unit managers.

Below, the stages are described in more detail (adapted from Potter et al., 2010):

1) Identify a topic that it is important to audit.

2) Establish the authoritative standards against which to audit (i.e. the National Guideline).

3) Develop audit criteria that will measure performance against the agreed standard.

4) Collect and analyse data and report results. 
5) Reflect on results and agree on improvement plan.

6) Implement the improvement plan.

7) Repeat the data collection to measure.

The researcher made an illustration to show the interaction between the A\&F cycle and the methods used to answer the research questions (see Figure 2). The figure show the A\&F cycle carried out by the DPC and when the research took place.

Figure 2: An illustration of the A\&F cycle (the case) with a study description (illustration made by MSP, 2019)

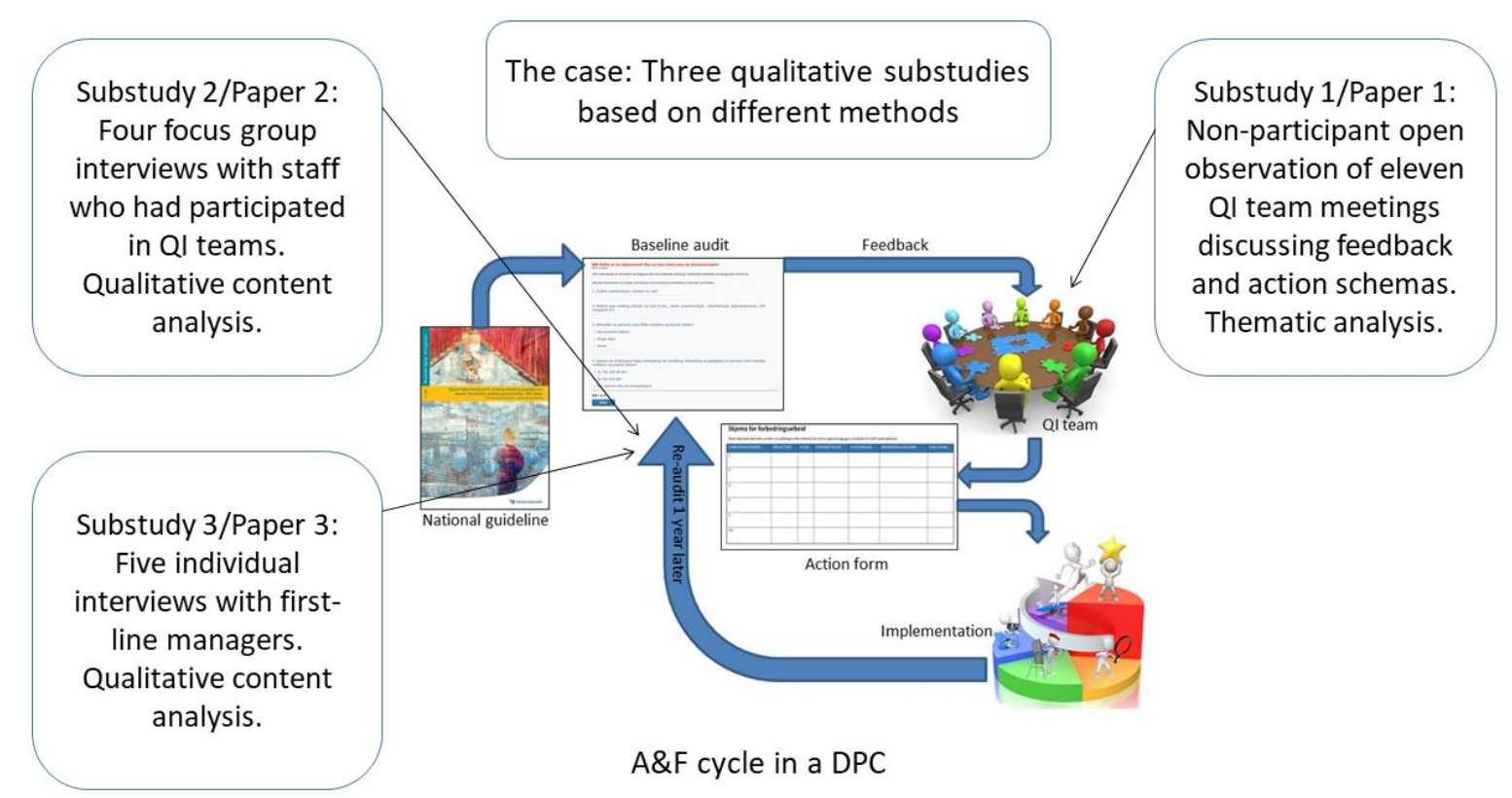

\subsection{Methods used for substudies 1-3}

This section describes the methods used for each substudy, as illustrated in Figure 2.

\subsubsection{Methods for substudy 1}

Substudy 1 used observations of QI team meetings as a method to generate data and thematic analysis (TA) to analyse the data. This is described in the following sections.

\subsubsection{Recruitment and description of the participants}

When the first audit was completed and feedback was given to the participants at the unit level, the QI teams came together to discuss the results and complete an action form. Each unit held separate meetings and had a different number of teams and team members (see Table 1). 
The unit manager chose the team members, with one to three QI teams per unit. Seven teams with 6-21 members (53 participants in total) were included. The QI teams reflected the unit staff: The two inpatient units included nurses, social educators or nursing assistants and one psychiatrist or psychologist per team. The QI team from the CRT also reflected the staff in the unit; it held more meetings and all staff on duty were included. The QI team from the general outpatient clinic had more doctors, psychologists and specialist nurses, which reflected the composition of the staff in the unit. The CRT was the only unit where the unit manager was present at the QI team meetings.

Table 1: Participants in the QI team meetings with number of teams and meetings per unit (table adapted from Pedersen, M. S., Landheim, A., Møller, M., \& Lien, L., 2018)

\begin{tabular}{|l|l|l|l|l|}
\hline & QI teams & $\begin{array}{l}\text { Number of } \\
\text { participants in } \\
\text { QI team } \\
\text { meetings }\end{array}$ & $\begin{array}{l}\text { Number of } \\
\text { meetings }\end{array}$ & $\begin{array}{l}\text { Unit leader } \\
\text { present at } \\
\text { meetings }\end{array}$ \\
\hline $\begin{array}{l}\text { General outpatient } \\
\text { clinic }\end{array}$ & 2 & 14 & 3 & No \\
\hline Inpatient unit 1 & 3 & 21 & 3 & No \\
\hline Inpatient unit 2 & 1 & 6 & 1 & No \\
\hline CRT & 1 & 12 & 4 & Yes \\
\hline Total & 7 & 53 & 11 & \\
\hline
\end{tabular}

\subsubsection{Observations of the quality improvement team meetings}

Observation is "a process by which people interacting in their natural settings are studied so that their behaviours and words can be put into their proper context" (Angrosino, 2016). Observation was used to explore and describe an early stage of an improvement process: how the results from an $\mathrm{A} \& \mathrm{~F}$ are discussed and thematised when $\mathrm{QI}$ teams in a DPC work to complete an action form as part of an A\&F cycle. The purpose of using observations as a method of gathering data was to study the work the participants did in their own work environment, their interactions and language (i.e. what they did and said in their context).

Non-participant open observation was chosen (Creswell, 2013, p. 166), allowing the researcher to openly observe participants in their regular work activity and environment, but without being part of the task accomplishment assigned to the QI teams.

During breaks and before and after the meetings, the researcher engaged in social conversations with the participants, described by Tjora (2012, p. 55) as interactive observation. This included answering any questions addressed to the researcher during the 
meetings. At the first meeting with a team, the researcher introduced herself, shaking hands with all the participants. A detailed presentation of the research project followed. It was emphasised that the researcher was not involved in deciding on or initiating the improvement process, nor implementing the A\&F. At the end of each team meeting, the researcher thanked the participants for allowing the observation and sometimes engaged in a brief discussion of how the participants experienced the presence of a researcher with an audio recorder.

The relatively well-defined units of analysis, the QI team meetings, enabled the observations. The research question for substudy 1 guided the observations: What is discussed and thematised when QI teams in a DPC work to complete an action form as part of an A\&F cycle? All seven QI teams were observed, over a total of 11 team meetings. The meetings lasted from 36 minutes to 112 minutes, giving a total of 11 hours. All of the meetings were held at the DPC, an environment familiar to the teams. The meetings were held in April and May 2014.

During the observations, the researcher made use of an audio recorder (Olympus LS-12 Linear PCM Recorder) to record words and other sounds rather than summaries alone. Written summaries were made in a structured template (observation protocol) during the meetings, showing the date, time and meeting number. The observation protocol had columns for descriptive (what happened) and reflexive (reflection and possible interpretations) notes as recommended (Creswell, 2013, p. 169; Tjora, 2012, p. 63). This was supplemented by reflections, written immediately after each observation on the atmosphere, statements the researcher wanted to highlight, agreements and disagreements in the teams and so on. Such notes are called different things in the literature, such as observational comments and field diaries (Tjora, 2012, p. 64). The purpose is to have a place for the observer's reflections, questions and experiences of the observations.

\subsubsection{Transcription of data}

To transcribe means to transform, from one form, the spoken word, to another, the written form to reproduce the content of the recorded meetings, making them more suitable for analysis (Brinkmann \& Kvale, 2015, p. 206). The researcher transcribed all of the recordings, as the transcription process is crucial as a first step of the analysis and also an important phase as part of a research education. The audio recordings were transcribed verbatim, including details such as long pauses and laughter. A first abstraction started at this point. The pages of transcribed data are constructions and a process of interpretation starts. It was essential to include the reflection notes, the observation notes and the audio files together with the 
transcribed data to be analysed. This was to ensure that there was a record of nuances such as irony, which are difficult to transcribe.

\subsubsection{Analysis of observation data}

TA as described by Braun and Clarke (2006) was used for this study, with the researcher looking for themes that were highlighted in the observed QI meetings. TA is appropriate to illuminate the specific nature of a group's conceptualisation of the phenomenon under study (Joffe, 2012) and was considered suitable for this substudy. Qualitative analysis can broadly be divided into two branches: It may be linked to or stem from a particular theoretical or epistemological position, or it may be independent of theory and epistemology. TA belongs to the latter branch, and is compatible with the constructivist paradigm (Braun \& Clarke, 2006), and the epistemological stance in this thesis.

The analysis was carried out in six steps as a TA suitable for instrumental case studies (Baxter \& Jack, 2008; Braun \& Clarke, 2006). Phase one involved becoming familiar with the data. This step included transcribing the audio recordings as described in the previous section. The computer software NVivo 10 (QSR International, 2012) was used to assist and organise the analysis, together with mind maps. The audio recordings were listened to repeatedly and all transcriptions and notes of reflection were reread to gain a sense of a whole.

Codes identifying semantic features of the data were assigned generously to ensure that nothing interesting or important was lost at this stage. This meant staying close to the spoken words. Such codes capture and supply a label for a characteristic of the data (Braun \& Clarke, 2012). A thorough review of the codes included uncoding and recoding them while comparing them with the text, to ensure a unified way of labelling and interpreting the text.

In the third phase, the codes were sorted into potential themes, "collapsing or clustering codes that seem to share some unifying feature together, so that they reflect and describe a coherent and meaningful pattern in the data" (Braun \& Clarke, 2012). Codes could appear across QI team meetings, but were sometimes apparent in just one meeting, providing a first impression of similarities and differences. Going back and forth between potential themes, the codes and the dataset was a way to ascertain whether the codes could form a theme. This phase included discarding codes that did not fit into the themes identified as able to achieve the aim of the study.

The next phase involved reviewing and refining the themes. This implies checking whether the themes work in relation to the coded extracts (Level 1). All the data were re-read to ensure 
that the themes fitted the dataset (Level 2). While assigning codes often involves a semantic or explicit level of analysis, assigning themes involves an interpretation that moves towards a latent level. An examination of assumptions and conceptualisations according to a constructivist paradigm starts here (Braun \& Clarke, 2006).

Phase five involved naming the themes and exploring the essence of each theme, and what aspects of the data it captured. A theme should be coherent, internally consistent and not too diverse or complex. A latent level of analysis was sought while staying true to the data.

The last phase was to produce the report, the story of the data. Adjustments were made until the end to make sure that the analysis and themes had captured the essence.

\subsubsection{Methods of substudy 2}

Substudy 2 used focus group interviews to generate data and qualitative content analysis to analyse data.

\subsubsection{Recruitment and description of the participants}

Focus group interviews were chosen to generate data for substudy 2. Participants were recruited from members of the ad hoc QI teams appointed at the outset of the process a year earlier. This was done when the second audit was completed and feedback was given to the DPC manager and unit managers. The unit managers selected the focus group participants at the researcher's request from among members of the QI teams. The participants were all health professionals working with patients on a daily basis representing several occupational groups. Each group consisted of four to six participants from the same unit, with the aim of homogeneity in experience and context within the group (see Table 2). However, to provide rich data, each group consisted of participants with different educational and professional backgrounds, such as psychologists, nurse specialists, medical doctors and social educators (Kitzinger, 1995), for a total of 20 persons. The aim of a focus group is to generate different viewpoints on a topic, not to reach consensus (Brinkmann \& Kvale, 2015, p. 175). None of the unit managers was present in the focus groups, to enable the staff to speak more freely. 
Table 2: QI teams and focus groups: (a) QI teams and total members from each unit; (b) focus group participants and how many participated in the QI teams one year earlier; and (c) educational background (table adapted from Pedersen, M.S., Landheim, A., Møller, M., \& Lien, L., 2018)

\begin{tabular}{|l|l|l|l|}
\hline & $\begin{array}{l}\text { QI teams (number } \\
\text { of members in total) }\end{array}$ & $\begin{array}{l}\text { Focus group participants } \\
\text { (number participating in } \\
\text { QI team meeting one year } \\
\text { earlier) }\end{array}$ & $\begin{array}{l}\text { Educational background of } \\
\text { focus group participants }\end{array}$ \\
\hline $\begin{array}{l}\text { General outpatient } \\
\text { clinic }\end{array}$ & $2(14)$ & $6(5)$ & $\begin{array}{l}\text { Specialist psychologist, } \\
\text { psychologists, nurse } \\
\text { specialists }\end{array}$ \\
\hline Inpatient unit 1 & $3(21)$ & $5(5)$ & $\begin{array}{l}\text { Psychologist, nurses, assistant } \\
\text { nurse, social worker }\end{array}$ \\
\hline Inpatient unit 2 & $1(6)$ & $4(3)$ & $\begin{array}{l}\text { Psychologist, nurse specialist, } \\
\text { social educator, assistant nurse }\end{array}$ \\
\hline CRT & $1(12)$ & $5(4)$ & Nurses and nurse specialists \\
\hline Total & $7(53)$ & $20(17)$ & \\
\hline
\end{tabular}

\subsubsection{Developing an interview guide for the focus group interviews}

A semi-structured interview guide was developed for substudy 2 (see Appendix 1). This was based on the broadly defined overall aim of the study and the aims and research question for substudy 2. The interview guide was designed to encourage reflections on the roles and experiences of the participants. As recommended by Brinkmann and Kvale (2015), the guide was also designed based on literature accessed during the writing of the research proposal and the literature searches conducted at the outset of the study (see Section 3.0). The interview guide was also informed by the researcher's attendance of A\&F group meetings arranged by the Advisory Unit, time spent at the DPC and particularly the observations of QI team meetings as measures to become familiar with the context and phenomenon under study. In accordance with the inductive approach of the study, the questions were not obtained from a specific theory. The interview guide was designed by the researcher and discussed with the supervisors. The interview questions were open-ended and developed around broader topics, leaving room in the interviews for the order of topic to be altered as the interviews evolved. The topics were also rather open areas of interest, concerning the usefulness and experience of participating in an A\&F cycle, the action form, the actions taken to implement the National Guideline and the experience of the whole process. Using an interview guide minimises inconsistency by ensuring that participants are asked more or less similar questions. The questions were open enough to ensure insight into several aspects of the phenomenon (Polit \& Beck, 2017, p. 510). 


\subsubsection{Focus group interviews of staff members}

Focus groups are groups of participants gathered for an interview to provide a variety of viewpoints on the topic in focus for the group, usually led by a moderator (Brinkmann \& Kvale, 2015, p. 175). Focus group interviews were completed in each unit. All the interviews were scheduled for June 2015, but two took place in June and two in September 2015. The cause of the delay was a lack of communication in the units regarding the meeting schedule. All the interviews took place in a setting familiar to the participants, in meeting rooms at the DPC. At the beginning of each focus group discussion, the researcher and co-moderator greeted all the participants, shook their hands and introduced themselves. The purpose of the research study was recapitulated, together with a brief overview of the process that had started a year earlier, the agreed areas of improvement and the actions decided on in the action forms. The interviews lasted approximately one hour and were led by the researcher with the assistance of an experienced co-moderator.

The interviews focused on the aim of the study and followed the interview guide, but with room for the researcher and the participants to explore other topics that emerged. Follow-up questions were asked to ascertain whether the researcher had understood the information. The interviews were summarised by the co-moderator at the end of each interview. While the researcher was responsible for the interviews, the co-moderator was present and had focus on the possibility of weaker and stronger voices in the group. The co-moderator was a registered psychiatric nurse with a master's degree and many years of experience with focus groups. She took notes, asked follow-up questions and read summaries to the participants to agree on or make additions or corrections. Discussions between researcher and co-moderator after every interview was audio recorded in addition to the researcher writing own reflection notes. The main points were recapitulated to ensure validation and the participants were given the opportunity to make changes or additional comments. The interviews were audio recorded (using an Olympus LS-12 Linear PCM Recorder) and summaries and reflection notes were made immediately after each interview by the author and the co-moderator.

\subsubsection{Transcription of data}

The aim of the transcription was to reproduce the content of the recorded meetings, making them more suitable for analysis (Brinkmann \& Kvale, 2015). The researcher transcribed the audio recordings verbatim, including details such as long pauses and laughter. Section 5.4.1.3 provides a more detailed description of the transcription process. 


\subsubsection{Analysis of focus group interview data}

To analyse substudy 2 , the researcher used qualitative content analysis in several steps as described by Graneheim and Lundman (2004). This method is suitable for analysing communication systematically; it allows for a focus on context and subject matter and emphasises both similarities and differences. The aim is to condense and describe the phenomenon and the outcome of the analysis in categories sharing the same meaning (Elo \& Kyngäs, 2008). This method assumes that reality can be interpreted in different ways and that understanding depends on a subjective interpretation (Graneheim \& Lundman, 2004), in line with the constructivist stance taken in this thesis.

The purpose of this study was to describe and explore how an A\&F cycle is experienced by staff in a DPC. Therefore, the researcher decided on a rather inductive content analysis with no pre-existing analytical framework, recommended when there is insufficient or fragmented knowledge of the phenomenon (Elo \& Kyngäs, 2008).

Qualitative content analysis has its roots in merely describing text, the obvious components, referred to as the manifest content. As the method expanded, a greater degree of interpretation of the underlying meaning of a text, referred to as the latent content, became part of the method (Graneheim \& Lundman, 2004). The level and depth of abstraction vary, but both manifest and latent content deal with interpretation.

The unit of analysis was transcripts of the focus group interviews with the staff, together with the reflection notes. The NVivo 10 qualitative data analysis software (QSR International, 2012) was used to facilitate the analysis.

The audio recordings were listened to and the transcripts were read several times to gain a sense of the whole and to gather ideas for further analysis. This is a crucial first step to get a sense of the whole.

The text was divided into meaning units; word, sentences or paragraphs that share content or are related to each other in a context. The meaning units must be short enough to ensure they do not contain various meaning, but also broad enough not to be fragmented. The text in the meaning unit was sometimes condensed with key content preserved.

The next step involved labelling the meaning units. This label is called a code. A label allows the researcher to see the data in a new way.

The following phase involved finding a thread running through the codes. That meant sorting codes into categories. This was done by being descriptive and close to the text. Categories are 
groups of content that share a commonality, they are grounded in the data, representing manifest content in the text (Graneheim \& Lundman, 2004). At this phase of the analysis, the researcher started to move between manifest and latent content. That is starting to interpret the underlying meaning of the text.

When all the text was coded and categorised, the search for themes started, involving the search for a more latent content, or finding a thread of underlying meaning. According to Graneheim and Lundman (2004) there are various ways to develop a theme. In this study the researcher tried to stay close to the participants' description of experience and find running threads of meaning-making to create a theme. This phase was done in close cooperation with the researcher's supervisors and included discussions with colleagues with clinical experience.

\subsubsection{Methods of substudy 3}

Individual interviews were used to generate data for substudy 3 , and the data were analysed using qualitative content analysis. This is described in this section.

\subsubsection{Recruitment and description of participants}

The interview participants were the unit managers (first-line managers) of the DPC. They were all registered nurses with several years of experience as managers. One unit manager was new to the organisation. There was one male and four females (all addressed as "she" in the text to obtain anonymity). One of the unit manager positions was vacant at the beginning of the A\&F cycle. This unit was led by the DPC manager (middle manager) in the period of vacancy, so she had a double role for a few months. A new unit manager was in place about half way into the A\&F cycle, and took over responsibility for the cycle. Interviews were conducted with both the DPC manager and the new unit manager in this unit to elicit data that was as rich as possible. All of the interviewees signed a declaration of consent to participate.

\subsubsection{Developing an interview guide for the individual interviews}

A semi-structured interview guide was developed for the individual interviews (see Appendix 1). It was based on the broadly defined overall aim of the study and the aims and research question of substudy 3 . The interview guide was designed to encourage reflections on the roles and experiences of the first-line managers. The topics were rather open areas of interest, concerning the usefulness and experience of participating in an A\&F cycle, the action form, the actions taken to implement the National Guideline and the experience of the whole 
process. Section 5.4.2.2 provides a more thorough description of developing an interview guide.

\subsubsection{Individual interviews of the first-line managers}

The purpose of the interviews was to describe and explore how first-line managers in a DPC experienced using an A\&F cycle as a basis for QI in specialist mental health care. The interviews were based on an open interview guide (see the previous section). The interviews took place as the full A\&F cycle was completed, one year after the outset of the process and a few weeks after the second audit was completed, in June 2015 (see Section 5.1, Figure 2). Each interview lasted about one hour and was led by the researcher as the only other person in the room. The interviews were held in the managers' own offices. All of the first-line managers, except the one who was new, knew the researcher from a year prior, when quite a lot of time was spent in the DPC to become familiar with the context. The interviews started with some small talk and a recapitulation of the aim, the beginning of the process and the areas of improvement decided on a year earlier. The interviews followed the interview guide, while being sensitive to topics raised by the participants. The researcher was inspired by Elton Mayo's interview method as described by Kvale and Brinkman (2015, p. 50). The method focuses on devoting full attention to the participants, listening, avoiding arguments and maintaining confidentiality. Follow-up questions were asked during the interviews to ascertain whether the researcher had understood the information. To ensure agreement on the essence of the interview, the researcher summarised notes taken during the interviews at the end of each session. An audio recorder (Olympus LS-12 Linear PCM Recorder) was used and reflection notes were made immediately after each interview.

\subsubsection{Transcription of data}

The aim of the transcription was to reproduce the content of the recorded meetings, making them more suitable for analysis (Brinkmann \& Kvale, 2015). A student transcribed two of the interviews. This was done according to routines established for the transcribing process in substudies 1 and 2. See Section 5.4.1.3 for a more detailed description of the transcription process. The researcher spent some extra time reading the transcripts done by the student while listening to the audio recordings to ensure that the transcripts were done according to established routines and to recall the interviews and the atmosphere. 


\subsubsection{Analysis of the individual interview data}

To analyse substudy 3 , the researcher used qualitative content analysis in several steps as described by Graneheim and Lundman (2004). The aim of this study was to describe and explore how first-line managers in a DPC experience using an A\&F cycle as a basis for QI in specialist mental health care. The researcher decided on a rather inductive content analysis with no pre-existing analytical framework, recommended when there is insufficient or fragmented knowledge of the phenomenon (Elo \& Kyngäs, 2008).

The purpose was to condense and describe the phenomenon. The outcome of the analysis was categories sharing the same meaning (Elo \& Kyngäs, 2008). This method assumes that reality can be interpreted in different ways and that understanding depends on a subjective interpretation (Graneheim \& Lundman, 2004), in line with the constructivist stance taken in this thesis. This is elaborated in Section 5.1.

The unit of analysis was the individual interviews with the first-line managers, together with the reflection notes. NVivo 10 qualitative data analysis software (QSR International, 2012) was used to facilitate the analysis. The audio recordings were listened to and the transcripts were read several times to gain a sense of the whole. This process also contributed to gathering ideas for further analysis. The text was divided into meaning units and condensed with the key content preserved and coded. Thereafter, codes were sorted into categories grounded in the data and representing manifest content in the text. When all the text was coded and categorised, the search for themes started, involving a search for more latent content (Graneheim \& Lundman, 2004). This phase was carried out in close cooperation with the researcher's supervisors. The researcher also discussed the analyses with clinically experienced colleagues. Se Section 5.4.2.5 for a more thorough description of the method of analysis.

\subsection{Ethical considerations}

\subsubsection{Funding and approval}

This study was funded entirely by Innlandet Hospital Trust [Case E13240].

The study was approved by the Data Protection Officer for Research at Oslo University Hospital [Case 2013/16177]. The Research Department at the study site also approved the study. Since the study was not seeking new knowledge on health or illness, it was not eligible for application to the Regional Committees for Medical and Health Research Ethics. The 
study was conducted according to the ethical guidelines of the Declaration of Helsinki (World Medical Association, 2013).

\subsubsection{Data storage and access}

Data collected in the study were stored in accordance with updated routines for information security and privacy in Innlandet Hospital Trust, in a folder in a sensitive structure on Sykehuset Innlandet's platform with strict access control. In addition to the researcher, the researcher's two supervisors, Lars Lien and Anne Landheim, had access. The project followed the regional protocol for updated dates for the anonymisation / deletion of personally identifiable data.

The transcribed interviews, transcriptions from the observations and notes of reflection were all stored in a de-identified form. Names and identifiable data were removed from the transcripts and replaced with "focus group interview 1, 2, 3" etc., "participant 1, 2, 3" etc. and “interviewee 1, 2, 3" etc. A list that linked data with personal information was kept separately in a filing cabinet dedicated to research data in a locked room in the Advisory Unit, with the keys stored in another locked office. All of the audio files were stored on the same platform as the transcribed material. Nothing was done to anonymise the audio files (e.g. by applying a masking sound whenever a name/place was mentioned). This probably should have been done. Given the secure storage of the data, it is reasonable to assume that this did not jeopardise the anonymity or harm the participants in any way.

\subsubsection{Ethics}

It has been argued that health care professionals, organisations and researchers have an ethical obligation to close the gap between EBP and actual patient care through implementing best known practice (Dixon, 2017; Dubois \& Prusaczyk, 2018). This places the implementation process initiated by the DPC in an ethical framework; they have an obligation to implement EBP. The Public Health Leadership Society (2002) stated in its "Principles of the Ethical Practice of Public Health" that people are responsible for acting on the basis of what they know. An underlying value and belief of these principles is that information should not be gathered for idle interest; public health should seek the information needed to implement effective policies and programmes that protect and promote health, and should seek to translate the available information into timely action. In contrast to implementation activities, implementation research aims to study the effects of interventions, the uptake of EBP or other variables such as process evaluation or the experience of the use of implementation strategies. 
Research on implementation may contribute to the goal of using EBP through independent responsibility for making implementation more effective (Dubois \& Prusaczyk, 2018).

It is crucial to determine whether a project is a QI programme (such as the A\&F cycle studied in this thesis, "the process") or an implementation research project, such as this study, which explores the A\&F cycle using scientific methods. A QI project normally does not require informed consent, while a research project considers the health personnel involved to be participants in a research study and thus requires informed consent (Macklin, 2014).

All of the first-line managers are referred to as "she" in the material to maintain anonymity. A choice was made not to name the DPC to protect the anonymity and integrity of the participants. Easily recognisable statements were rewritten in the quotes for the same reasons. In the information letter to potential participants, it was stated that only personnel related to the project would have access to the research material. In the information provided orally, it was emphasised that the data (audio recordings and transcripts) would not be made available to their superiors or anyone else in the organisation and would be stored in a way that ensured confidentiality.

All staff observed in the team meetings, the staff and managers interviewed and the R\&D nurses at the study site signed a declaration of consent, following ethical guidelines for qualitative research (Brinkmann \& Kvale, 2015, pp. 93-94), and approved by the Data Protection Office for Research at Oslo University Hospital. In addition to the written information about the research on the consent form, information was also given verbally on several occasions.

The participants were informed that they could contact the researcher after the observations and interviews in order to withdraw from the study at any point without any personal consequences. The researcher's contact information was given to all participants in the information letter. In retrospect, the information letter could have been more specific about the possibility of withdrawing without consequences for the participants. None of the participants contacted the researcher in this regard. If one or more participants had withdrawn from the project after the observations had started, the data from the whole team observed would have been discarded. The same would have applied to the focus groups or the individual interviews. This could have jeopardised the results and thus the whole case study, lowering the possibility of a rich description and exploration of the aim of the study. The DPC manager and the first-line managers were a gateway to gain access to the site. Because of that, 
it is impossible to be certain that everyone who signed the consent to participate did so entirely voluntarily. It is possible that members of the QI teams who were asked to participate in the focus groups, did not feel able to refuse for various reasons (for example, out of loyalty to the leader or fear of losing earned benefits, such as being on the QI team). Given that ethics are inherent in this paradigm and due to the inclusion of the participants' values in the inquiry (Guba \& Lincoln, 1994), participants could have faced a risk in openly sharing their values and thoughts. The observed team meetings may have been even more vulnerable, as some teams were rather large and members could have felt that it would compromise the rest of the team's work or the research project to withdraw from participation. The researcher could have mitigated this through a short interview or a simple question posed to each of the participants. This was not done, leaving doubts regarding the issue of complete consent.

The data collection in this study lasted for more than a year; data were collected at the beginning of the implementation process (the QI teams) and after one year (the focus group interviews and manager interviews). The participants were mostly the same at both points in time, with just a few differences in the focus groups and one new manager. It cannot be assumed that informed consent given at the start of a study remains valid throughout an extended study. This should probably have been discussed with the participants and a new consent form should have been offered, particularly to the focus group participants. However, information about the research project was emphasised throughout the process and especially ahead of all data collection, such as the focus group interviews.

The registered nurse (MM) who facilitated the practical implementation of the A\&F was employed at the hospital (thus not in the DPC). She was acquainted with some of the participants and the DPC. She contributed to validation of the results and the write-up of the papers, but was not present during any of the data gathering, and did not read the datatranscripts to protect the participants' anonymity and integrity. 


\subsection{Results}

The overall aim of this study was to add to the knowledge of the use and experience of an A\&F cycle in a DPC in Norway. This was done by exploring an A\&F cycle over a year from different angles: by observing QI team meetings at the outset of the process and interviewing groups of personnel and first-line managers at the end of the cycle, together forming a case study. The main results of each paper are presented in this section.

\subsection{Paper 1: Acting on audit and feedback: A qualitative instrumental case study on mental health services in Norway}

$A \& \mathrm{~F}$ is commonly used as the starting point of an implementation process. It aims to measure the research-practice gap, but its effect varies greatly. Little is known about how A\&F is used in natural settings in mental health care. The aim of substudy 1 was to describe and investigate what is discussed at the beginning of an A\&F cycle.

The results of the first audit showed a mismatch between recommendations in the National Guideline and local practices in several areas, across all units. Feedback on the results was given at the unit level and discussed in QI team meetings with the aim of working out action plans to close the gaps and implement recommendations from the National Guideline.

The QI team meetings consisted of discussions of practice in general, the National Guideline and various organisational issues. The A\&F contributed to the awareness of recommendations from the guidelines, best practice and how to meet divergent demands in an open and collaborative way. When a new CPG arrives, self-reported audits seem valuable as an implementation strategy, particularly in areas where no benchmarked data exist.

Not all teams had a first-line manager present. Completing action forms clarified that new tasks and responsibilities could be the result, particularly in the inpatient units. An A\&F shakes up adopted practice standards and forces a reconsideration, particularly concerning roles and responsibilities. The presence of a first-line manager probably benefitted the discussions and helped lift the discussions on task allocations, responsibilities and job expectations. The A\&F brought forth discussions on "knowledge", concerning a lack of knowledge, valid sources of knowledge and where to seek knowledge. The discussions on A\&F uncovered that personnel such as registered nurses and social educators used to turn to the consultants for all kinds of questions concerning practice and clinical knowledge. When other sources of information were discussed, a lack of information competence was 
uncovered. From this perspective, A\&F contributes to the awareness of information competence.

Persons with concurrent substance use disorders and mental disorders are a complex group of patients. A CPG alone is not enough to solve research-practice gaps concerning these patients. The A\&F raised the awareness of this group of patients and the complexity of the illness and the system of care. The complex organisation of health care across several levels and departments became a difficult issue to solve for several teams. The majority of health care personnel assumedly know how health care systems are organised. The A\&F turned out to be important to clarify the patients' needs in a local context and on a micro level; for example, it illuminated the consequences for each unit, for individuals' everyday work and in relation to the bigger picture, the broader health care system with which the staff must cooperate.

\section{Conclusion}

QI team meetings after A\&F seem to be a suitable and welcome setting for discussing practice, enhancing the awareness of good practice and recommendations from CPGs and exploring how to meet divergent demands in an open and collaborative manner. Registered nurses and social educators easily turn to consultants for clinical questions and show low confidence or a lack of routine in seeking research-based information. In addition, the existence of the National Guideline in the area of concurrent substance use disorder and mental disorder came as a surprise to some members of the QI teams. This led to the conclusion that training in EBP and information-seeking behaviour for all professional groups might need to be emphasised.

\subsection{Paper 2: Audit and feedback in mental healthcare: Staff experiences}

A\&F is widely used in implementation projects. However, it has variable effects, with no apparent explanation for this. We need to understand how A\&F works in real-life situations and in particular how A\&F is used, understood and accepted by staff in order to enhance the knowledge of improving A\&F cycles. The aim of this paper was to describe and explore how specialist mental health service staff experience working with an A\&F cycle as a basis for implementation to gain real-life process knowledge.

The staff viewed the A\&F as valuable for several reasons. One obvious and intended reason was to reveal areas requiring improvement. Another reason was that A\&F confirmed good practice and highlighted competencies hidden in everyday practice. The staff also experienced 
increased awareness and a greater sense of responsibility. This was in relation to the particular CPG the audit measured against and the group of patients addressed. All focus groups experienced that an $\mathrm{A} \& \mathrm{~F}$ alone did not have much value; it had to be part of a larger process, an A\&F cycle, to be experienced as valuable.

Yet, the staff reported feeling alone in an A\&F cycle; no one seemed to take full responsibility for initiating or following up on decided actions. The initial sense of enthusiasm slowly fizzled out and there was a lack of attention to the A\&F cycle. Reminder functions and particularly a process facilitator were among the suggested improvements, particularly since first-line managers were experienced as having more than enough on their plates. Despite experiencing $A \& F$ as valuable and drawing necessary attention to an important area, the staff felt that there was a never-ending flow of guidelines, procedures and projects from organisational and national bodies. The staff felt that there was a lack of prioritisation and that they were not given enough time to become good at something. Insufficient follow-up, process leadership and prioritisation caused a sense of an absence of ownership of the full A\&F cycle. This lack of ownership was experienced despite the fact that staff were invited to participate in the process through QI team meetings deciding on areas of improvement to be prioritised and measures that could be taken to implement recommendations from the National Guideline.

\section{Conclusion}

This study offers valuable insight into staff needs and the possibilities for organisational facilitation in health care organisations. Designated facilitators are needed in an A\&F cycle, as are leaders who are able to give meaning and purpose to the process and maintain its momentum throughout changing conditions and daily routines. Failing this, it seems challenging to maintain a full A\&F cycle, even when tools for implementation are at hand and staff are invited to contribute to the process. The A\&F cycle was viewed as particularly valuable for confirming knowledge and skills that are otherwise often hidden and for acknowledging practices in line with recommendations in a CPG.

\subsection{Paper 3: First-line managers' experience of the use of an audit and feedback cycle in specialist mental health care: A qualitative case study}

$\mathrm{A} \& \mathrm{~F}$ was used as a main strategy to implement recommendations from the National Guideline. Studies have shown that leadership support is an important contextual factor that may contribute to implementation success. The aim of this study was to describe and explore 
how first-line managers in a DPC experience using an A\&F cycle as basis for QI in specialist mental health care.

All the first-line managers expressed a positive attitude towards A\&F as a strategy for implementation and as a management tool. They experienced being in a better place professionally than before the process, in line with the results of the second audit, which showed improvement in the chosen areas.

The first-line managers saw it as their responsibility and role to ensure that the A\&F cycle was completed, including prioritising, providing reminders and facilitating the process. Nonetheless, administrative daily tasks took up most of their time and left little room for them to facilitate the A\&F cycle. Despite a rather enthusiastic start-up, the process slowly faded from focus. One reason for this, according to the first-line managers, was the absence of support and attention from the management level above. They requested a stronger organisational focus in the DPC as a whole and a forum for discussing the process. They invited the R\&D nurses to participate in the process but gave them little responsibility aside from organising demarcated tasks such as educational courses. They also invited the staff to participate in the A\&F cycle by inviting them to QI team meetings; however, they made little use of the teams after the initial work was completed.

Even though the first-line managers thought that the process itself was valuable, it was still considered a top-down process being imposed on them. This was despite their being asked to participate on behalf of their unit and their engagement in numerous meetings before the inception of the A\&F cycle. Related to this was a feeling of being flooded with top-down initiatives from superior authorities expecting the initiatives to be implemented in the clinic. These initiatives, such as CPGs or organisational procedures, were seen more as directives than as decision aids for better quality practice. The first-line managers indicated a feeling of a distance between organisational levels. Although they were loyal to the decision and to initiating the process, they expressed that they did not think that management higher in the organisational hierarchy or issuing bodies understood daily life in a busy clinic. One of the first-line managers expressed scepticism as to whether the A\&F cycle was worth the effort, indicating that this project came on top of other things demanding attention from a manager. A distance was also present between the roles and responsibilities of first-line managers and therapists. Therapists play a key role in the treatment of patients, as they are professionally and legally responsible for medication and the course of treatment. It became clear that there 
were discrepancies between the way in which the first-line managers wanted to run the units and the decisions taken by the therapists. High turnover, with new therapists coming and going at a fast pace, impeded the development of stable relationships. This seemed to decrease the staff's determination, as they were not necessarily given the opportunity to use their inherent competence and managers defined themselves as part of the staff rather than as unit managers.

\section{Conclusion}

The complexity in the role of a manager in relation to staff, higher management levels and professional leaders was perceived as a challenge; first-line managers felt torn between different commitments, without the autonomy to act as process drivers or facilitators and without taking a leadership role. They did not seem to be sufficiently experienced or skilled to drive an A\&F cycle. Limited organisational support and capacity to respond effectively to A\&F partly constrained the accomplishment and impact of the A\&F cycle. 


\subsection{Discussion}

In this section, the main findings across the three articles forming the case study in the thesis are discussed in light of existing knowledge and a critical reflection on the study. This is because the purpose of an instrumental case study is to understand not the various parts of the case alone, but the overall case: the experience of the A\&F cycle (Baxter \& Jack, 2008). Another reason for this is that this study incorporates the full A\&F cycle, in contrast to most other studies.

\subsection{Discussion of the main results}

The overall aim of this study was to add to the knowledge of the use and experience of an A\&F cycle in a DPC in Norway.

\subsubsection{An A\&F cycle creates an opportunity for open and sharing practice}

All three papers show that staff and first-line management in the DPC have an overall positive attitude towards A\&F, finding it to be an eye-opener, and to shed light on and confirm their competencies and good practice and reveal differences in practice. Discussions of the feedback in QI teams were a welcoming opportunity to delve into various aspects of practice. This is in line with other studies from different clinical settings (Ivers, Barnsley, et al., 2014; Kristensen \& Hounsgaard, 2014; Rattray et al., 2020; Shepherd et al., 2010; Sinuff et al., 2015; Taylor et al., 2016; van Braak et al., 2019; Webster et al., 2016). This became clear particularly at the beginning, when QI teams met to plan for actions, where the teams needed to contextualise the feedback and discuss implications for local practice. Despite a range of barriers and unmet needs, positive attitude towards A\&F was still present at the end of the implementation process, mostly in the inpatient units and the CRT. The phenomenon concern the way the A\&F is followed by work in QI teams, where the results are discussed in an orderly manner prompted by the audit results, and the way this enables formal participation in an improvement process. This is consistent with the final recommendation in Brehaut's suggestion for optimising feedback interventions: to construct feedback through social interaction (Brehaut et al., 2016). It is also found in other qualitative studies to be an important arena to interpret and contextualise the feedback reports and learn from colleagues (Cooke et al., 2018; Rattray et al., 2020; van Braak et al., 2019). Given the importance most participants placed on this particular feature of the A\&F cycle, it would be vital for an organisation, that would be managers at all levels, to prioritise this part of the A\&F cycle, 
giving an opportunity to "translate" the feedback reports and the recommendations from a CPG to everyday tasks and roles.

A finding in this study is the value of A\&F and the QI team meetings in specialist mental health care for validating existing practice. Earlier studies has found that feedback reporting practice to be in line with, or better than set goals or benchmarked data. This may create a sense of pride in physicians, being a competitive and high achieving group (Smiddy et al., 2019; Webster et al., 2016). Our study found this to be present by all professional groups, not only physicians. This provides a picture of best practice as a motivational factor in all professional groups. It is important to take into account that this particular feedback under study was group-based and not individual. It thus gives first-line managers an important tool to appreciate a group (e.g. the ward or team), for doing a "good job". For the individual health care personnel this could be a significant inspiration to participate in QI processes based on $A \& F$ - to see where under-utilized competence may become useful, and thereby enhance empowerment. For first-line managers this could be an important knowledge both as means to improve practice and to learn to know team members better and to apply beneficial competence in new tasks or roles appearing in the process.

\subsubsection{Attitudes to and knowledge of EBP and information competency as barriers to} A\&F

It is problematic to discuss A\&F without also discussing its relation to EBP, as expounded in the Background section. In this study, CPGs were frequently seen as coming from "above", either from the upper level management or from other health authorities. They could interrupt usual practice, or were seen as a standard practice not necessarily easily agreed on or adopted. This attitude towards CPGs or other EBP initiatives was seen at the outset of the process, and came up in the focus group interviews and in the individual interviews, and could easily have impeded the A\&F cycle, since one factor that may moderate an implementation process is staff attitudes towards EBP (Aarons, Hurlburt, \& Horwitz, 2011).

There are several ways of trying to understand this finding, as a constraint on resources such as time or it is possible to speculate whether this could be interpreted as a negative attitude towards EBP or as a lack of knowledge of EBP. Better information competence and knowledge of EBP could reduce the experience of being the victim of getting directives from above. However, all three sub-studies (Paper 1-3) show a desire to provide better treatment to fill the "research-practice gap". This might seem a contradiction, where staff on the one hand would like to improve quality of health care offered, but find it difficult to accept CPGs or 
other practice recommendations coming from health care authorities - trust in sources and evidence.

Qualitative research has shown that nurses often find it difficult to search for evidence-based knowledge and do not necessarily trust evidence-based research sources (Renolen \& Hjalmhult, 2015), also questioning the relevance and applicability of CPGs (Prytys et al., 2011). There are studies showing that staff such as registered nurses and social educators lack knowledge of EBP or information retrieval skills (Clarke, Belden, Koopman, Steege, Moore, Canfield, \& Kim, 2013; Koivunen, Valimaki, \& Hatonen, 2010; O'Leary D \& Mhaolrunaigh, 2012). A Norwegian study show that nurses searched for answers amongst each other and from doctors, or by using printed procedures, paper checklists and the doctor's desktop reference with the aim of spending as little time as possible and quickly finding an easy solution (Renolen, Hoye, Hjalmhult, Danbolt, \& Kirkevold, 2018). They more rarely used scientific knowledge, and sometimes dismissed what they found because it was difficult and not necessarily in line with existing practice. The study by Kristensen and Hounsgaard (2014) found an expressed need for somebody to be in charge of providing new knowledge and enabling the experience of using it in daily practice. This may imply insecurity about putting knowledge into practice, but also a need for knowledge brokering in the sense of translating recommendations into local settings.

There was also professional scepticism about standardised practice in the general outpatient clinic. The staff there were in general more familiar with CPGs, and aware of their existence, but did not necessarily agree with their recommendations or in more general terms with standardised practices. This was largely based on their professional standing, whether consultants or specialist psychologists, but could also be on theoretical grounds, accepted as professional differences. A Norwegian study found that clinicians in mental health care have rather negative attitudes towards new forms of therapy if these feels like they are imposed on them (Egeland, Ruud, Ogden, Lindstrom, \& Heiervang, 2016). The way EBP is operationalised can easily miss some crucial elements for optimal clinical practice. As outlined in this thesis, EBP is linked with the development of CPGs (and therefore with interventions aiming to implement guideline-based recommendations). This thesis does not examine the strengths and weaknesses of EBP, but EBP is a foundation for carrying out an $\mathrm{A} \& \mathrm{~F}$, and thus important to discuss in connection with the experience of using an A\&F. Random patient experiences could risk becoming the principal factor in the discussion following A\&F without a clear knowledge of CPGs as a foundation for EBP. The staff are 
already well qualified in their respective fields, presumably performing their tasks well. The findings in this thesis suggests a lack of skilled information-seeking behaviour and knowledge of how to use that information on an everyday basis. Put bluntly, it seems that consultants are the ones to keep themselves updated, while the rest of the staff rely more on their knowledge and effort.

\subsubsection{Disclaiming responsibility and limited leadership throughout the A\&F cycle}

"Disclaiming responsibility and limited leadership throughout the A\&F cycle" is found throughout the A\&F cycle, and may be defined as a main finding in the overall case study. Staff handed over responsibility to the management, or if they were milieu personnel, to the therapists. The QI teams were given the opportunity to contribute to the A\&F cycle, but did not take the opportunity. Instead, they declared that they were not being led. The first-line managers declared responsibility, but lost focus, and wished for someone responsible for the entire A\&F cycle. This may be interpreted as a systematic disclaiming of responsibility, resulting is a lost opportunity to make the most of the A\&F cycle.

Specialist mental health care is subject to a wealth of CPGs, most of them addressing one condition at a time while patients often have multi-comorbidities, making it more difficult to navigate between CPGs (Austad, Hetlevik, Mjølstad, \& Helvik, 2015). In addition, there are other guidelines, clinical pathways, and local procedures. This supports the feeling of being overwhelmed as described by participants in this thesis. A DPC may be involved in more than one QI project simultaneously, adding to an explanation for disclaiming responsibility (McCleary et al., 2020).

The mental health clinic is a complex system with sometimes blurred roles and hierarchical structures possible making it difficult for an individual staff member or first-line manager to take full responsibility. The relationship between leadership abilities, and in particular transformational leadership, and implementation of new practices has been established (Michaelis, Stegmaier, \& Sonntag, 2010). First-line managers experience a balancing act between organisational requirements, the management level above, the management and support of staff and the consultants as the professional leaders of the clinic. The staff for their part expressed insecurity about roles and responsibilities in daily practice. Studies from mental health care indicate role confusion and insecurity and the need for a specialist on the team to provide reassurance and learning from colleagues' services (Shepherd et al., 2010). Leadership is an organisational contextual factor that contributes to a climate of implementation (Aarons et al., 2014). Transformational leadership is important to create such 
a climate (Aarons et al., 2015). There is no data in the three substudies to indicate laissez-faire leadership, but explicit transformational leadership was not present either, where the leaders inspired their staff to implement EBP. Instead, first-line managers appeared to be operating more as union leaders, defining themselves more as part of the staff group than leaders of it. They typically listened to comments that guidelines are "just another thing coming from above" and agreed with them, not taking the lead in educating, inspiring and leading staff towards an understanding of CPGs as a source of optimal care provision within their particular context, which would reduce undesirable inequality. The effect of reducing the gaps revealed by the $A \& F$ and benefitting from the work accomplished in the QI teams may thus be decreased. A Norwegian study from mental health care found that practitioners emphasised the importance of their leaders (Egeland et al., 2019). The leaders needed to have clear goals and show engagement in the intervention in the clinic to sustain implementation. Leadership is about having vision and mission and directing, inspiring and motivating. This differs from management, which is about budgeting, staffing, organising, and identifying and solving problems (Kotterman, 2006). Wagner and colleagues (2019) stated that performance feedback is important, but probably not sufficient to promote QI, while an ongoing coaching of the process is central to achieving change in practice.

One theme seen across the three different studies is the wish for someone to keep a steady hand on the A\&F cycle, remind staff about the process, inquire on progress and follow up on decision. This could be a process facilitator, a success factor seen in other studies (Kristensen \& Hounsgaard, 2014; Payne \& Hysong, 2016; Wagner et al., 2019). On the contrary, Cooke and colleagues (2018) found that discussing EBP and moving to action planning was more due to the group members' interaction, indicating that having colleagues present is as important as having a facilitator present. In the latter study the participants were physicians. In other studies, the participants particularly asked for increased involvement by senior medical staff (Sinuff et al., 2015). Senior medical staff were not interviewed in particular in this study, although this might have added value to the overall case study. However, a psychologist or consultants were present in most QI teams, and were thus among those who reported experience of using A\&F. Although mental health care promotes interdisciplinary teamwork it still seems to be a large share of the responsibility that is put on the professional leadership (consultants) and middle management.

It is beyond the scope of the study to discuss organisational readiness to change. At the same time, since a main theme in this thesis is disclaiming responsibility and limited leadership 
throughout the A\&F cycle, it is reasonable to try to find possible explanations. Factors such as personal readiness, institutional readiness, innovation readiness, change processes, and organisational dynamics might constrain (or facilitate) the possibility to make the most of an implementation process (Attieh, Gagnon, Estabrooks, Legare, Ouimet, Vazquez, \& Nuno, 2014). Lack of QI skills is shown in several qualitative studies to be a barrier to facilitate A\&F cycles (Glenngård \& Anell, 2021; Harvey et al., 2012; Ivers, Barnsley, et al., 2014; Trietsch et al., 2014; Wagner et al., 2019). This could be an explanatory factor as well.

\subsection{Methodological considerations}

Critical reflection is an inherent aspect of any scientific investigation. Research is a systematic and reflexive process in which disciplined methods are used to answer questions and develop knowledge that can be shared (Polit \& Beck, 2017). This section discusses the research design and the methods used in relation to trustworthiness of the study in order to provide a basis for reflection in all stages of the research process (Creswell \& Creswell, 2018).

\subsubsection{Discussion of the research design and methods}

\subsubsection{Case studies}

The qualitative case study is a research approach that facilitates the exploration of a phenomenon in its context using a variety of data sources (Baxter \& Jack, 2008). To promote a constructivist perspective, a choice was made to draw predominantly on Stake's work on case studies, which recognises multiple perspectives and the researcher's role in constructing interpretations (Stake, 1995).

Cases are bound in time, place and activity (Creswell, 2014), and the case in this thesis was bounded by the period from spring 2014 to autumn 2015. The place boundary was one DPC (with four units) in one hospital. The decision was made to write an instrumental case, foregrounding the phenomenon of interest. This can compromise descriptions and explorations of the complexity of the case itself, but it improves the exploration of the phenomenon (Stake, 1994). The outer and inner context of the study was thoroughly described in section 5.2 and 5.3. Nevertheless, a wide and deep understanding of the complexity of the context where the A\&F cycle was undertaken might be lacking. Possible reasons for this are the researchers' initial unfamiliarity with the DPC and the fact that the researcher is not a health care provider. 
The first paper was termed a multiple instrumental case study, although could advantageously been called an instrumental case study. A retrospective criticism of Paper 1 is that there is little and vague comparison of the different cases, particularly between the outpatient unit and the other units. The paper would have gained from either not aimed to be a multiple case study (i.e. aimed to compare units) or from presenting a more marked comparison between units. However, the researcher learned as the study progressed that the units were closely interconnected under similar conditions, especially in relation to management and overall organisational structures. The second paper was not termed a case study, but with the other two articles forms the whole instrumental case study. Paper 3 was termed a case study, which would have been most correct title for all three papers. Choosing a multiple case study might have painted a more complex picture, particularly regarding the differences between the units and thus the tension between roles in the DPC. Given the retrospective insight described in the materials and methods, results and discussion sections, it is unlikely that this would have altered the results, but it could have allowed richer and deeper analyses and descriptions of the results.

Naturalistic case studies provide experiential narratives of health care personnel, often under ordinary circumstances (Stake, 1994). If one manages to create an effective description of the phenomenon or case under study, this may provide a vicarious experience from which readers can learn (Lincoln \& Guba, 1990). In this way, knowledge from this thesis may be linked to other kinds of knowledge about A\&F and the experience of those working in a DPC and may broaden the knowledge of A\&F.

\subsubsection{Observation}

Substudy 1 aimed to describe and investigate what was discussed and thematised when QI teams complete action forms as part of an A\&F cycle. This includes team members' actions, decisions, roles and behaviour and therefore, observation as a data collection method was considered fruitful (Walshe, Ewing, \& Griffiths, 2012). Through interaction between individuals and groups, personal and cultural identities are formed and understood. Employees enters group meetings with a set of constructions, individually, or shared with the group. These constructions are open to continuous reconstruction, and the researcher will try grasp the meaning, the shared constructs and possibly reconstructions (Lincoln \& Guba, 2013). The participants are observed while constructing meaning of the social act in which they are involved, and the researcher are constructing meaning through interpretation - and by presence. When a researcher starts the analysis, there is an ongoing communication between 
the researcher and the text produced from the observations. This communication started and was shaped in the act of communication between the researcher and the participants in the meetings (Graneheim \& Lundman, 2004).

A major limitation of observation is that it does not allow the participants meaning of the events occurring to be included (Morse, 2012, p. 87). If we had chosen to interview the QI team members in addition to observing the meetings, the researcher could have gained deeper knowledge, particularly about how individuals experienced and made meaning of the events observed. It could have elicited thoughts and reflections on how and why the participants reached the decisions they actually took and what they emphasised in a more explicit way. Not all "events" are in themselves meaningful and available for inspection (Atkinson \& Coffey, 2003), but interviews would have allowed for topics to be elaborated. What constraints and opportunities did the participants see as meaningful or as an implicit understanding that the observer did not see or understand? In particular, the result concerning the understanding of roles might have been elucidated if interviews had been conducted. This would not have challenged the credibility of the research, by it could have challenged the interpretation (Morse, 2012).

The use of an audio recorder and the presence of an observer are very noticeable elements in a meeting room, called "the researcher effect" or "observer effect" (Monahan \& Fisher, 2010). Researchers within the paradigm of this thesis interpret data in light of the knowledge that participants are aware of and sometimes adapt their statements to the presence of an observer.

These responses to a researcher's presence are important data themselves (Monahan \& Fisher, 2010) and constitutes co-creation of knowledge. In this thesis, there is a possibility that the results on low confidence and skills in information-seeking behaviour may have been enriched by the researchers presence and interpretation. The researcher was introduced as an information scientist, which might have caused the participants to introduce the phenomenon. Additionally, this background in itself made the researcher particular aware of the emerging theme.

\subsubsection{Focus group interviews}

Focus group interviews allow interactions, relationships and discussions among the participants (Polit \& Beck, 2017) and were thus considered an appropriate method to achieve the aim of substudy 2 . There are limitations to the method regarding stronger and weaker voices in a group, including professional hierarchies and group norms not accepted by everyone. 
Although no precise number of focus groups (or participants) is recommended, most of the literature recommends two to five groups per category of participants and four to twelve participants per group; most authors take this as a "rule of thumb" (Carlsen \& Glenton, 2011). The term "theoretical saturation" was introduced to grounded theory and implies an iterative process of data collection until no new perspectives or no new data within a category are obtained. The term has since spread to most qualitative research environments, often referred to as "data saturation" and implemented in a simplified version (Carlsen \& Glenton, 2011). The data collection in this study was of a practical nature. The number of focus groups is set according to the number of units, and the small number of groups is a limitation in this study. There was no information on how many units would accept the invitation to be part of a research project before the study started. A different decision from a unit manager would have altered the way the research project was conducted. For a couple of units, it might have been possible to organise two focus groups with the aim of achieving richer data. Morse (2015a) claims that with few participants or sparse data, analysis is more difficult and important features in the data may be missing or overlooked. The study used a semi-structured interview guide, being another argument for more groups (Morse, 2015a). The focus group interviews did reveal themes not described in qualitative research before, presenting an argument of enough groups to give rich data. Since all four units of the DPC agreed to participate, it is possible to venture the claim that the focus groups gave a rich contribution to the overall case study. However, seen in retrospect, more groups could possibly have gained different or more mature results.

\subsubsection{Individual interviews}

Brinkmann and Kvale (2015, p. 3) note that "The qualitative research interview attempts to understand the world from the subjects' point of view, to unfold the meaning of their experience, to uncover their lived world prior to scientific explanation”. Individual interviews of first-line managers were considered an appropriate method to explore the aim of the third study. Five individual interviews were conducted. The researcher was acquainted with four of the interviewees from a year earlier and time spent in the DPC. This was considered an advantage, as it allowed trust and familiarity, setting the stage for interviews that allowed participants to talk about their roles as managers. The researcher also met the newest managers several times before the interview. One of the managers forgot the interview appointment, but decided to go through with the interview. Here unit had a very busy day and she seemed a little stressed. This could have affected the quality of the interview. In hindsight, 
the researcher should probably have moved the interview to a more suitable time for the manager. Nevertheless, the same interview guide was used as for the other participants, the manager reflected on all the areas of the interview guide ant the researcher felt confident that the interview was as good as the rest. Data saturation is discussed in relation to focus groups (Section 7.2.1.3), and would apply to the individual interviews as well.

A limitation of the study is a lack of separate interviews with the professional leaders (the consultants of the DPC). When discussing the results with clinician colleagues, the researcher concluded that substudy three and thus the case study probably would have gained from such data. However, consultants or psychologists were present in the QI meetings and the focus group interviews and their voices were heard that way.

\subsubsection{Discussion of the analysis}

Various qualitative methods share a similar goal in that they seek to understand a phenomenon from the perspective of those experiencing it. This thesis used two different methods to analyse the data; TA (Paper 1) (Braun \& Clarke, 2012), and qualitative content analysis (Paper 2 and 3) (Graneheim \& Lundman, 2004). Both methods concerns cutting across data and to search for patterns and themes (Vaismoradi, Turunen, \& Bondas, 2013), and may be done inductive or deductive. Inductive can be used where there are little previous knowledge and the coded categories are derived directly from the text data (Hsieh \& Shannon, 2005) and thus strongly linked to the data. This study used inductive analysis strategies for all three studies. There is a continuum in the levels of analysis, from merely organising and describing the data set at a semantic level to a latent level aiming to examine assumptions, conceptualisations and underlying ideas (Braun \& Clarke, 2006). According to Graneheim and Lundman (2004), both manifest and latent content deal with interpretation, but the interpretation varies in depth and level of abstraction. In contrast, TA incorporates both manifest and latent aspects. It means that the analysis of latent content of data is an inseparable part of the manifest analysis approach (Braun \& Clarke, 2006).

A comparison of the terminology in the two methods is possible. In TA data corpus, data item, data extract, code, and theme is used. This are equivalent to the unit of analysis, meaning unit, condensed meaning unit, code, and category/theme in content analysis (Braun \& Clarke, 2006; Graneheim \& Lundman, 2004; Vaismoradi et al., 2013). Qualitative content analysis is less rigours in the performing analytical steps than TA. Where TA is performed in six steps, Graneheim and Lundman describes different ways the analytical process may be conducted (Graneheim \& Lundman, 2004). The first phases are equivalent in both 
approaches; to familiarise with data, transcribe the interview (audio recordings), and obtain a sense of the whole by reading the transcripts several times.

Graneheim and Lundman (2004) are clear on the constructivist basis in their 2004 paper, while Braun and Clarke (2006) stats that TA are flexible and compatible with constructivist paradigms. There are significant similarities between the two methods of analysis used, and particularly also when comparing the way they have been implemented and understood in this study, prompting the question whether one method of analysis could have been used throughout the study. The answer is probably yes. Reading through the project log while writing up the thesis, made it clear that no substantial differences that could have altered, added or withdrawn important features of the results was found. To use two different methods of analysis has rather resulted in a greater workload for the researcher.

\subsubsection{Trustworthiness}

Integrity and quality are central issues in qualitative research, as in all research. The literature on methodology uses different approaches to examine the rigor of the methods used, the trustworthiness of the findings and whether they have value beyond themselves. In the 1980s, Lincoln and Guba established a framework for developing trustworthiness in qualitative research and proposed four criteria for evaluation; credibility, dependability, confirmability and transferability (Guba \& Lincoln, 1982). This framework is suitable to the constructionist paradigm (Nowell, Norris, White, \& Moules, 2017) and thus chosen as a framework in this study. Other researchers have criticised the framework (Morse, 2015b) and used validity, reliability and generalisability to establish rigour in qualitative research (Brinkmann \& Kvale, 2015; Morse, 2015b; Morse, Barrett, Mayan, Olson, \& Spiers, 2002). Literature by various authors are applied in this thesis, although not necessarily using the terminology from social constructivism.

\subsubsection{Credibility}

Credibility relates to showing confidence in the findings and interpretations of a research study (Lincoln \& Guba, 2013, p. 104), giving readers possibility to draw meaningful conclusions about the quality of the study (Polit \& Beck, 2017, p. 568). Although inherent in the whole research process, there are techniques for ensuring credibility although not all of them applicable to all kinds of qualitative research (Morse, 2012). In this study, triangulation, member checking, rich, thick descriptions, spending prolonged time in the field and persistent observation, and peer debriefing are used (Denzin \& Lincoln, 2018; Lincoln \& Guba, 2013). 
Triangulation referes to using multiple different sources, methods, investigators or theories to allow the researcher to take different perspectives on an issue or to answer the research question (Denzin \& Lincoln, 2018, p. 452). This study used three different methods; observations, focus group interviews and individual interviews, to answer the overall aim of the study. This included different sources (staff and firs-line managers) to shed light on the issue from three different angles, providing triangulation in both sources and methods to enhance credibility. Triangulation of researchers is another method to enhance credibility of data (Lincoln \& Guba, 2013, p. 104). The researcher conducted the observations and individual interviews. In the focus group interviews, the researcher was assisted by a comoderator, who contributed positively to the interviews (Tjora, 2012, p. 124). Although the researcher was responsible for observation, individual interviews and the analysis, the interview guide, the process, analytical categories and themes were discussed in the research group to enhance credibility of the data.

Member checking involves sharing with the participants the results of transcriptions or analysis to ascertain whether they feel the results (transcripts, themes, or paper draft) are accurately captured or interpreted (Creswell \& Creswell, 2018, p. 200; Lincoln \& Guba, 2013, p. 108). Morse (2015b) did not recommend member checking for credibility (or validity in her terms) evaluation and member checking was omitted in this study. The argument that participants should not be given the opportunity to change their minds after reading the transcripts. If presented as the analysis this would (as in this study) be interpreted as interview data from several participants, deconstructed and reconstructed. Morse argued that the researche'r background in theory and research outranks the participants' views in this case. However, all the participants received a summary of the main points after the interview sessions, with the possibility to ask questions and to justify the summary. Another reason for doing member checking is to give the participants an opportunity to reflect on how participation in the study has affected their thoughts or values (Koelsch, 2013). The interviews partly mirrored themes that emerged during the observations a year earlier. In that sense, they can partly be seen as member checking. Nonetheless, particularly after the observations for substudy 1 , member checking the interviews could have deepened or even changed the results. See otherwise discussions on observations in section 7.2.1.2. This is because this was the first data collection process for the whole case study and the researcher was less familiar with the study site and less experienced as a researcher. 
Rich, thick descriptions was used to describe outer and inner context of the case in as much detail as necessary to make it transparent and allow the readers to follow the process as closely and vividly as possible. The Norwegian health system, the National Guideline, the audit survey, the case, the setting and the study participants have been described as richly as possible without jeopardising anonymity.

Prolonged engagement and persistent observation in the field involves learning the culture and building trust with the participants. It is considered particularly important for novice researchers to have exposure to the phenomenon under study to enable multiple perspectives and understanding (Baxter \& Jack, 2008). As described in Section 5.0 the author spent several days at the DPC becoming familiar with the organisation, the meeting structures and the employees. This was to prepare for the observations and interviews, but also to get a feeling of the level of enthusiasm or negativity towards implementing the National Guideline, particularly since implementation readiness was not measured. The researcher's presence in a management meeting led to all units arguing for their participation in the project; none wanted to be left out. The supervisor from the health authority became a gatekeeper, introducing the researcher to the DPC managers, thus helping to achieve smooth access to the site.

The analysis and results from all three studies were discussed with two colleagues with extensive experience in the field of mental health care, both registered nurses with $\mathrm{PhDs}$ and with the A\&F facilitator at site. This is called peer debriefing (Polit \& Beck, 2017). This was particularly important, as the researcher has no clinical experience. In addition, the project was presented to a health services research group at the Advisory Unit at several stages. The study was presented as it progressed, and the results were discussed, making it possible to rethink the analysis and thus the results. The article drafts and final manuscripts were repeatedly presented to the project's supervisors for detailed discussion and review. Contextualising the results to avoid obvious misinterpretations, and asked questions not to miss important themes has been particularly valuable.

Overall, and with the limitations accounted for, the researcher maintains that the choices made throughout this research project have been accounted for and satisfy credibility of the thesis.

\subsubsection{Dependability}

Dependability is related to the trustworthiness and consistency of the study findings (Brinkmann \& Kvale, 2015) or the stability of data over time and under different conditions (Elo, Kääriäinen, Kanste, Pölkki, Utriainen, \& Kyngäs, 2014). To account for this, several 
procedures are suggested running through the process: document the procedures, check the transcripts, compare the data with the codes, communicate the codes and ensure intercoder agreement (Creswell \& Creswell, 2018, p. 202).

A project log, or reflexive journal, was kept from the very beginning of the project, as recommended within the constructivist paradigm (Guba \& Lincoln, 1982; Lincoln \& Guba, 2013). The log became voluminous, containing descriptions of every step in the process. In addition, it held stories of significant events in the researchers' life during the process. This to record and reflect on what happened to the researcher as the human instrument of research and a meaning-maker. It was particularly useful in the analysing and writing processes, where reflections and decisions mirror the back and forth exercise.

The researcher transcribed all of the recordings verbatim, except two individual interviews (done by an external student) (se section 5.4). When the transcripts was ready, each audio recording was re-listened to eliminate errors and omissions, considered particularly important for the two interviews transcribed by the student. The researcher conducted all the data gathering, which is considered an advantage in relation to avoiding misunderstanding in the audio recordings and ensure the transcriptions as accurately as possible reflected what was said (Brinkmann \& Kvale, 2015, p. 211).

The researcher coded the data. The software NVivo was of considerable help ensuring that there was no drift in the definition of codes by using memos and constantly checking the codes against assigned text segments. It is considered important to constantly perpetuate this back and forth process with the codes to ensure consistency (Creswell \& Creswell, 2018, p. 202). The study probably could have benefitted from having more than one coder to ensure agreement, particularly given that the researcher is not a health care worker. When initial themes was accomplished, these were written up together with quotes and discussed with the research group (the two supervisors). For all three studies, this was an iterative process that continued until the final version of the articles. In this sense, an intercoder agreement was partly applied. All of the recordings were re-listened after the analysis was completed. This was to ensure the analysis had not drifted as of the inductive approach to the data, and the research question was answered (Braun \& Clarke, 2012).

The researcher has described and justified what was done and the choices made to show that the results are consistent. In this study, the goal was to contribute to knowledge of the use and experience of an A\&F cycle in a DPC in Norway. In line with these justifications, the 
researcher maintains that the methods and the procedures used are consistent and stable to answer the research questions.

\subsubsection{Transferability}

The question of transferability concerns whether the results are primarily of local interest or whether they could be transferred to another case, context or situation (Brinkmann \& Kvale, 2015, p. 295; Polit \& Beck, 2017). As the case in this study was selected on the basis of availability (a pragmatic approach), the results of this study cannot be statistically/empirically generalised to a wider context. However, the hallmark of good qualitative research lies more in the particularity than in the generalisability (Creswell, 2014, p. 204), and qualitative methods seek to understand a phenomenon from the perspective of those experiencing it. This research project focuses entirely on one context, one case. This may affect the transferability to other contexts. A clear description of the context, the selection and characteristics of participants, the data collection and the process of analysis are important factors in assessing transferability (Elo et al., 2014; Graneheim \& Lundman, 2004). The patient group, the Norwegian health care system, the CPG and the employees were described to enable the reader to understand the context of the case. This provides an opportunity to consider how similar or different this case is to another case or organisation and to evaluate if the findings might be transferable to another context (Lincoln \& Guba, 2013, p. 109). This is particularly important given the sparse literature available for mental health care context on the phenomenon A\&F.

A key question is whether this qualitative case study answers the research questions or merely describes a custom-made tool. There are challenges in that this kind of research can seem to be commonplace or merely a description of a process. This study sought to capture the ordinary: the everyday complexity of a QI process and a strategy such as an A\&F cycle, and the complexity of working in a mental health environment with a group of patients demanding compound services. This was done by using the process as a case, and the use of a timeline to see the phenomenon from different angles. Various perspectives was sought to capture some of this complexity, although the choice of an instrumental case study places the focus more on the phenomenon under study than on the complexity of the context, as described in Section 5.1.2.

The researcher believes that this study has relevance to other settings in and outside mental health care services, and that knowledge gained from this study may contribute to the 
planning and execution of A\&F cycles. Several of the findings in this study are consistent with or similar to, findings from other studies independent of context and patient group (inside and outside mental health care). "Vicarious experience" may best be explained as the readers translating the experience from a case study to their own context, helped by descriptions of various perspectives and participants' meanings and contexts in the case report. (Abma \& Stake, 2014; Lincoln \& Guba, 2013). Constructions formulated in one context, may be adapted by someone holding a competing construction by accepting a given construction in their own context (Lincoln \& Guba, 2013). Kessler and Glasgow (2011) specified the need for more qualitative research in real-world settings to gain robust knowledge across settings. There is little disagreement that case study methodology is suitable for describing, exploring and understanding a phenomenon in its real-life context (Creswell, 2013; Stake, 1995). The researcher therefore considers this case study a suitable and valuable contribution to the knowledge of the use and experience of A\&F across settings.

The Norwegian Directorate of Health regularly produces CPGs aimed at mental health services. The Advisory Unit has developed several audit tools to aid the implementation of these CPGs in recent years. Stakeholders using the same A\&F tools, the action forms and the instructions may use the findings from this study to improve their understanding of a QI process. This could involve a broadened understanding of aspects of the A\&F cycle (conceptual use) or specific changes to how a process is planned and implemented (instrumental use) (Adams, Nnawulezi, \& Vandenberg, 2015).

\subsubsection{Reflexivity}

Reflexivity concerns the role of the researcher in various parts of the research process (Thornquist, 2018, p. 245). It seeks to gain insight into the work that will guide actions and interpretations through an active and conscious process. In a social constructivist paradigm, reflexivity also means investigating the dynamics of the relationship between the researcher and the researched and how the research is co-constituted (Finlay, 2002).

The research team in this project consisted of two supervisors and the reseracher. The supervisors have different professional backgrounds; one psychiatrist and one sociologist. Both with extended experience in research and particular in the field of persons with concurrent substance use disorders and mental disorders. Both supervisors are professors. The researchers' background and preunderstanding contributes to shape the interest in how the field of healthcare services implements EBP. The background as an information scientist in 
the field of health care has shaped the birth of the study, although done in close cooperation with the supervisors.

The project log, or reflexive journal, contained descriptions of what was done in the research process, considered an important tool for reflexivity (Polit \& Beck, 2017, p. 561). In addition it had reflections on the process, reflections from the supervisors, decisions made (particularly in the analysis processes) and serious events in the researcher personal life during the $\mathrm{PhD}$ process. This log was useful when the project had to be put on hold for a period of time. It also made the researcher aware of her own learning process as it outlined her victories and setbacks. Not being health care worker with experience from clinical work may have given the researcher an opportunity to see things different to an experienced health care worker, or to gain a different meaning from what was observed or heard. However, there is also a risk misunderstanding or misinterpreting. The researcher sought to mitigate this risk by discussing the analysis process with the research team and by presenting the analysis and preliminary results to the research group to elicit questions, corrections and reflections. This helped to comprehend the analysis in the particular context. Every data gathering session led to quite detailed reflection notes written immediately after the session. The notes contained descriptions of the settings, the environment, such as the features of the room, disturbances in the room and noticeable noise from outside. This was particularly useful in the analysis process and made it possible to ask additional questions of the material. One of the units held all the meetings in the common meeting room in the unit. This made the situation familiar for the participants, but there were also disturbing elements such as phones ringing and people entering the room. At one point, the audio recorder was turned off during the observation because a situation arose with a patient and needed to be discussed. This was done to protect patient anonymity, but it gave the researcher useful insight into the daily life of the unit, which is believed to enhance the researcher's understanding and analysis. 


\subsection{Conclusions and implications for practice}

This study used a qualitative case study design enabling systematic descriptions and an interpretive understanding of the experience of those involved in an implementation process using $A \& F$ as a main strategy. In light of this, the study has contributed novel insights into the perceived value and use of and contextual barriers to A\&F in specialist mental health care. The main finding from this study is that staff and first-line managers experienced A\&F as useful. In addition to revealing undesired practice gaps, the A\&F confirmed good practice and highlighted competencies hidden in everyday practices. A\&F make practice explicit to staff and first-line managers that as it shed light on and confirmed good practice and revealed hidden competencies. The researchers understanding is that A\&F is not just "measuring practice",but it adds to positive reinforcement of the staffs' competency and indicates A\&F to be a beneficial management tool, adding impact to active utilisation of QI teams.

The increasing need for improved mental health care, particularly for persons with concurrent substance use disorders and mental disorders, will place a premium on QI skills, including on A\&F. New CPGs will continue to come, imposing new demands on staff and leaders in mental health care. A lack of knowledge of EBP and its relationship with CPGs may cause an A\&F cycle to become detached as a QI process, leaving staffs with a sense of being overrun by directives. This suggests strengthening implementation leadership focusing on communicating why A\&F is important, how it works with EBP, and QI skills such as knowledge of change management. This could enhance understanding and autonomy amongst staff and strengthen ownership of the A\&F cycle.

Limited organisational support and capacity to respond effectively partly curbed the accomplishment and impact of the full A\&F cycle. Interdisciplinary teamwork could cause blurred understanding of roles and responsibilities in DPCs. This could be important for firstline managers to be aware of when implementing recommendations that could potentially change role opportunities and task execution. To be able to maintain, prioritise and facilitate an A\&F cycle over a period, first-line managers need support and follow-up. Staff needs a facilitator to be able to follow up on actions. This means that the A\&F cycle must be anchored by and followed up at several levels of management; a strengthened organisational QI infrastructure.

CPGs need to be followed by tools to ease their implementation to clinical practice. How this best can be done is an important message to health politicians and issuing bodies of CPGs. 
The knowledge of health care organisations showing low QI infrastructure would be vital to act on when issuing new initiative or procedure.

This thesis focuses on A\&F, but this is only one small piece of a bigger picture in the complex world of QI. A\&F alone is not enough. Broad frameworks and theories have outlined a bigger picture of implementation science, but there is a persistent need to understand the bits and pieces to enhance understanding of the whole. Implementation science is still a rather new science, constantly developing to contribute to better quality in health services. CPGs are only one way to support EBP. EBP is contextually bound to political, legal and cultural factors, and should be discussed and contested in academic and clinical environments. 


\subsection{Implications for further research}

More research on the value of QI teams as a collective learning environment could strengthen the knowledge of the use and experience of such teams among staff participating in $A \& F$ cycles.

Further research on EBP and information competency could shed light on how deeper knowledge of EBP and CPGs can increase the understanding and ownership of an A\&F cycle in mental health care: its purpose, knowledge base and use in practice.

More research on implementation leadership in Norway in general and from mental health care in particular could strengthen $A \& F$ as a valuable tool in these fields. It would be beneficial to explore how training managers at several levels of mental health care on using $\mathrm{A} \& \mathrm{~F}$ as an implementation strategy might improve the execution of the entire A\&F cycle.

The weight of the research on $A \& F$ are still on single phases and parts. There is still a lack of research on the complete $A \& F$ cycle, which could strengthen its efficacy in health care services, and thus better contribute to better services. 


\subsection{References}

Abma, T. A. \& Stake, R. E. (2014). Science of the particular: An advocacy of naturalistic case study in health research. Qualitative Health Research, 24(8), 1150-1161. doi:10.1177/1049732314543196

Act of 2 July 1999 No. 64 relating to Health Personnel etc. [Helsepersonelloven], (1999).

Act of 2 July 1999 No. 61 relating to Specialised Health Services

[Spesialisthelsetjenesteloven], (1999).

Adams, A. E., Nnawulezi, N. A. \& Vandenberg, L. (2015). "Expectations to Change” (E2C): A Participatory method for facilitating stakeholder engagement with evaluation findings. American Journal of Evaluation, 36(2), 243-255. doi:10.1177/1098214014553787

Advisory Unit. (2013, 2018). [Audits] Gap-undersøkelser. Retrieved from http://gap.rop.no/skjemamaler/for-behandlere-i-psykisk-helsevern.-versjon-2.0

Albarqouni, L., Hoffmann, T., Straus, S., Olsen, N. R., Young, T., Ilic, D., . . Glasziou, P. (2018). Core Competencies in Evidence-Based Practice for Health Professionals: Consensus Statement Based on a Systematic Review and Delphi Survey. JAMA Netw Open, 1(2), e180281. doi:10.1001/jamanetworkopen.2018.0281

Alving, B. E., Christensen, J. B. \& Thrysøe, L. (2018). Hospital nurses' information retrieval behaviours in relation to evidence based nursing: a literature review. Health Information \& Libraries Journal, 35(1), 3-23.

Angrosino, M. V. (2016). Naturalistic Observation. New York: Taylor and Francis.

Arvidsson, E., Dahlin, S. \& Anell, A. (2021). Conditions and barriers for quality improvement work: a qualitative study of how professionals and health centre managers experience audit and feedback practices in Swedish primary care. $B M C$ Family Practice, 22(1), 113. doi:10.1186/s12875-021-01462-4

Atkinson, P. \& Coffey, A. (2003). Revisiting the relationship between participant observation and interviewing. In J. A. Holstein \& J. F. Gubrium (Eds.), Inside interviewing: new leses, new concerns (pp. 415-428). Thousand Oaks: Sage.

Attieh, R., Gagnon, M. P., Estabrooks, C. A., Legare, F., Ouimet, M., Vazquez, P. \& Nuno, R. (2014). Organizational readiness for knowledge translation in chronic care: a Delphi study. BMC Health Services Research, 14, 1-12. doi:10.1186/s12913-0140534-0 
Austad, B., Hetlevik, I., Mjølstad, B. P. \& Helvik, A.-S. (2015). General practitioners' experiences with multiple clinical guidelines: A qualitative study from Norway. Quality in Primary Care, 23(2), 70-77.

Banerjee, A., Stanton, E., Lemer, C. \& Marshall, M. (2012). What can quality improvement learn from evidence-based medicine? Journal of the Royal Society of Medicine, 105(2), 55-59. doi:10.1258/jrsm.2011.110176

Barbui, C. (2017). Evidence, knowledge, implementation: glossary of terminology. Epidemiology \& Psychiatric Science, 26(2), 1-2. doi:10.1017/S2045796016001037

Barbui, C., Girlanda, F., Ay, E., Cipriani, A., Becker, T. \& Koesters, M. (2014). Implementation of treatment guidelines for specialist mental health care (Review). Cochrane Database of Systematic Reviews, 2014(1), 1-43. doi:10.1002/14651858.CD009780.pub2

Baxter, P. \& Jack, S. (2008). Qualitative case study methodology: Study design and implementation for novice researchers. The qualitative report, 13(4), 544-559. Retrieved from http://nsuworks.nova.edu/tqr/vol13/iss4/2

Bet, P. M., Hugtenburg, J. G., Penninx, B. W., Balkom, A., Nolen, W. A. \& Hoogendijk, W. J. (2013). Treatment inadequacy in primary and specialized care patients with depressive and/or anxiety disorders. Psychiatry Research, 210(2), 594-600. doi:10.1016/j.psychres.2013.06.023

Bighelli, I., Ostuzzi, G., Girlanda, F., Cipriani, A., Becker, T., Koesters, M. \& Barbui, C. (2016). Implementation of treatment guidelines for specialist mental health care (Review). Cochrane Database Systematic Reviews, 2016(12), 1-46. doi:10.1002/14651858.CD009780.pub3

Booth, A. (2006). "Brimful of STARLITE": toward standards for reporting literature searches. Journal of the Medical Library Association, 94(4), 421-429, e205.

Booth, A. (2016). Searching for qualitative research for inclusion in systematic reviews: a structured methodological review. Syst Rev, 5, 74. doi:10.1186/s13643-016-0249-x

Braun, V. \& Clarke, V. (2006). Using thematic analysis in psychology. Qualitative Research in Psychology, 3(2), 77-101. doi:10.1191/1478088706qp063oa

Braun, V. \& Clarke, V. (2012). Thematic analysis. In H. Cooper (Ed.), APA handbook of research methods in psychology (Vol. 2: Research designs, pp. 57-71). Washington, DC: American Psychological Association. 
Braun, V. \& Clarke, V. (2014). What can "thematic analysis" offer health and wellbeing researchers? International Journal of Qualitative Studies on Health and Well being, 9, 1-2. doi:10.3402/qhw.v9.26152

Brehaut, J., Colquhoun, H. L., Eva, K., Carroll, K., Sales, A., Michie, S., . . Grimshaw, J. (2016). Practice feedback interventions: 15 suggestions for optimizing effectiveness. Annals of Internal Medicine, 164(6), 435-441. doi:10.7326/M15-2248

Brehaut, J. C. \& Eva, K. W. (2012). Building theories of knowledge translation interventions: Use the entire menu of constructs. Implementation Science, 2012(7), 1-10. doi:10.1186/1748-5908-7-114

Brinkmann, S. \& Kvale, S. (2015). InterViews : learning the craft of qualitative research interviewing (3rd ed.). Thousand Oaks, CA: Sage.

Brown, B., Gude, W. T., Blakeman, T., van der Veer, S. N., Ivers, N., Francis, J. J., . . . Daker-White, G. (2019). Clinical Performance Feedback Intervention Theory (CPFIT): A new theory for designing, implementing, and evaluating feedback in health care based on a systematic review and meta-synthesis of qualitative research. Implementation Science, 2019(14), 1-25. doi:10.1186/s13012-019-0883-5

Brownson, R. C., Colditz, G. A. \& Proctor, E. K. E. (2017). Dissemination and implementation research in health: Translating science to practice (2nd ed.). New York, NY: Oxford University Press USA.

Buckley, P. F. (2006). Prevalence and consequences of the dual diagnosis of substance abuse and severe mental illness. Journal of Clinical Psychiatry, 67(Suppl 7), 5-9.

Burgers, J. S., Smolders, M., Van der Weijden, T., Davis, D. \& Grol, R. (2013). Clinical practice guidelines as a tool for improving patient care. In R. Grol, M. Wensing, M. P. Eccles, \& D. Davis (Eds.), Improving patient care: the implementation of change in health care (2nd ed.). Chichester, UK: Wiley.

Burgess, R. (Ed.) (2011). New principles of best practice in clinical audit (2nd ed.). London: Radcliffe Publ.

Burke, R. E. \& Friedman, L. H. (2011). Essentials of management and leadership in public health. Sudbury, MA: Jones \& Bartlett Learning.

Busse, R., Klazinga, N., Panteli, D. \& Quentin, W. (Eds.). (2019). Improving healthcare quality in Europe: Characteristics, effectiveness and implementation of different strategies. Copenhagen: WHO. 
Cabana, M. D., Rand, C. S., Powe, N. R., Wu, A. W., Wilson, M. H., Abboud, P. A. \& Rubin, H. R. (1999). Why don't physicians follow clinical practice guidelines? A framework for improvement. JAMA, 282(15), 1458-1465. doi:doi: 10.1001/jama.282.15.1458

Campbell, S. M., Roland, M. O. \& Buetow, S. A. (2000). Defining quality of care. Social Science and Medicine, 51(11), 1611-1625. doi:10.1016/s0277-9536(00)00057-5

Carlsen, B. \& Glenton, C. (2011). What about N?: A methodological study of sample-size reporting in focus group studies. BMC Medical Research Methodology, 11, 1-10. doi:10.1186/1471-2288-11-26

Carver, C. S. \& Scheier, M. F. (1982). Control theory: a useful conceptual framework for personality-social, clinical, and health psychology. Psychological Bulletin, 92(1), 111135.

Choong, M. K., Galgani, F., Dunn, A. G. \& Tsafnat, G. (2014). Automatic evidence retrieval for systematic reviews. Journal of Medical Internet Research, 16(10), e223. doi:10.2196/jmir.3369

Christina, V., Baldwin, K., Biron, A., Emed, J. \& Lepage, K. (2016). Factors influencing the effectiveness of audit and feedback: nurses' perceptions. Journal of Nursing Management, 24(8), 1080-1087. doi:10.1111/jonm.12409

Clarke, M. A., Belden, J. L., Koopman, R. J., Steege, L. M., Moore, J. L., Canfield, S. M. \& Kim, M. S. (2013). Information needs and information-seeking behaviour analysis of primary care physicians and nurses: a literature review. Health Information \& Libraries Journal, 30(3), 178-190. doi:10.1111/hir.12036

Claudi, T., Ingskog, W., Cooper, J. G., Jenum, A. K. \& Hausken, M. F. (2008). [Quality of diabetes care in Norwegian general practice]. Tidsskrift for den Norske Laegeforening, $128(22), 2570-2574$.

Cloney, T., Vinluan, J., Chen, A., Retegan, C. \& McCahy, P. (2021). Stakeholder's perceived value of surgical audit data provided by the Victorian Audit of Surgical Mortality. Health Information Management, 50(1-2), 55-63. doi:10.1177/1833358319885223

Cochrane Collaboration. (2013). Archie Cochrane: the name behind Cochrane. Retrieved from https://community.cochrane.org/archie-cochrane-name-behind-cochrane

Cochrane Collaboration. (2020). The Effective Practice and Organisation of Care (EPOC) Group. Retrieved from http://epoc.cochrane.org/

Colquhoun, H., Michie, S., Sales, A., Ivers, N. M., Grimshaw, J. M., Carroll, K., . . Brehaut, J. (2016). Reporting and design elements of audit and feedback interventions: a 
secondary review. BMJ Quality \& Safety, 26(1), 54-60. doi:10.1136/bmjqs-2015005004

Cooke, L. J., Duncan, D., Rivera, L., Dowling, S. K., Symonds, C. \& Armson, H. (2018). How do physicians behave when they participate in audit and feedback activities in a group with their peers? Implementation Science, 2018(13), 1-9. doi:10.1186/s13012018-0796-8

Creswell, J. W. (2013). Qualitative inquiry \& research design: choosing among five approaches (3rd ed.). Thousand Oaks, CA: Sage.

Creswell, J. W. (2014). Research design : qualitative, quantitative, and mixed methods approaches (4th ed.). Los Angeles, CA: Sage.

Creswell, J. W. \& Creswell, J. D. (2018). Research design: qualitative, quantitative \& mixed methods approaches (5th ed.). Thousand Oaks, CA: Sage.

Damschroder, L. J., Aron, D. C., Keith, R. E., Kirsh, S. R., Alexander, J. A. \& Lowery, J. C. (2009). Fostering implementation of health services research findings into practice: a consolidated framework for advancing implementation science. Implementation Science, 2009(4), 1-15. doi:10.1186/1748-5908-4-50

Dawson, C. H. (2015). A case study of healthcare professional views on the meaning of data produced by hand hygiene auditing. J Infect Prev, 16(6), 248-254. doi:10.1177/1757177415592010

Denzin, N. K. \& Lincoln, Y. S. (Eds.). (2018). The SAGE handbook of qualitative research (5th ed.). Los Angeles: SAGE.

Desveaux, L., Ivers, N. M., Devotta, K., Ramji, N., Weyman, K. \& Kiran, T. (2021). Unpacking the intention to action gap: a qualitative study understanding how physicians engage with audit and feedback. Implementation Science, 16(1), 19. doi:10.1186/s13012-021-01088-1

Dixon, N. (2017). Guide to managing ethical issues in quality improvement or clinical audit projects. Retrieved from https://www.hqip.org.uk/resources/guide-to-managingethical-issues-in-quality-improvement-or-clinical-audit-projects/

Dixon, N. \& Pearce, M. (2011). Guide to using quality improvement tools to drive clinical audits. Retrieved from http://www.hqip.org.uk/resources/hqip-guide-to-using-qualityimprovement-tools-to-drive-clinical-audit/

Dogherty, E. J., Harrison, M., Graham, I. \& Keeping-Burke, L. (2014). Examining the use of facilitation within guideline dissemination and implementation studies in nursing. 
International Journal of Evidence-Based Healthcare, 12(2), 105-127.

doi:10.1097/xeb.0000000000000008

Donabedian, A. (1988). The quality of care. How can it be assessed? JAMA, 260(12), 17431748. doi:10.1001/jama.260.12.1743

Dubois, J. M. \& Prusaczyk, B. (2018). Ethical issues in dissemination and implementation research. In R. C. Brownson, G. A. Colditz, \& E. K. Proctor (Eds.), Dissemination and implementation research in health: Translating science to practice. (Vol. 2, pp. 6471). Oxford: Oxford University Press.

Eccles, M. P., Armstrong, D., Baker, R., Cleary, K., Davies, H., Davies, S., . . Sibbald, B. (2009). An implementation research agenda. Implementation Science, 4, 18. doi:10.1186/1748-5908-4-18

Eccles, M. P. \& Mittman, B. S. (2006). Welcome to Implementation Science. Implementation Science, 2006(1), 1-3. doi:10.1186/1748-5908-1-1

Edwards, N., Bureau, M., Prichard, S., Barer, M., McInnes, R., Frank, J., . . Forest, P.-G. (2004). Knowledge translation strategy 2004-2009: Innovation in action (MR2156/2004E-HTML). Ottawa, Canada: Canadian Institutes of Health Research Retrieved from https://cihr-irsc.gc.ca/e/documents/kt_strategy_2004-2009_e.pdf

Egeland, K. M., Hauge, M. I., Ruud, T., Ogden, T. \& Heiervang, K. S. (2019). Significance of leaders for sustained use of evidence-based practices: A qualitative focus-group study with mental health practitioners. Community Mental Health Journal, 55(8), 13441353. doi:10.1007/s10597-019-00430-8

Egeland, K. M., Ruud, T., Ogden, T., Lindstrom, J. C. \& Heiervang, K. S. (2016). Psychometric properties of the Norwegian version of the Evidence-Based Practice Attitude Scale (EBPAS): To measure implementation readiness. Health Research Policy \& Systems, 14(1), 47. doi:10.1186/s12961-016-0114-3

Elo, S. \& Kyngäs, H. (2008). The qualitative content analysis process. Journal of Advanced Nursing, 62(1), 107-115. doi:10.1111/j.1365-2648.2007.04569.x

Elo, S., Kääriäinen, M., Kanste, O., Pölkki, T., Utriainen, K. \& Kyngäs, H. (2014). Qualitative content analysis: A focus on trustworthiness. Sage Open, 4, 1-10. doi:10.1177/2158244014522633

EPOC. (2015). EPOC Taxonomy. Retrieved from https://epoc.cochrane.org/epoc-taxonomy Evidence-Based Medicine Working Group. (1992). Evidence-based medicine. A new approach to teaching the practice of medicine. JAMA, 268(17), 2420-2425. 
Finlay, L. (2002). "Outing” the Researcher: The Provenance, Process, and Practice of Reflexivity. Qualitative Health Research, 12(4), 531-545. doi:10.1177/104973202129120052

Fischer, F., Lange, K., Klose, K., Greiner, W. \& Kraemer, A. (2016). Barriers and Strategies in Guideline Implementation-A Scoping Review. Healthcare (Basel), 4(3). doi:10.3390/healthcare4030036

Flottorp, S. A., Jamtvedt, G., Gibis, B. \& McKee, M. (2010). Using audit and feedback to health professionals to improve the quality and safety of health care (Policy summary 3). Copenhagen, DK: World Health Organization Retrieved from https://www.euro.who.int/_data/assets/pdf_file/0003/124419/e94296.pdf

Flottorp, S. A., Oxman, A. D., Krause, J., Musila, N. R., Wensing, M., Godycki-Cwirko, M., . . Eccles, M. P. (2013). A checklist for identifying determinants of practice: a systematic review and synthesis of frameworks and taxonomies of factors that prevent or enable improvements in healthcare professional practice. Implementation Science, 2013(8), 1-11. doi:10.1186/1748-5908-8-35

Foy, R. \& Eccles, M. (2009). Audit and feedback interventions. In S. E. Straus, J. Tetroe, \& I. D. Graham (Eds.), Knowledge translation in health care: moving from evidence to practice (pp. 126-131). Chichester: Blackwell.

Foy, R., Eccles, M. P., Jamtvedt, G., Young, J., Grimshaw, J. M. \& Baker, R. (2005). What do we know about how to do audit and feedback? Pitfalls in applying evidence from a systematic review. BMC Health Services Research, 5, 1-7. doi:10.1186/1472-6963-550

Francke, A. L., Smit, M. C., de Veer, A. J. \& Mistiaen, P. (2008). Factors influencing the implementation of clinical guidelines for health care professionals: A systematic metareview. BMC Medical Informatics and Decision Making, 8, 1-11. doi:10.1186/14726947-8-38

Gagliardi, A. R. (2012). Translating knowledge to practice: optimizing the use of guidelines. Epidemiology \& Psychiatric Science, 21(3), 231-236. doi:10.1017/s2045796012000212

Gifford, W., Davies, B., Edwards, N., Griffin, P. \& Lybanon, V. (2007). Managerial leadership for nurses' use of research evidence: An integrative review of the literature. Worldviews on Evidence-Based Nursing, 4, 126-145. doi:10.1111/j.17416787.2007.00095.x 
Girlanda, F., Fiedler, I., Becker, T., Barbui, C. \& Koesters, M. (2017). The evidence-practice gap in specialist mental healthcare: Systematic review and meta-analysis of guideline implementation studies. British Journal of Psychiatry, 210(1), 24-30. doi:10.1192/bjp.bp.115.179093

Glenngård, A. H. \& Anell, A. (2021). The impact of audit and feedback to support change behaviour in healthcare organisations - a cross-sectional qualitative study of primary care centre managers. BMC Health Services Research, 21(1), 663. doi:10.1186/s12913-021-06645-4

Graham, I. D., Straus, S. E. \& Tetroe, J. (Eds.). (2009). Knowledge translation in health care: moving from evidence to practice. Chichester: Wiley-Blackwell.

Graneheim, U. H. \& Lundman, B. (2004). Qualitative content analysis in nursing research: Concepts, procedures and measures to achieve trustworthiness. Nurse Education Today, 24(2), 105-112. doi:10.1016/j.nedt.2003.10.001

Greenhalgh, T. \& Russell, J. (2006). Promoting the skills of knowledge translation in an online master of science course in primary health care. Journal of Continuing Education in the Health Professions, 26(2), 100-108. doi:10.1002/chp.58

Grimshaw, J., Ivers, N., Linklater, S., Foy, R., Francis, J. J., Gude, W. T. \& Hysong, S. J. (2019). Reinvigorating stagnant science: Implementation laboratories and a metalaboratory to efficiently advance the science of audit and feedback. BMJ Quality \& Safety, 28(5), 416-423. doi:10.1136/bmjqs-2018-008355

Grimshaw, J. M., Eccles, M. P., Lavis, J. N., Hill, S. J. \& Squires, J. E. (2012). Knowledge translation of research findings. Implementation Science, 2012(7), 1-17. doi:10.1186/1748-5908-7-50

Grimshaw, J. M., Thomas, R. E., MacLennan, G., Fraser, C., Ramsay, C. R., Vale, L., . . Donaldson, C. (2004). Effectiveness and efficiency of guideline dissemination and implementation strategies. Health Technology Assessment, 8(6), 1-94. doi: $10.3310 /$ hta 8060

Grol, R. (2008). Knowledge transfer in mental health care: How do we bring evidence into day-to-day practice? Canadian Journal of Psychiatry, 53(5), 275-276. doi:10.1177/07067437080530050

Grol, R., Wensing, M. \& Eccles, M. (2005). Improving patient care: The implementation of change in clinical practice. Edinburgh: Elsevier.

Grol, R., Wensing, M., Eccles, M. \& Davis, D. (Eds.). (2013). Improving patient care: The implementation of change in health care (2nd ed.). Chichester: Wiley-Blackwell. 
Gråwe, R. W. \& Ruud, T. (2006). [Substance abuse and mental disorders in mental health care for adults]: Rus og psykiske lidelser i psykisk helsevern for voksne (STF78 A06003). Trondheim: SINTEF Helse Retrieved from https://www.sintef.no/globalassets/upload/helse/psykisk-helse/pdffiler/rapport_stf78_a06003_rus_og_psykiske_lidelser.pdf

Guba, E. G. \& Lincoln, Y. S. (1982). Epistemological and Methodological Bases of Naturalistic Inquiry. Educational communication and technology, 30(4), 233-252.

Guba, E. G. \& Lincoln, Y. S. (1994). Competing paradigms in qualitative research. In N. K. Denzin \& Y. S. Lincoln (Eds.), Handbook of qualitative research (Vol. 2, pp. 105117).

Gude, W. T., Roos-Blom, M. J., van der Veer, S. N., Dongelmans, D. A., de Jonge, E., Peek, N. \& de Keizer, N. F. (2019). Facilitating action planning within audit and feedback interventions: a mixed-methods process evaluation of an action implementation toolbox in intensive care. Implementation Science, 14(1), 90. doi:10.1186/s13012-0190937-8

Guerrero, E. G., Aarons, G. A., Grella, C. E., Garner, B. R., Cook, B. \& Vega, W. A. (2016). Program capacity to eliminate outcome disparities in addiction health services. Administration and Policy in Mental Health, 43(1), 23-35. doi:10.1007/s10488-0140617-6

Haddock, G., Eisner, E., Boone, C., Davies, G., Coogan, C. \& Barrowclough, C. (2014). An investigation of the implementation of NICE-recommended CBT interventions for people with schizophrenia. Journal of Mental Health, 23(4), 162-165. doi:10.3109/09638237.2013.869571

Harrison, H., Birks, M., Franklin, R. \& Mills, J. (2017). Case study research: Foundations and methodological orientations. Forum Qualitative Sozialforschung, 18(1). doi:10.17169/fqs-18.1.2655

Hartz, S. M., Pato, C. N., Medeiros, H., Cavazos-Rehg, P., Sobell, J. L., Knowles, J. A., . . . Genomic Psychiatry Cohort, C. (2014). Comorbidity of severe psychotic disorders with measures of substance use. JAMA Psychiatry, 71(3), 248-254. doi:10.1001/jamapsychiatry.2013.3726

Harvey, G., Kitson, A. \& Munn, Z. (2012). Promoting continence in nursing homes in four European countries: the use of PACES as a mechanism for improving the uptake of evidence-based recommendations. Int J Evid Based Healthc, 10(4), 388-396. doi:10.1111/j.1744-1609.2012.00296.x 
Havassy, B. E., Alvidrez, J. \& Mericle, A. A. (2009). Disparities in use of mental health and substance abuse services by persons with co-occurring disorders. Psychiatric Services, 60(2), 217-223. doi:10.1176/appi.ps.60.2.217

Helseth, V., Lykke-Enger, T., Johnsen, J. \& Waal, H. (2009). Substance use disorders among psychotic patients admitted to inpatient psychiatric care. Nordic Journal of Psychiatry, 63(1), 72-77. doi:10.1080/08039480802450439

Henrotin, Y. (2009). Need for high-standard translation methodology for the dissemination of guidelines. Osteoarthritis and Cartilage, 17(12), 1536-1538. doi:10.1016/j.joca.2009.06.005

Hsieh, H. F. \& Shannon, S. E. (2005). Three approaches to qualitative content analysis. Qualitative Health Research, 15(9), 1277-1288. doi:10.1177/1049732305276687

Hysong, S. J., Best, R. G. \& Pugh, J. A. (2006). Audit and feedback and clinical practice guideline adherence: Making feedback actionable. Implementation Science, 2006(1), 1-10. doi:10.1186/1748-5908-1-9

Hysong, S. J., Kell, H. J., Petersen, L. A., Campbell, B. A. \& Trautner, B. W. (2017). Theorybased and evidence-based design of audit and feedback programmes: Examples from two clinical intervention studies. BMJ Quality \& Safety, 26(4), 323-334. doi:10.1136/bmjqs-2015-004796

Hysong, S. J., Smitham, K., SoRelle, R., Amspoker, A., Hughes, A. M. \& Haidet, P. (2018). Mental models of audit and feedback in primary care settings. Implementation Science, 2018(13), 1-11. doi:10.1186/s13012-018-0764-3

Institute of Medicine (US) Committee on Standards for Developing Trustworthy Clinical Practice Guidelines. (2011). Clinical practice guidelines we can trust R. Graham, M. Mancher, D. M. Wolman, S. Greenfield, \& E. Steinberg (Eds.). Retrieved from https://www.ncbi.nlm.nih.gov/books/NBK209539/doi:10.17226/13058

Institute of Medicine Committee on Quality of Health Care in, A. (2001). Crossing the Quality Chasm: A New Health System for the 21st Century. Washington (DC): National Academies Press.

Ivers, N. M., Barnsley, J., Upshur, R., Tu, K., Shah, B., Grimshaw, J. \& Zwarenstein, M. (2014). "My approach to this job is...one person at a time": Perceived discordance between population-level quality targets and patient-centred care. Canadian Family Physician, 60(3), 258-266.

Ivers, N. M., Grimshaw, J. M., Jamtvedt, G., Flottorp, S., O'Brien, M. A., French, S. D., . . . Odgaard-Jensen, J. (2014). Growing literature, stagnant science? Systematic review, 
meta-regression and cumulative analysis of audit and feedback interventions in health care. Journal of General Internal Medicine, 29(11), 1534-1541. doi:10.1007/s11606014-2913-y

Ivers, N. M., Jamtvedt, G., Flottorp, S., Young, J. M., Odgaard-Jensen, J., French, S. D., . . . Oxman, A. D. (2012). Audit and feedback: Effects on professional practice and healthcare outcomes (Review). Cochrane Database of Systematic Reviews, 2012(6), 1227. doi:10.1002/14651858.CD000259.pub3

Ivers, N. M., Sales, A., Colquhoun, H., Michie, S., Foy, R., Francis, J. J. \& Grimshaw, J. M. (2014). No more 'business as usual' with audit and feedback interventions: Towards an agenda for a reinvigorated intervention. Implementation Science, 2014(9), 1-8. doi:10.1186/1748-5908-9-14

Jamtvedt, G., Young, J. M., Kristoffersen, D. T., O'Brien, M. A. \& Oxman, A. D. (2006). Audit and feedback: Effects on professional practice and health care outcomes. Cochrane Database of Systematic Reviews, 2006(2). doi:10.1002/14651858.CD000259.pub2

Jenuwine, E. S. \& Floyd, J. A. (2004). Comparison of Medical Subject Headings and textword searches in MEDLINE to retrieve studies on sleep in healthy individuals. Journal of the Medical Library Association, 92(3), 349-353.

Joffe, H. (2012). Thematic analysis. In D. Harper \& A. R. Thompson (Eds.), Qualitative research methods in mental health and psychotherapy : a guide for students and practitioners. Malden, Mass.: Wiley-Blackwell.

Kao, L. (2014). Implementation Science and Quality Improvement In D. J \& G. C (Eds.), Success in Academic Surgery: Health Services Research. London: Springer. Retrieved from. doi:doi.org/10.1007/978-1-4471-4718-3_8

Keizer, J., Beerlage-De Jong, N., Al Naiemi, N. \& van Gemert-Pijnen, J. (2020). Finding the match between healthcare worker and expert for optimal audit and feedback on antimicrobial resistance prevention measures. Antimicrob Resist Infect Control, 9(1), 125. doi:10.1186/s13756-020-00794-7

Kessler, R. \& Glasgow, R. E. (2011). A proposal to speed translation of healthcare research into practice: Dramatic change is needed. American Journal of Preventive Medicine, 40(6), 637-644. doi:10.1016/j.amepre.2011.02.023

Khokhar, J. Y., Dwiel, L. L., Henricks, A. M., Doucette, W. T. \& Green, A. I. (2018). The link between schizophrenia and substance use disorder: A unifying hypothesis. Schizophrenia Research, 194, 78-85. doi:10.1016/j.schres.2017.04.016 
Kluger, A. \& DeNisi, A. (1996). The effects of feedback interventions on performance: A historical review, a meta-analysis, and a preliminary feedback intervention theory. Psychological Bulletin, 119(2), 254-284. doi:10.1037/0033-2909.119.2.254

Koelsch, L. E. (2013). Reconceptualizing the member check interview. International journal of qualitative methods, 12(1), 168-179.

Koivunen, M., Valimaki, M. \& Hatonen, H. (2010). Nurses' information retrieval skills in psychiatric hospitals: Are the requirements for evidence-based practice fulfilled? Nurse Education in Practice, 10(1), 27-31. doi:10.1016/j.nepr.2009.03.004

Kotterman, J. (2006). Leadership versus management: What's the difference? The Journal for Quality and Participation, 29(2), 13.

Kredo, T., Bernhardsson, S., Machingaidze, S., Young, T., Louw, Q., Ochodo, E. \& Grimmer, K. (2016). Guide to clinical practice guidelines: the current state of play. International Journal for Quality in Health Care, 28(1), 122-128. doi:10.1093/intqhe/mzv115

Kristensen, H. \& Hounsgaard, L. (2014). Evaluating the impact of audits and feedback as methods for implementation of evidence in stroke rehabilitation. British Journal of Occupational Therapy, 77(5), 251-259. doi:10.4276/030802214x13990455043520

Lai, H. M., Cleary, M., Sitharthan, T. \& Hunt, G. E. (2015). Prevalence of comorbid substance use, anxiety and mood disorders in epidemiological surveys, 1990-2014: A systematic review and meta-analysis. Drug and Alcohol Dependence, 154, 1-13. doi:10.1016/j.drugalcdep.2015.05.031

Larsen, B. I. \& Bjørneboe, G. E. A. (2009). Psykisk helsevern for voksne. Distriktspsykiatriske sentre - med blikket vendt mot kommunene og spesialiserte sykehusfunksjoner i ryggen (IS-1388 Veileder). Oslo: Sosial- og helsedirektoratet Retrieved from https://omsorgsforskning.brage.unit.no/omsorgsforskning$\underline{\text { xmlui/handle/11250/2444716 }}$

Lau, R., Stevenson, F., Ong, B. N., Dziedzic, K., Treweek, S., Eldridge, S., . . Murray, E. (2016). Achieving change in primary care--causes of the evidence to practice gap: systematic reviews of reviews. Implementation Science, 11, 40. doi:10.1186/s13012016-0396-4

Laur, C., Sribaskaran, T., Simeoni, M., Desveaux, L., Daneman, N., Mulhall, C., . . Ivers, N. M. (2021). Improving antibiotic initiation and duration prescribing among nursing home physicians using an audit and feedback intervention: a theory-informed qualitative analysis. BMJ Open Qual, 10(1). doi:10.1136/bmjoq-2020-001088 
Liang, L., Abi Safi, J. \& Gagliardi, A. R. (2017). Number and type of guideline implementation tools varies by guideline, clinical condition, country of origin, and type of developer organization: Content analysis of guidelines. Implementation Science, 2017(12), 1-12. doi:10.1186/s13012-017-0668-7

Lincoln, Y. S. \& Guba, E. G. (1990). Judging the quality of case study reports. International Journal of Qualitative Studies in Education, 3(1), 53-59. doi:10.1080/0951839900030105

Lincoln, Y. S. \& Guba, E. G. (2013). The Constructivist Credo. Walnut Creek: Walnut Creek: Taylor \& Francis Group.

Livorsi, D. J., Goedken, C. C., Sauder, M., Vander Weg, M. W., Perencevich, E. N. \& Reisinger, H. S. (2018). Evaluation of Barriers to Audit-and-Feedback Programs That Used Direct Observation of Hand Hygiene Compliance: A Qualitative Study. JAMA Netw Open, 1(6), e183344. doi:10.1001/jamanetworkopen.2018.3344

Locke, E. \& Latham, G. (2002). Building a practically useful theory of goal setting and task motivation: A 35-year odyssey. American Psychologist, 57(9), 705-717. doi:10.1037/0003-066X.57.9.705

Lumadi, T. G. (2017). The perceptions of midwives regarding audit and feedback on the use of the partogram at Vhembe District of Limpopo Province, South Africa. Curationis, 40(1), e1-e6. doi:10.4102/curationis.v40i1.1770

Macklin, R. (2014). Ethical challenges in implementation research. Public Health Ethics, 7(1), 86-93. doi:10.1093/phe/phu003

Malterud, K. (2016). Theory and interpretation in qualitative studies from general practice: Why and how? Scand J Public Health, 44(2), 120-129. doi:10.1177/1403494815621181

Malterud, K. (2017). Kvalitative forskningsmetoder for medisin og helsefag (4. utg. ed.). Oslo: Universitetsforl.

Mazza, D., Bairstow, P., Buchan, H., Chakraborty, S. P., Van Hecke, O., Grech, C. \& Kunnamo, I. (2013). Refining a taxonomy for guideline implementation: results of an exercise in abstract classification. Implementation Science, 8(32). doi:10.1186/1748$5908-8-32$

McCleary, N., Desveaux, L., Reis, C., Linklater, S., Witteman, H. O., Taljaard, M., . . Presseau, J. (2020). A multiple-behaviour investigation of goal prioritisation in physicians receiving audit and feedback to address high-risk prescribing in nursing homes. Implement Sci Commun, 1, 33. doi:10.1186/s43058-020-00019-3 
McGlynn, E. A., Asch, S. M., Adams, J., Keesey, J., Hicks, J., DeCristofaro, A. \& Kerr, E. A. (2003). The quality of health care delivered to adults in the United States. New England Journal of Medicine, 348(26), 2635-2645. doi:10.1056/NEJMsa022615

McHugh, R. K. \& Barlow, D. H. (2012). Dissemination and implementation of evidencebased psychological interventions. New York: Oxford University Press.

McKibbon, K. A. \& Lokker, C. (2009). Searching for research findings and KT litterature. In S. E. Straus, J. Tetroe, \& I. D. Graham (Eds.), Knowledge translation in health care: moving from evidence to practice (pp. 46-55). Chichester: Wiley-Blackwell.

McKibbon, K. A., Lokker, C., Wilczynski, N. L., Haynes, R. B., Ciliska, D., Dobbins, M., . . . Straus, S. E. (2012). Search filters can find some but not all knowledge translation articles in MEDLINE: an analytic survey. Journal of Clinical Epidemiology, 65(6), 651-659. doi:10.1016/j.jclinepi.2011.10.014

McKibbon, K. A., Wilczynski, N. L. \& Haynes, R. B. (2006). Developing optimal search strategies for retrieving qualitative studies in PsycINFO. Evaluation and the Health Professions, 29(4), 440-454.

Meld. St. 7 (2019-2020). (2019). [National Health and Hospital Plan (2020-2023)] Nasjonal helse- og sykehusplan (2020-2023) (white paper). Oslo: Ministry of Health and Care Services.

Meld. St. 11 (2015-2016). (2015). [National Health and Hospital Plan (2016-2019)] Nasjonal helse- og sykehusplan (2016-2019) (white paper). Oslo: Ministry of Health and Care Services.

Meld. St. 11 (2020-2021). (2020). [Quality and Patient Safety 2019] Kvalitet og pasientsikkerhet 2019 (white paper). Oslo: Ministry of Health and Care Services.

Meld. St. 16 (2011-2015). (2011). [National Health and Care Plan (2011-2015)] Nasjonal helse- og omsorgsplan (2011-2015) (white paper). Oslo: Ministry of Health and Care Services.

Melnyk, B. M. \& Fineout-Overholt, E. (2015). Evidence-based practice in nursing \& healthcare : a guide to best practice (3rd ed.). Philadelphia: Wolters Kluwer Health.

Michaelis, B., Stegmaier, R. \& Sonntag, K. (2010). Shedding light on followers' innovation implementation behavior. Journal of Managerial Psychology, 25(4), 408-429. doi:10.1108/02683941011035304

Michie, S., Fixsen, D., Grimshaw, J. \& Eccles, M. (2009). Specifying and reporting complex behaviour change interventions: the need for a scientific method. Implementation Science, 2009(4), 1-6. doi:10.1186/1748-5908-4-40 
Mills, J. \& Birks, M. (Eds.). (2014). Qualitative methodology: A practical guide. London: Sage.

Moher, D., Liberati, A., Tetzlaff, J., Altman, D. G. \& Group, P. (2009). Preferred reporting items for systematic reviews and meta-analyses: the PRISMA Statement. BMJ, 339. doi:10.1136/bmj.b2535

Monahan, T. \& Fisher, J. A. (2010). Benefits of "Observer Effects": Lessons from the Field. Qual Res, 10(3), 357-376. doi:10.1177/1468794110362874

Morisano, D., Babor, T. \& Robaina, K. (2014). Co-occurrence of substance use disorders with other psychiatric disorders: Implications for treatment services. Nordic Studies on Alcohol and Drugs, 31(1), 5-25. doi:10.2478/nsad-2014-0002

Morris, Z. S., Wooding, S. \& Grant, J. (2011). The answer is 17 years, what is the question: understanding time lags in translational research. Journal of the Royal Society of Medicine, 104(12), 510-520. doi:10.1258/jrsm.2011.110180

Morse, J. M. (2012). Qualitative Health Research: Creating a New Discipline. Walnut Creek: Walnut Creek: Taylor \& Francis Group.

Morse, J. M. (2015a). Analytic Strategies and Sample Size. Qualitative Health Research, 25(10), 1317-1318. doi:10.1177/1049732315602867

Morse, J. M. (2015b). Critical Analysis of Strategies for Determining Rigor in Qualitative Inquiry. Qualitative Health Research, 25(9), 1212-1222. doi:10.1177/1049732315588501

Morse, J. M., Barrett, M., Mayan, M., Olson, K. \& Spiers, J. (2002). Verification Strategies for Establishing Reliability and Validity in Qualitative Research. International journal of qualitative methods, 1(2), 13-22. doi:10.1177/160940690200100202

Nguyen, T., Seiler, N., Brown, E. \& O'Donoghue, B. (2019). The effect of Clinical Practice Guidelines on prescribing practice in mental health: A systematic review. Psychiatry Research, 284(112671). doi:10.1016/j.psychres.2019.112671

Nortvedt, M. W. (2007). [Working and teaching knowledge-based: a workbookfor nurses]: $\AA$ arbeide og undervise kunnskapsbasert: en arbeidsbokfor sykepleiere. Oslo: Norsk sykepleierforbund.

Norwegian Directorate of Health. (2012). [National guideline for assessment, treatment and social rehabilitation of persons with concurrent substance use disorders and mental disorders] : Nasjonal faglig retningslinje for utredning, behandling og oppfølging av personer med samtidig ruslidelse og psykisk lidelse - ROP-lidelser. (IS-1948). Oslo: Helsedirektoratet Retrieved from 
https://helsedirektoratet.no/Lists/Publikasjoner/Attachments/188/Nasjonal-fagligretningslinje-personer-med-rop-lidelser-IS-1948.pdf.

Norwegian Directorate of Health. (2017, 2020). [Mental health care regulations with comments] Psykisk helsevernforskriften med kommentarer. Retrieved from https://www.helsedirektoratet.no/rundskriv/psykisk-helsevernforskriften-medkommentarer

Norwegian Directorate of Health. (2019). [On the Norwegian Directorate of Health's normative products]: Om Helsedirektoratets normerende produkter. Retrieved from https://www.helsedirektoratet.no/produkter/om-helsedirektoratets-normerendeprodukter

Norwegian Directorate of Health \& Pedersen, P. B. (2016). [District Psychiatric Services 2015: Indicator for district psychiatrice centres] Distriktspsykiatriske tjenester 2015: Driftsindikatorer for distrikspsykiatriske sentre (IS-2579). Oslo: The Norwgian Directorate of Health Retrieved from https://www.helsedirektoratet.no/rapporter/distriktspsykiatriske-tjenesterdriftsindikatorer-for-distriktspsykiatriske-sentre

Norwegian Electronic Health Library. (2016). [Evidence-based practice]: Kunnskapsbasert praksis. Retrieved from https://www.helsebiblioteket.no/kunnskapsbasert-praksis

Nowell, L. S., Norris, J. M., White, D. E. \& Moules, N. J. (2017). Thematic analysis: Striving to meet the trustworthiness criteria. International journal of qualitative methods, 16(1), 1609406917733847.

O'Leary D, F. \& Mhaolrunaigh, S. N. (2012). Information-seeking behaviour of nurses: Where is information sought and what processes are followed? Journal of Advanced Nursing, 68(2), 379-390. doi:10.1111/j.1365-2648.2011.05750.x

Parand, A., Dopson, S., Renz, A. \& Vincent, C. (2014). The role of hospital managers in quality and patient safety: A systematic review. BMJ Open, 4(9), e005055. doi:10.1136/bmjopen-2014-005055

Payne, V. L. \& Hysong, S. J. (2016). Model depicting aspects of audit and feedback that impact physicians' acceptance of clinical performance feedback. BMC Health Services Research, 16, 1-12. doi:10.1186/s12913-016-1486-3

Pedersen, M. S., Landheim, A., Møller, M. \& Lien, L. (2018). Acting on audit \& feedback: A qualitative instrumental case study in mental health services in Norway. BMC Health Services Research, 18, 1-11. doi:10.1186/s12913-018-2862-y 
Pedersen, M. S., Landheim, A., Møller, M. \& Lien, L. (2018). Audit and feedback in mental healthcare: Staff experiences. International Journal of Health Care Quality Assurance, 31(7), 822-833. doi:10.1108/IJHCQA-08-2017-0142

Polit, D. F. \& Beck, C. T. (2017). Nursing Research : generating and assessing evidence for nursing practice (10th ed. ed.). Philadelphia: Wolters Kluwer.

Potter, J., Fuller, C. \& Ferris, M. (2010). Local clinical audit: handbook for physicians. Retrieved from https://www.hqip.org.uk/resource/hqip-local-clinical-audit-handbookfor-physicians/

Priestland, A. \& Hanig, R. (2005). Developing first-level leaders. Harvard Business Review, 83(6), 112-120, 150.

Prior, M., Guerin, M. \& Grimmer-Somers, K. (2008). The effectiveness of clinical guideline implementation strategies--a synthesis of systematic review findings. Journal of Evaluation in Clinical Practice, 14(5), 888-897. doi:10.1111/j.13652753.2008.01014.X

Proctor, E. K., Landsverk, J., Aarons, G. A., Chambers, D., Glisson, C. \& Mittman, B. (2009). Implementation research in mental health services: An emerging science with conceptual, methodological, and training challenges. Administration and Policy in Mental Health, 36(1), 24-34. doi:10.1007/s10488-008-0197-4

Prytys, M., Garety, P. A., Jolley, S., Onwumere, J. \& Craig, T. (2011). Implementing the NICE guideline for schizophrenia recommendations for psychological therapies: A qualitative analysis of the attitudes of CMHT staff. Clinical Psychology \& Psychotherapy, 18(1), 48. doi:10.1002/cpp.691

Public Health Leadership Society. (2002). Principles of the Ethical Practice of Public Health. Version 2.2. Retrieved from https://nnphi.org/wpcontent/uploads/2015/08/PHLSposter-95321.pdf

QSR International. (2012). NVivo qualitative data analysis [Computer software] (Version 10): QSR International Pty Ltd. .

Rabin, B. A. \& Brownson, R. C. (2012). Developing the terminology for dissemination and implementation research. In R. C. Brownson, G. A. Colditz, \& E. K. Proctor (Eds.), Dissemination and implementation research in health (pp. 23-51). New York, NY: Oxford.

Rattray, N. A., Damush, T. M., Miech, E. J., Homoya, B., Myers, L. J., Penney, L. S., . . Bravata, D. M. (2020). Empowering Implementation Teams with a Learning Health System Approach: Leveraging Data to Improve Quality of Care for Transient 
Ischemic Attack. Journal of General Internal Medicine, 35(Suppl 2), 823-831. doi:10.1007/s11606-020-06160-y

Reichenpfader, U., Carlfjord, S. \& Nilsen, P. (2015). Leadership in evidence-based practice: A systematic review. Leadersh Health Serv (Bradf Engl), 28(4), 298-316. doi:10.1108/lhs-08-2014-0061

Renolen, A. \& Hjalmhult, E. (2015). Nurses experience of using scientific knowledge in clinical practice: A grounded theory study. Scandinavian Journal of Caring Sciences, 29(4), 633-641. doi:10.1111/scs.12191

Renolen, A., Hoye, S., Hjalmhult, E., Danbolt, L. J. \& Kirkevold, M. (2018). "Keeping on track"-Hospital nurses' struggles with maintaining workflow while seeking to integrate evidence-based practice into their daily work: A grounded theory study. International Journal of Nursing Studies, 77, 179-188. doi:10.1016/j.ijnurstu.2017.09.006

Saban, A. \& Flisher, A. J. (2010). The association between psychopathology and substance use in young people: a review of the literature. Journal of Psychoactive Drugs, 42(1), 37-47. doi:10.1080/02791072.2010.10399784

Sackett, D. L., Rosenberg, W. M., Gray, J. A., Haynes, R. B. \& Richardson, W. S. (1996). Evidence based medicine: what it is and what it isn't. BMJ, 312(7023), 71-72. doi:10.1136/bmj.312.7023.71

Saeed, S. A., Bloch, R. M. \& Silver, S. (2015). Role of leadership in narrowing the gap between science and practice: Improving treatment outcomes at the systems level. Psychiatric Quarterly, 86(3), 311-323. doi:10.1007/s11126-015-9372-4

Sandström, B., Borglin, G., Nilsson, R. \& Willman, A. (2011). Promoting the implementation of evidence-based practice: A literature review focusing on the role of nursing leadership. Worldviews on Evidence-Based Nursing, 8(4), 212-223. doi:10.1111/j.1741-6787.2011.00216.x

Sandström, B., Willman, A., Svensson, B. \& Borglin, G. (2015). Perceptions of national guidelines and their (non) implementation in mental healthcare: a deductive and inductive content analysis. Implementation Science, 10(43), 1-13. doi:10.1186/s13012015-0234-0

Schuster, M. A., McGlynn, E. A. \& Brook, R. H. (2005). How good is the quality of health care in the United States? 1998. Milbank Quarterly, 83(4), 843-895. doi:10.1111/j.1468-0009.2005.00403.x 
Scottish Intercollegiate Guidelines Network. (2019, 2012). SIGN Grading System: 19992012. Retrieved from https://www.sign.ac.uk/assets/sign_grading_system_1999_2012.pdf

Sederer, L. I. (2009). Science to practice: Making what we know what we actually do. Schizophrenia Bulletin, 35(4), 714-718. doi:10.1093/schbul/sbp040

Shekelle, P., Woolf, S., Grimshaw, J. M., Schünemann, H. J. \& Eccles, M. P. (2012). Developing clinical practice guidelines: Reviewing, reporting, and publishing guidelines; updating guidelines; and the emerging issues of enhancing guideline implementability and accounting for comorbid conditions in guideline development. Implementation Science, 2012(7), 1-7. doi:10.1186/1748-5908-7-62

Sheldon, T. A., Cullum, N., Dawson, D., Lankshear, A., Lowson, K., Watt, I., . . Wright, J. (2004). What's the evidence that NICE guidance has been implemented?: Results from a national evaluation using time series analysis, audit of patients' notes and interviews. BMJ, 329(7473), 1-8. doi:10.1136/bmj.329.7473.999

Shepherd, N., Meehan, T. J., Davidson, F. \& Stedman, T. (2010). An evaluation of a benchmarking initiative in extended treatment mental health services. Australian Health Review, 34(3), 328-333. doi:10.1071/ah09698

Sinuff, T., Muscedere, J., Rozmovits, L., Dale, C. M. \& Scales, D. C. (2015). A qualitative study of the variable effects of audit and feedback in the ICU. BMJ Quality \& Safety, 24(6), 393-399. doi:10.1136/bmjqs-2015-003978

Smiddy, M. P., Murphy, O. M., Savage, E. \& Browne, J. P. (2019). The influence of observational hand hygiene auditing on consultant doctors' hand hygiene behaviors: A qualitative study. American Journal of Infection Control, 47(7), 798-803.e791. doi:10.1016/j.ajic.2018.12.024

Springer, M. V., Sales, A. E., Islam, N., McBride, A. C., Landis-Lewis, Z., Tupper, M., .. . Skolarus, L. E. (2021). A step toward understanding the mechanism of action of audit and feedback: a qualitative study of implementation strategies. Implementation Science, 16(1), 35. doi:10.1186/s13012-021-01102-6

Stake, R. E. (1994). Case study: Composition and performance Bulletin of the Council for Research in Music Education(122), 31-44.

Stake, R. E. (1995). The art of case study research. Thousand Oaks, CA: Sage.

Statistics Norway. (2020). 09551: Mental health care institutions for adults. Man-years, by education and health enterprise 2008 - 2020. Retrieved from https://www.ssb.no/en/statbank/table/09551/ 
Straus, S. E., Tetroe, J. \& Graham, I. (2009). Defining knowledge translation. CMAJ:

Canadian Medical Association Journal, 181(3-4), 165-168. doi:10.1503/cmaj.081229

Suri, H. (2011). Purposeful sampling in qualitative research synthesis. Qualitative research journal, 11(2), 63-75.

Sykes, M., Thomson, R., Kolehmainen, N., Allan, L. \& Finch, T. (2020). Impetus to change: a multi-site qualitative exploration of the national audit of dementia. Implementation Science, 15(1), 45. doi:10.1186/s13012-020-01004-Z

Sykes, M., Thomson, R., Kolehmainen, N., Allan, L. \& Finch, T. (2021). Opportunities to enhance ward audit: a multi-site qualitative study. BMC Health Services Research, 21(1), 226. doi:10.1186/s12913-021-06239-0

Taylor, A., Neuburger, J., Walker, K., Cromwell, D. \& Groene, O. (2016). How is feedback from national clinical audits used? Views from English National Health Service trust audit leads. Journal of Health Services Research and Policy, 21(2), 91-100. doi:10.1177/1355819615612826

Taylor, S. L., Dy, S., Foy, R., Hempel, S., McDonald, K. M., Øvretveit, J., . . . Shekelle, P. G. (2011). What context features might be important determinants of the effectiveness of patient safety practice interventions? BMJ Quality \& Safety, 20(7), 611-617. doi:10.1136/bmjqs.2010.049379

Thomassen, M. (2006). Vitenskap, kunnskap og praksis : innføring $i$ vitenskapsfilosofi for helse- og sosialfag. Oslo: Gyldendal akademisk.

Thornquist, E. (2018). Vitenskapsfilosofi og vitenskapsteori: for helsefag (2nd ed.). Bergen: Fagbokforl.

Tjora, A. H. (2012). Kvalitative forskningsmetoder i praksis (2nd ed.). Oslo: Gyldendal akademisk.

Trietsch, J., van Steenkiste, B., Hobma, S., Frericks, A., Grol, R., Metsemakers, J. \& van der Weijden, T. (2014). The challenge of transferring an implementation strategy from academia to the field. Journal of Evaluation in Clinical Practice, 20(6), 1162-1171. doi:10.1111/jep.12287

Turner, T., Misso, M., Harris, C. \& Green, S. (2008). Development of evidence-based clinical practice guidelines (CPGs): Comparing approaches. Implementation Science, 2008(3), 1-8. doi:10.1186/1748-5908-3-45

Vaismoradi, M., Turunen, H. \& Bondas, T. (2013). Content analysis and thematic analysis: Implications for conducting a qualitative descriptive study. Nursing \& Health Sciences, 15(3), 398-405. doi:10.1111/nhs.12048 
van Braak, M., Visser, M., Holtrop, M., Statius Muller, I., Bont, J. \& van Dijk, N. (2019). What motivates general practitioners to change practice behaviour? A qualitative study of audit and feedback group sessions in Dutch general practice. BMJ Open, 9(5), e025286. doi:10.1136/bmjopen-2018-025286

Van Den Bulck, S., Spitaels, D., Vaes, B., Goderis, G., Hermens, R. \& Vankrunkelsven, P. (2020). The effect of electronic audits and feedback in primary care and factors that contribute to their effectiveness: a systematic review. International Journal for Quality in Health Care, 32(10), 708-720. doi:10.1093/intqhc/mzaa128

Vandvik, P. O. \& Eiring, Ø. (2011). Foretaksprosjektet: mot kunnskapsbasert praksis $i$ spesialisthelsetjenesten (16-2011). Oslo: Kunnskapssenteret Retrieved from https://www.fhi.no/publ/2011/foretaksprosjektet-mot-kunnskapsbasert-praksis-ispesialisthelsetjenesten/

Versteeg, M., Laurant, M., Franx, G., Jacobs, A. \& Wensing, M. (2012). Factors associated with the impact of quality improvement collaboratives in mental healthcare: An exploratory study. Implementation Science, 2012(7), 1-12. doi:10.1186/1748-5908-7-1

von Ranson, K. M., Wallace, L. M. \& Stevenson, A. (2013). Psychotherapies provided for eating disorders by community clinicians: Infrequent use of evidence-based treatment. Psychotherapy research, 23(3), 333-343. doi:10.1080/10503307.2012.735377

Wagner, D. J., Durbin, J., Barnsley, J. \& Ivers, N. M. (2017). Beyond quality improvement: exploring why primary care teams engage in a voluntary audit and feedback program. BMC Health Services Research, 17(1), 803. doi:10.1186/s12913-017-2765-3

Wagner, D. J., Durbin, J., Barnsley, J. \& Ivers, N. M. (2019). Measurement without management: qualitative evaluation of a voluntary audit $\&$ feedback intervention for primary care teams. BMC Health Services Research, 19, 1-13. doi:10.1186/s12913019-4226-7

Walshe, C., Ewing, G. \& Griffiths, J. (2012). Using observation as a data collection method to help understand patient and professional roles and actions in palliative care settings. Palliative Medicine, 26(8), 1048-1054. doi:10.1177/0269216311432897

Webster, F., Patel, J., Rice, K., Baxter, N., Paszat, L., Rabeneck, L. \& Tinmouth, J. (2016). How to make feedback more effective? Qualitative findings from pilot testing of an audit and feedback report for endoscopists. Can J Gastroenterol Hepatol, 2016(4983790). doi:10.1155/2016/4983790 
Weinmann, S., Koesters, M. \& Becker, T. (2007). Effects of implementation of psychiatric guidelines on provider performance and patient outcome: Systematic review. Acta Psychiatrica Scandinavica, 115(6), 420-433. doi:10.1111/j.1600-0447.2007.01016.x

WHO. (n.d.). Lexicon of alcohol and drug terms. Retrieved from https://www.who.int/substance_abuse/terminology/who_lexicon/en/

World Health Organization. (2013). Mental health action plan 2013-2020. Geneva: WHO Retrieved from http://apps.who.int/iris/bitstream/handle/10665/89966/9789241506021_eng.pdf;jsessi onid=CB04629BC457A7F74A6891D6FBF3F978? sequence $=1$

World Medical Association. (2013). WMA Declaration of Helsinki-Ethical Principles for Medical Research Involving Human Subjects. Retrieved from https://www.wma.net/policies-post/wma-declaration-of-helsinki-ethical-principles-formedical-research-involving-human-subjects/

Yin, R. K. (2014). Case study research: design and methods (5th ed.). Los Angeles, CA: Sage.

Aarons, G. A., Ehrhart, M. G., Farahnak, L. R. \& Hurlburt, M. S. (2015). Leadership and organizational change for implementation (LOCI): a randomized mixed method pilot study of a leadership and organization development intervention for evidence-based practice implementation. Implementation Science, 2015(10), 1-12. doi:10.1186/s13012-014-0192-y

Aarons, G. A., Ehrhart, M. G., Farahnak, L. R. \& Sklar, M. (2014). Aligning leadership across systems and organizations to develop a strategic climate for evidence-based practice implementation. Annual Review of Public Health, 35, 255-274. doi:10.1146/annurev-publhealth-032013-182447

Aarons, G. A., Hurlburt, M. S. \& Horwitz, S. M. (2011). Advancing a conceptual model of evidence-based practice implementation in public service sectors. Administration and Policy in Mental Health and Mental Health Services Research, 38(1), 4-23. doi:10.1007/s10488-010-0327-7 

I 



\title{
Acting on audit \& feedback: a qualitative instrumental case study in mental health services in Norway
}

\author{
Monica Stolt Pedersen ${ }^{1,2^{*}}$, Anne Landheim ${ }^{1,3}$, Merete Møller ${ }^{4}$ and Lars Lien ${ }^{1,5}$
}

\begin{abstract}
Background: The National Guideline for Assessment, Treatment and Social Rehabilitation of Persons with Concurrent Substance Use and Mental Health Disorders, launched in 2012, is to be implemented in mental health services in Norway. Audit and feedback (A\&F) is commonly used as the starting point of an implementation process. It aims to measure the research-practice gap, but its effect varies greatly. Less is known of how audit and feedback is used in natural settings. The aim of this study was to describe and investigate what is discussed and thematised when Quality Improvement (QI) teams in a District Psychiatric Centre (DPC) work to complete an action form as part of an A\&F cycle in 2014.

Methods: This was an instrumental multiple case study involving four units in a DPC in Norway. We used open non-participant observation of QI team meetings in their natural setting, a total of seven teams and eleven meetings.

Results: The discussions provided health professionals with insight into their own and their colleagues' practices. They revealed insufficient knowledge of substance-related disorders and experienced unclear role expectations. We found differences in how professional groups sought answers to questions of clinical practice and that they were concerned about whether new tasks fitted in with their routine ways of working.

Conclusion: Acting on A\&F provided an opportunity to discuss practice in general, enhancing awareness of good practice. There was a general need for arenas to relate to practice and QI team meetings after A\&F may well be a suitable arena for this. Self-assessment audits seem valuable, particular in areas where no benchmarked data exists, and there is a demand for implementation of new guidelines that might change routines and develop new roles. QI teams could benefit from having a unit leader present at meetings. Nurses and social educators and others turn to psychiatrists or psychologists for answers to clinical and organisational questions beyond guidelines, and show less confidence or routine in seeking research-based information. There is a general need to emphasise training in evidence-based practice and information seeking behaviour for all professional groups.
\end{abstract}

Keywords: Audit and feedback, Implementation, Mental health services, Co-occurring disorders, Qualitative methods, Case studies

\footnotetext{
* Correspondence: monica.stolt.pedersen@sykehuset-innlandet.no

Norwegian National Advisory Unit on Concurrent Substance Abuse and

Mental Health Disorders, Innlandet Hospital Trust, P.B. 104, 2340 Brumunddal,

Norway

${ }^{2}$ Faculty of Medicine, University of Oslo, Oslo, Norway

Full list of author information is available at the end of the article
}

\section{Ciomed Central}

(c) The Author(s). 2018 Open Access This article is distributed under the terms of the Creative Commons Attribution 4.0 International License (http://creativecommons.org/licenses/by/4.0/), which permits unrestricted use, distribution, and reproduction in any medium, provided you give appropriate credit to the original author(s) and the source, provide a link to the Creative Commons license, and indicate if changes were made. The Creative Commons Public Domain Dedication waiver (http://creativecommons.org/publicdomain/zero/1.0/) applies to the data made available in this article, unless otherwise stated. 


\section{Background}

Audit and feedback (A\&F) is often the starting point of quality improvement projects. It aims to close the gap between recommended and actual practice. A\&F may be defined as a 'summary of the clinical performance of healthcare provider(s) over a specified period of time' [1]. It can be a useful intervention to improve health professionals' compliance with desired practice and is one of the most widely used strategies for improving practice [1-3]. A\&F may be described as a circular process with several stages $[4,5]$. It is often designed to be a part of a multifaceted improvement strategy, where audit with feedback is theorised to promote health professionals' motivation to improve practice [1, 6-8]. Reflecting on results, agreeing on where improvement is needed and producing an improvement plan are essential components of the process.

The past 10-15 years have seen an increasing interest in guideline implementation strategies [9]. The Norwegian National Health Plan (white paper) states that evidence-based practice is a goal in Norwegian health policy [10]. Health authorities produce clinical guidelines in order to encourage a more evidence-based practice and more harmonised services [6]. Clinical guidelines give recommendations for best practice and may be used as benchmarks against which clinical practice may be evaluated [11]. The Norwegian Directorate of Health is the only organisation with a mandate to develop and disseminate national clinical guidelines in Norway. Recommendations in national guidelines are not legally binding (unless tied to a legal act), but normative by pointing to the desired and recommended courses of action [12].

Several studies show high co-occurrence between substance use disorders and mental health problems. This is well documented through clinical and epidemiological studies [13-17]. "The National Guideline for Assessment, Treatment and Social Rehabilitation of Persons with Concurrent Substance Use and Mental Health Disorders" [18] (hereafter the National Guideline) was launched in March 2012 and as one of several initiatives designed to improve services for people with concurrent substance use disorders and mental illness (see Additional file 1). The Norwegian National Advisory Unit on Concurrent Substance Abuse and Mental Health Disorders (hereafter the National Advisory Unit) has developed a standardised electronic audit questionnaire mirroring the recommendations in the National Guideline [19]. This is a predetermined audit aimed at District Psychiatric Centres (DPC), to support implementation of the National Guideline, and to be used together with an action form.

Despite broad agreement on the importance of guidelines, they are not always easily translated into practice [20], often referred to as barriers to change [21]. Several strategies and theories exist as to how recommendations from research might be implemented [22-24], including process models aimed at describing and guiding the process [25]. A recent Cochrane Review [26] was unable to identify the effectiveness of implementation strategies in mental health care. The Effective Practice and Organisation of Care (EPOC) Group is a Cochrane Review Group [27], whose tasks include reviewing implementation strategies aimed at health professionals. One of the implementation strategies are A\&F [1]. A key function of $A \& F$ is to identify sub-optimal performance and recognise the need for change $[8,28,29]$. Studies show that the effect of A\&F on professional behaviour and patient outcome ranges from little or no effect to a substantial effect $[1,30]$ and this may be due to the characteristics of the behaviour it is targeted at, the healthcare staff audited, their context, the patients/consumers, or the components of the intervention itself [31, 32]. A\&F may be most effective when the research-practice gap is large, the person responsible for the $A \& F$ is a supervisor or colleague, it is conducted more than once, it is given both verbally and in writing, and it includes clear targets as well as an action plan [1, 29]. We still do not fully understand the key ingredients of a successful A\&F intervention or the mechanisms of action of effective A\&F interventions in healthcare [7, 29]. Most of the research concerns the effect of A\&F and how and when feedback is given. To our knowledge, less is known about how health care professionals discuss and use the results from the A\&F when they meet in quality improvement (QI) teams with the purpose of selecting improvement areas, i.e. acting on the results from the audit with the purpose of improving service quality in a mental health care setting.

The aim of this study was to describe and investigate what is discussed and thematised when QI teams in a DPC work to complete an action form as part of an A\&F cycle.

\section{Methods}

The process described followed a common A\&F cycle, and this study involved Phases 3 and 4; the audit had been completed, feedback had been given, and QI teams met to fill out action forms (see Fig. 1).

\section{Design}

This was a qualitative, instrumental, multiple case study $[33,34]$. The phenomenon we sought insight into was part of an improvement process: how QI teams discussed results from $A \& F$ and completed action forms in a "natural setting".

\section{Study site}

The study took place in a DPC in South-Eastern Norway. The DPC is part of a larger hospital trust and 


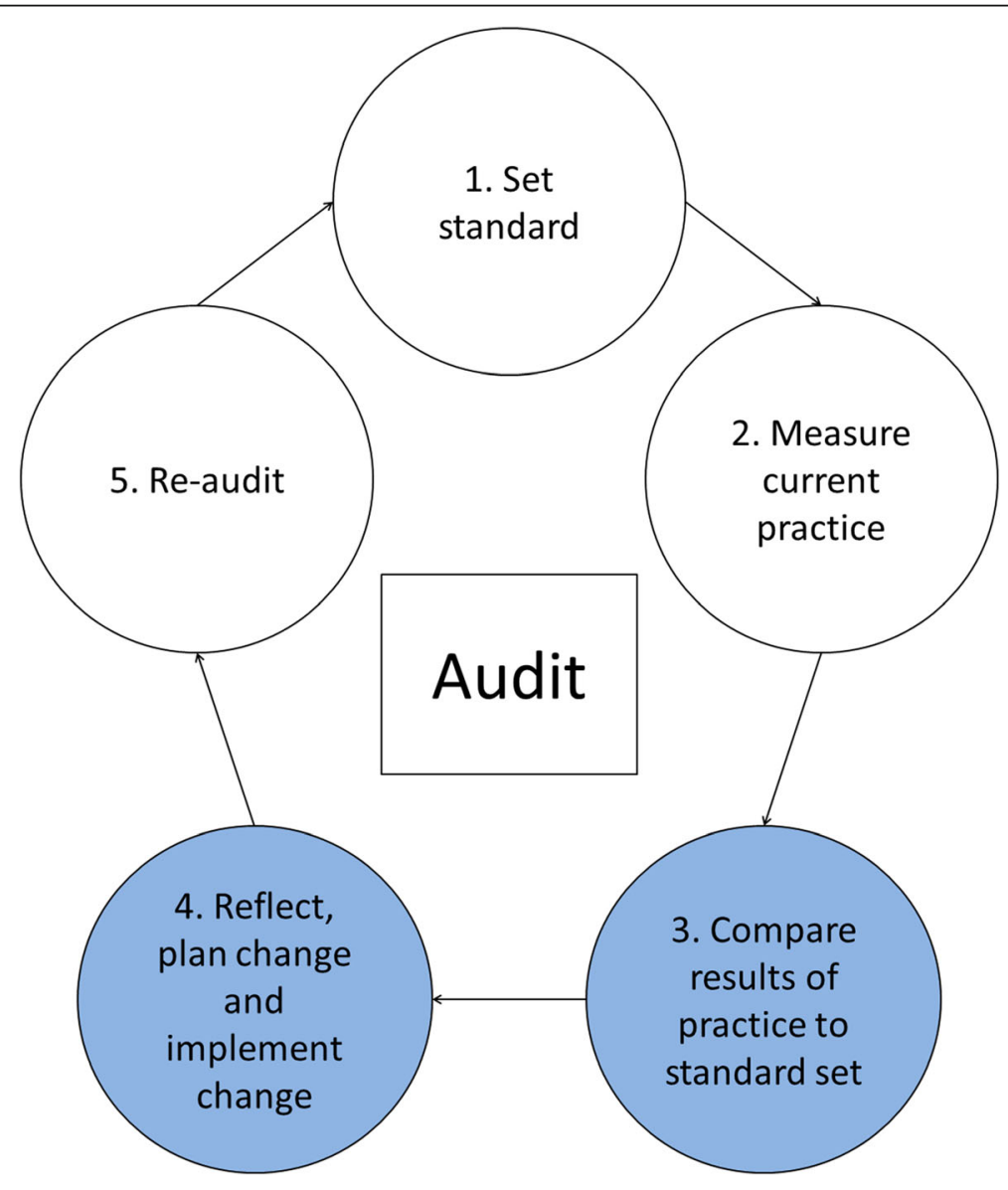

Fig. 1 An audit-cycle

consists of four units, two outpatient units and two inpatient units, each representing a case; where specialist mental health services are offered to approximately 72,000 inhabitants. Each unit is subject to various organisational and professional frameworks and is thus considered a separate case. Meanwhile, they belong to the same DPC, with the same management and the same organisational and legal conditions providing a common external conceptual framework connecting the cases and the activities involved.

The two inpatient units had similar staff in terms of number and type and length of education. In Norwegian inpatient units, nurses and social educators (minimum three-year bachelor's degree) and assistant nurses are commonly referred to as milieu personnel, while psychologists and psychiatrists are often referred to as therapists. The units had somewhat different groups of patients; one had more patients with psychosis-related disorders and another had more patients within general psychiatry or personality disorders. The staff consisted mainly of milieu personnel and 1-2 therapists in both inpatient units. One outpatient unit was a crisis resolution team (CRT), mainly consisting of staff like nurses, social educators or others with similar relevant qualifications, such as social workers, and had a psychologist and psychiatrist attached to the unit. They reached out from the hospital setting to patients mostly referred from GPs or other hospital departments. The second outpatient unit was mainly staffed by therapists such as a psychiatrists, psychologists or specialist nurses, operating as a general psychiatric outpatient clinic with regular hours and booked appointments.

\section{Recruitment and implementation process}

An improvement process for the entire DPC was proposed by the leader group of the Hospital Trust in October 2013 and thereafter agreed upon by the DPC later the same year, with an anticipated start in the units in the beginning of 2014. The decision was to implement the National Guideline guided by the implementation process outlined by the National Advisory Unit. The DPC was selected since they were ready to start an improvement process and we were looking for a site to study the implementation process. The implementation process was owned and executed by the DPC and would have taken place without the research project. 
The National Advisory Unit had developed tools to support implementation of the National Guideline as part of the development of the guideline. One was a brief description of an implementation process in stages adapted from the implementation of change model of Grol and colleagues [23]. This was accompanied by an electronic survey to audit practice in DPCs and a standardised action form with a template of how to use it. The action form contained columns for areas of improvement, goals, actions, progress plan, main responsibility, economic assessments and evaluation. The survey contained 46 questions about screening practices, assessment of target group, integrated treatment, collaboration, use of evidence-based methods and competence requirements, and was a self-report questionnaire. The audit survey was designed to be applicable to mental health services and was available with templates at the National Advisory Unit web site [19].

An audit of existing practice was conducted in February and March 2014. A project supervisor (MM) from the Health Trust, with special responsibility for concurrent substance abuse and mental health disorders, assisted in the execution of the audit. All four units of the DPC were included in the audit. Feedback of the results was given verbally and in writing by the project supervisor to each unit separately at meetings for the whole unit with unit leaders present. Results were presented at unit level, together with sessions on evidence-based practice, recommendations in the National Guideline and how to conduct an improvement process informed by the Knowledge-to-Action cycle [35]. The meetings were led by the project supervisor in March 2014.

The DPC formed QI teams from each unit to facilitate the process. Each unit leader selected who should participate in the group. Seven QI teams were set up with participants and meeting schedule, to start about one month after the audit results were presented. The participants in the teams reflected the staff in each unit in terms of education and job position as described above. Only one of the teams (from the CRT) had the unit leader present at QI team meetings, the teams from the general outpatient units had an appointed leader with senior experience, and the inpatient unit teams had a more flat leader structure. A total of 11 meetings were held (see Table 1).

Meetings of the QI teams were held in April and May 2014. The purposes of the meetings were outlined by the National Advisory Unit [36]:

1. to discuss the results of the audit and identify any gaps between the recommendations of the guideline and local practice

2. to choose areas for improvement on this basis
Table 1 Quality Improvement teams in the DPC. Numbers of teams, team members and meetings

\begin{tabular}{llll}
\hline & Ql teams & $\begin{array}{l}\text { Participants } \\
\text { in QI teams }\end{array}$ & Meetings \\
\hline General outpatient clinic & 2 & 14 & 3 \\
Inpatient unit 1 & 3 & 21 & 3 \\
Inpatient unit 2 & 1 & 6 & 1 \\
Crisis Resolution Team (CRT) & 1 & 12 & 4 \\
Total & 7 & 53 & 11 \\
\hline
\end{tabular}

3. to discuss local context and barriers and enablers for the improvement areas

4. to choose suitable actions for the goal of improvement

5. to discuss how to monitor and evaluate

The discussions in the QI meetings were based on the collected audit data and the participants' professional and organisational experience. A joint action plan for the DPC was adopted in June 2014 with common areas for improvement, actions, work schedule, responsibilities, budget assessment and evaluation, based on the work conducted in the QI teams. Three improvement areas were selected: 1) Screening the use of substances with AUDIT (Alcohol Use Identification Test) and DUDIT (Drug Use Identification Test), 2) Enhancing knowledge of the treatment of concurrent substance abuse and mental illness, and 3) Strengthening integration between the DPC, substance abuse departments and community health care. The actual implementation phase was planned for autumn 2014 to spring 2015, with a re-audit in spring 2015.

One researcher (MSP) spent some time at the study site before the actual data collection started, attending management meetings and talking to the project supervisor, the unit leaders and the department manager. This was to gain an understanding of the general context of the cases.

\section{Data collection}

All seven QI teams, with eleven team meetings, were observed, resulting in $11 \mathrm{~h}$ of recordings. The meetings lasted between $36 \mathrm{~min}$ and $1 \mathrm{~h}$ and $52 \mathrm{~min}$. All were held at the hospital, in familiar environments for the teams.

In this study, we mainly used open non-participant observation to describe and investigate an early stage of an improvement process: how and what the staff discussed when aiming to adopt the recommendations in the $\mathrm{Na}$ tional Guideline by filling out the action forms as part of completing the audit cycle. To be able to record words rather than summaries, we used an audio recorder together with the observer's reflection notes. These were always written on the same day as the meeting, to 
ensure fresh reflections on the atmosphere, surprising statements and agreements or disagreements in the teams.

One observer (MSP) was present at the meetings. The researcher was unfamiliar with the DPC and its staff before the process started. It was considered important to explain that the researcher was not the one to initiate or decide on the improvement process or to perform the A\&F. At her first meeting with a team, the researcher introduced herself, shook hands with all the participants and presented the research project in detail. The researcher has a background as an information scientist in medicine and organisational learning, with a focus on evidence-based practice and implementation. The observer sat at the table together with the participants in the meeting. This enabled open observation without unduly disturbing the process.

\section{Data analysis}

The audio recordings from the meetings were transcribed verbatim and in detail. Together with the reflection notes, this formed the data base. Such an analysis relies largely on the spoken word, hence the use of an audio recorder. But the reflection notes were also part of the analysis, to make sense of the atmosphere in the room, the relationship between the participants, etc., and to observe what was not verbalised. The computer software QSR International's NVivo 10 was used to help to organise the analytical process.

A short, but thorough description of the cases was written, together with necessary context.

The analysis was performed in six steps as a thematic analysis suitable for instrumental case studies [33, 37]. Each transcription and reflection notes was read and listened to several times. Codes were assigned to meaningful units in the text, rather generously to ensure that nothing interesting or important was lost at this stage. The codes identified semantic features of the data. Codes were assigned to the data base, case by case. A thorough review of the codes was undertaken, with uncoding and recoding while comparing with the text, to ensure a unified way of labelling and interpreting the text. The third phase was to start searching for themes, by sorting codes into potential themes. The codes could appear across the cases, but were sometimes apparent in just one case and gave a first glance at similarities and differences in the cases. We sought to ascertain whether the codes could form a theme, going back and forth between potential themes, the codes and the dataset. Phase four consisted of reviewing and refining the themes. At this phase, all the data was reread to ensure that the themes fitted with the dataset. In phase five, we defined and named the themes. Phase six was to produce the report. We made adjustments until the end to make sure the analysis and themes had captured the essence.

In a multiple instrumental case study, we are interested in understanding the phenomenon under study [38]. We sought to shed light on the research question by using multiple cases bound together by organisational belonging and the common activity undertaken. We needed to strike a balance between the particular and the common features of each of our four cases while looking for similarities and differences. We mainly reported on general perspectives where present, in order to form an idea of the use of an audit in a DPC as a whole [33, 38, 39].

\section{Results}

The aim of this study was to describe and investigate what is discussed and thematised when QI teams in a DPC work to complete an action form as part of an A\&F cycle. The results of the audit showed a mismatch between recommendations in the National Guideline and local practices in several areas. This applied to all units, albeit somewhat differently within the various topics in the audit.

A whole range of issues regarding daily tasks, leader engagement, organisational issues at the unit or the DPC, cooperation, responsibilities and busy schedules were up for debate when the QI teams gathered to discuss their audit results. The audit seemed to prompt much more than just finding improvement areas and filling out action forms. Acting on the audit may thus be seen as important for various purposes, such as allowing for in-depth discussions on different aspects of work.

\section{Eye-opening and sharing practices}

When the QI teams gathered, some began immediately to complete the action forms and came back to the audit results afterwards, but most devoted time to the actual process of reflection and discussion of their own unit's results. They focused on the results showing the largest gaps between recommended and actual practice. It was a realisation of a research-practice gap, an eye-opener.

The staff seemed to become aware of their own practice in a different way through the discussions. Important events in some of the meetings were participants asking about and listening to details of colleagues' practices. "How do you do this?", "Are you using the recommended questionnaire or do you ask questions more randomly?" are examples of comments when they began to delve into their own practice. Sometimes they seemed somewhat surprised when listening to each other's stories about how they perceived everyday tasks or actually performed them in detail. It became clear that practice could sometimes develop in different directions, and 
that the staff did not necessarily have the same knowledge base for their practice.

Many participants realised for the first time that there existed a standard, i.e. a national guideline; a typical statement was "I wasn't aware there was a standard for this, I've only done what seemed best or what was closest to my previous knowledge or educational background". Several times there were statements about the newly discovered gap, but they would also literally point at the audit results, holding them up like a proof of practice - or lack of best practice. This awareness seemed to be important in enabling the start of an implementation process, or choosing improvement areas and filling out the action forms as required, representing willingness to take action.

\section{Lack of knowledge and unclear role expectations}

Without exception, all QI teams acknowledged their lack of knowledge about the patients with concurrent substance use disorder and mental illness, although some members of staff had experience and expertise in the field. Several of the teams talked about lack of knowledge about substances, their impact and what signs to look for in patients in active intoxication, withdrawal phases or long-term effects.

QI teams from three of the units seemed to be uncertain about the expectations placed on them. What tasks were they expected to perform and what expertise was required in implementing recommendations from the National Guideline? A decision on screening for substance use as an improvement area arose fairly early in the discussions, followed by the question "What do we do when we know?", i.e. "How do we deal with the awareness that a patient has a concurrent substance use disorder and mental illness?"

In all teams there were discussions related to uncertainty about the participants' own competence, but they manifested themselves differently in the general outpatient clinic on the one hand, and in the three remaining units on the other. In the latter, the QI teams appeared mainly to be uncertain about what they were supposed to know and work expectations, and we found that the temperature in the discussions sometimes rose concerning expectations from the management and we could see signs of despondency and even anger. These statements usually came after recognition of the research-practice gap from the audit. Some of the employees seemed to feel taken by surprise by the gap, or felt that they should have known already and taken care of this and that this responsibility lay with the management.

We also found insecurity around whether they were actually giving the best treatment to the patients with co-occurring disorders. So when they discussed the audit results, their own practice, and implementation of new recommendations, we noted statements and reflections that what they were used to doing was no longer valid or good enough. We often found that the staff demanded in-service courses and seminars, and stated that they should have been offered this earlier. It was clear that the statements about lack of knowledge arising from the audit results led to a decision to gain enhanced knowledge of the treatment of concurrent substance abuse and mental illness.

The QI teams from the general outpatient clinic also recognised a lack of knowledge in the field of substance use disorders. Otherwise, they recognised themselves as professionals. Their uncertainty was related to whether their expertise was acknowledged by the management and taken into account as they felt it should be. They talked about "we, as professionals", and we could trace dejection and slight defiance when this topic was discussed in both teams from the general outpatient clinic.

\section{Where to seek answers to clinical questions}

The psychiatrists and psychologists seemed to be the ones to "own" the knowledge. They were the ones to keep themselves updated by virtue of education or position. Then the nurses, assistant nurses and social educators could harvest from this knowledge. We found this phenomenon to be present when they were looking for someone to hold educational courses and when they addressed clinical questions to colleagues, and also when they referred to where or whom they got knowledge from. When discussing "best practice", statements like "psychiatrists have different opinions" appeared. Milieu personnel, nurses and social educators seemed to be used to seeking answers from psychiatrists or psychologists, but found it frustrating when they had divergent opinions on the same matter. It seemed to give rise to confusion and professional insecurity.

None of the professions or QI teams talked about evidence-based practice, systematic reviews or the fact that knowledge might be found in the hospital's medical library. Some of the teams talked about "building a library", but less about what should be in it other than certain academic textbooks. There were, however, in some teams references to the National Guideline as a source of knowledge of the area, and it was also held up like a "proof of best practice" with statements like "This is the knowledge base" in a couple of teams. But there were also those who clearly questioned the National Guideline as trustworthy or as a source of best practice.

In the QI teams formed by the outpatient clinic, the discussions were somewhat different. They acknowledged a professional disagreement, and solved the disagreement by either accepting a professional discussion or by simply sweeping the whole disagreement under 
the rug and accepting differences in practice, mainly due to differences in specialities.

\section{New practices in old systems}

All QI teams talked about how the recommendations fitted in with their usual practice and that new ways of working and new practices often felt fragmented and not integrated with current practice. They used the A\&F to discuss local practice and possible barriers to new practice, like resources, knowledge of substance abuse, organisation of daily tasks, and lack of time. They assumed that if they put the National Guideline recommendations into practice, it would be uncertain how this would fit in with their usual practice, the way the unit and its tasks were organised - and the way the DPC works. This was perceived as a clear barrier to implementing the recommendations from the Guideline.

At a system level, there were statements about the lack of connected and integrated treatment. Seven questions in the audit survey concerned cooperation and integrated treatment. These particular questions generated discussion in most of the QI teams. All the teams realised that they did not cooperate to any great extent with others, whether GPs, local authorities or substance abuse treatment units. They found that patients with the most severe co-occurring disorders fell between cracks also at a system level, and were thus not receiving appropriate treatment. The audit results were used to discuss how the system worked, especially for people with concurrent substance use disorder and mental illness. Several teams, particularly from the inpatient units, stated that they did not know the system they were working within well enough, and were therefore unable to offer integrated or optimal services, leading to interrupted and fragmented chains of treatment. This was clearly seen as a barrier, but not one they could easily find a solution to. It was considered a management or organisational problem.

\section{Discussion}

We found that acting on A\&F stirred up a wealth of discussions around local practice, organisational issues and responsibilities and was also used as a way of showing resistance to management. The QI team meetings were important to gain awareness of local practice and to recognise a lack of knowledge on substance abuse and a neglected group of patients, namely those with concurrent substance use disorder and mental illness, and also to identify unclear role expectations. Health professionals such as nurses, social educators or nursing assistants usually seek knowledge from psychiatrists or psychologists, but get frustrated when the answers diverge depending on whom they ask. There were concerns about whether new tasks arising from the guideline recommendations would fit in with the organisation's usual way of working and current resources.

Our research concurs with earlier research on quality improvement from various areas of health services [4042] in that working with an A\&F cycle involving completion of action forms in QI meetings was a useful, welcome and necessary opportunity to discuss practice amongst practitioners also in mental health services. It seemed to open the door to negotiations on improvement areas, task allocations and multidisciplinary work and could be considered important steps on the way to implement recommendations from the National Guideline.

Acting on A\&F created an awareness of local practice and a standard for practice in a national guideline which is in line with the intentions of an A\&F process: to prompt the need for change [2, 29]. Although the team members were not instructed to look for the largest gaps in the audit feedback, the QI teams usually ignored the results showing that practice was more or less in line with the guideline, and acted upon the greatest discrepancies, as also shown in previous studies [1, 8, 28, 29]. As an example, the QI team acted upon results showing gaps in the use of screening tools for detection of substances, and in general knowledge about substances and substance abuse treatment. There were no benchmarked data from other services or national audits to compare the audit results with, and the QI teams therefore discussed the data in a subjective manner. Self-assessments are subjective to bias [43], and may therefore give poor data quality. We might question whether the addition of audit data from patient records could have given better and perhaps different results, providing a richer and more accurate picture and adding to the team discussions more usefully than self-completed questionnaires alone. However, audits from patient record alone would possibly not give sufficiently accurate data, due to inadequate patient record keeping, reported by the Norwegian Board of Health Supervision [44] and the Norwegian System of Patient Injury Compensation [45]. Studies show that self-assessments contribute to professional development, learning and practice change [46] and are thus a valuable tool. All of the teams had senior staff present and representatives from various professions, which gave the team broad competence and experience of practice and context and added credibility to the meetings and discussions.

Our study found a lack of knowledge on substance related disorders and unclear role expectations among the health professionals. Other studies have found that for example nurses experience a lack of alcohol-related knowledge and skills, which was considered a barrier to the implementation of screening tools [47], while participants in a Swedish study asked how they were supposed to change clinical practice when they did not have 
adequate skills to use recommended tools [48]. The lack of familiarity with the guideline and lack of faith in one's own influence on the quality of care reported in the feedback are known barriers to implementation [32, 49]. The National Guideline came with a strong emphasis on concurrent substance use disorder and mental illness and placed greater responsibility on mental health care for patients with substance use disorders. Tasks and responsibilities, for example screening with appropriate tools to detect substance abuse, previously seemed to lie with one professional group in the DPC, but were now expanded to a larger group of professionals, from only psychologists or psychiatrists to also include nurses or social educators. From other studies we know that interchangeable roles and responsibilities may cause tension and power struggles, but more often interprofessional collaboration is beneficial for team functioning [50]. For collaboration to be successful, all team members should have a sense of autonomy, suggesting independent and self-determined practice to ensure a true complementary contribution. We may question whether job expectations and professional roles were inadequately formulated from leaders to all professional groups, particularly in the inpatient units. It might also be a general lack of arenas to discuss practice and to develop collaborative practices. Discussions concerning roles and responsibilities might have been more successful if unit leaders had been present at all meetings. Support from management or inspirational team leadership appear to be important in QI teams, bringing different professionals together [51]. We might also speculate on whether the staff are disclaiming responsibility in not taking national guidelines into account or not readily taking on the responsibility of new tasks or roles in the QI meetings. These issues might not easily be solved with educational courses or improving clinical skills alone, but more general with empowerment of all health professionals in autonomous contribution to collaborative work, which is also addressed by other authors [50,52].

The psychiatrist/psychologist group had legal authority for decision making and patient treatment responsibility, but our findings seem to show that the responsibility was expanded to a "definition of knowledge". This could be a natural consequence of the responsibility associated with the psychiatrist in a unit (as medical doctors are the only profession legally entitled to prescribe medication). Nurses, social educators, etc. approached the group of psychiatrists and psychologists instead of their own professions or the "evidence", i.e. clinical guidelines or research, for support in their practice. We know from international studies that physicians and nurses pursue roughly half of the questions they raise in clinical practice [53], and colleagues are a preferred source for answers [53-55]. Information-seeking behaviour may vary between nurses and physicians; nurses more often ask a colleague for answers to clinical questions, while physicians more often turn to online databases [56]. A hierarchical system might help to explain the expansion to "all kinds" of knowledge, but also a lack of training in information-seeking behavior, maybe particularly in the group of nurses and social educators.

Integrated treatment requires staff to coordinate collaboration between service providers [57]. The feeling of a lack of connected and integrated services at a system level found at this DPC is not unfamiliar [58-62]. The National Guideline recommended integrated treatment, which was a responsibility of the DPC, and took a pragmatic approach in stating that different and independent entities should coordinate their services for patients in an orderly manner. The important factor is that the patient experiences the treatment as integrated and connected [18]. We know that aspects of the guideline itself can be a major barrier to its implementability [32]. The National Guideline was assessed for implementability by the GLIA instrument [63], and found to be not easily implemented due to somewhat general recommendations which were not necessarily easy to transfer to practice [18]. This is therefore a possible explanation for the feeling of lack of connected and integrated services.

\section{Strengths and limitations}

A major strength of this study was the natural setting where the A\&F cycle took place. This allowed for an exploration of what happened in the QI teams after A\&F when the process was organised by the DPC itself, without a research team being part of the project, and thus reflected real people in real settings. In many similar projects, the research team has had an important and visible presence in all parts of the A\&F cycle, from setting the standard, auditing practice, giving feedback and facilitating the work of the QI teams and in that way possibly having an impact on the process itself. Case studies are useful for gaining an in-depth understanding of an issue and answering the "how" questions when the behaviour of those involved cannot be, or is not desired to be, manipulated [33]. They focus on contemporary events in real-life contexts, where the phenomenon of interest is interdependent with the context of study [39]. An instrumental case is used to illuminate the "problem"; the case itself is not the most important part [33]. We use the case to understand and answer the research question and it is thus instrumental to accomplishing this understanding [34].

Qualitative research and case studies may be limited in their generalisability. A common conclusion in implementation research is that the effect of the context makes the findings less relevant in other settings. However, we believe that our study has relevance to other 
settings in and outside mental health care services, and knowledge gained from this study may contribute to the planning and execution of A\&F cycles under similar circumstances.

There are certain considerations involved in choosing a multiple case study design. One is vulnerability, in that that the supposedly common cases may turn out to be less common than originally thought in certain aspects, and thus do not shed light on the research question as expected. However, we believe that the cases in this study are quite representative for many Norwegian DPCs in an initial phase of the implementation process, enabling generalisation to other DPCs. We have described the case in as much detail as necessary to account for this risk and make it transparent. A strength of the study is the use of instrumental multiple cases, allowing for a holistic view of the phenomenon, less dependent on the individual context. It is nevertheless worth noting that the cases are linked to a general context, the DPCs being similar in all cases.

There are strengths of open non-participant observation considered important enough to choose it as a method. Open observation allows for conceptualisation of health professionals behaviour and interaction in their natural environment [64] and the direct evidence of observed outcomes and processes, as opposed to reported accounts. It may also capture the flavour of the setting and provide specific examples. Open observation, not driven by theory, was enabled by the relatively demarcated units of analysis, the QI team meetings.

There is no doubt that both the use of an audio recorder and the presence of an observer are very noticeable elements in a meeting room ("the researcher effect"). It is uncertain whether the observer or the audio recorder is the more significant element for the participants. The observer not being a health professional, but with extensive experience from administrative parts of health services, gives a possibility for a fresh look at a health care setting, allowing for new insight. We believe the use of an audio recorder and reflection notes immediately after meetings helped to ensure the verifiability and thus the reliability of the observations.

\section{Conclusions}

The aim of this study was to describe and investigate what is discussed and thematised when QI teams in a DPC work to complete an action form as part of an A\&F cycle. The A\&F was based upon current knowledge of the most effective interventions and pre-made tools to support the process. The study showed that acting on A\&F provided a welcome opportunity to discuss practice in general, enhancing awareness of good practice. There was a general need for arenas to meet and discuss current practice, best practice and recommendations from guidelines and also how to meet divergent demands in an open and collaborative way. QI team meetings after A\&F may well be a suitable arena for this. The study also showed that self-assessment audits seemed valuable, particularly in areas where no benchmarked data exists, and there was a demand for implementation of new guidelines that might change routines and develop new roles. QI teams could benefit from having a supportive leader present at team meetings to provide direction particularly on organisational questions, and team members might also benefit from a general empowerment to autonomous contribution to interprofessional collaboration.

Nurses and social educators turn to psychiatrists or psychologists for answers to clinical and organisational questions beyond the National Guideline, and show less confidence or routine in seeking research-based information. There is a general need to emphasise training in evidence-based practice and information-seeking behaviour for all professional groups. New guidelines will keep coming, putting new demands on staff in mental health care, and increased knowledge in these areas could hopefully lead to less insecurity about roles and practice, and to discussions of audit results based on researchknowledge familiar to all professional groups.

\section{Additional file}

Additional file 1: Information on The National Guideline for Assessment Treatment and Social Rehabilitation of Persons with Concurrent Substance Use and Mental Health Disorders. (DOCX 16 kb)

\section{Abbreviations}

A\&F: Audit and Feedback; AUDIT: Alcohol Use Identification Test; CRT: Crisis Resolution Team; DPC: District Psychiatric Centre; DUDIT: Drug Use Identification Test; QI team: Quality Improvement Team; The National Advisory Unit: The Norwegian National Advisory Unit on Concurrent Substance Abuse and Mental Health Disorders; The National

Guideline: National Guideline for Assessment, Treatment and Social Rehabilitation of Persons with Concurrent Substance Use and Mental Disorders

Funding

Innlandet Hospital Trust funded the design of the study and collection and analysis of data and in writing the manuscript.

Availability of data and materials

The datasets will not be shared. In recordings or transcripts, individuals are easily identified by their their statements and views. None of the datasets are translated to any other language than Norwegian.

\section{Authors' contributions}

$A L$ and $L L$ participated in the design of the study and formulation of the research question and drafted the manuscript. MM participated in the acquisition of data and participated in coordination of the study and helped to draft the manuscript. MSP conceived the study, and participated in its design and formulation of the research question. She performed the observations and analysis and drafted the manuscript. The final version was prepared and revised by all authors and all authors approved for submission. 


\section{Ethics approval and consent to participate}

The study was supported by Innlandet Hospital Trust, and approved by the Data Protection Officer for Research at Oslo University Hospital. All of the staff observed in meetings, managers and R\&D nurses at the site of study signed a declaration of consent.

\section{Consent for publication}

Not applicable

\section{Competing interests}

$\mathrm{AL}$ has been a member of the working group at The Norwegian Directorate of Health who produced the National guideline for assessment, treatment and social rehabilitation of persons with concurrent substance use and mental health disorders, launched in 2012. None of the other authors have competing interests.

\section{Publisher's Note}

Springer Nature remains neutral with regard to jurisdictional claims in published maps and institutional affiliations.

\section{Author details}

Norwegian National Advisory Unit on Concurrent Substance Abuse and Mental Health Disorders, Innlandet Hospital Trust, P.B. 104, 2340 Brumunddal, Norway. ${ }^{2}$ Faculty of Medicine, University of Oslo, Oslo, Norway. ${ }^{3}$ Norwegian Centre for Addiction Research, University of Oslo, Oslo, Norway. ${ }^{4} \varnothing$ stfold Hospital Trust, Grålum, Norway. Inland Norway University of Applied Sciences, Campus Elverum, Elverum, Norway.

\section{Received: 3 June 2016 Accepted: 21 January 2018}

Published online: 31 January 2018

\section{References}

1. Ivers NM, Jamtvedt G, Flottorp S, Young JM, Odgaard-Jensen J, French SD, et al. Audit and feedback: effects on professional practice and healthcare outcomes. Cochrane Database Syst Rev. 2012;6:CD000259.

2. Jamtvedt G, Young JM, Kristoffersen DT, O'Brien MA, Oxman AD. Does telling people what they have been doing change what they do? A systematic review of the effects of audit and feedback. Qual Saf Health Care. 2006;15(6):433-6.

3. Hysong SJ. Meta-analysis audit and feedback features impact effectivenes on care quality. Med Care. 2009:47(3):356-63.

4. Potter J, Fuller C, Ferris M: Local clinical audit: handbook for physicians. In: Healthcare quality improvement partnership. London: HQIP. 2010. https:// www.hqip.org.uk/resources/hqip-local-clinical-audit-handbook-forphysicians/. Accessed 25 Jan 2018.

5. Dixon N, Pearce M, Quest HQ: Guide to using quality improvement tools to drive clinical audits. In: Healthcare quality improvement partnership. London: HQIP. 2011. http://www.hqip.org.uk/resources/hqip-guide-to-using quality-improvement-tools-to-drive-clinical-audit/. Accessed 2 Oct 2015.

6. Grimshaw JM, Thomas RE, MacLennan G, Fraser C, Ramsay CR, Vale L, et al. Effectiveness and efficiency of guideline dissemination and implementation strategies. Health Technol Assess. 2004:8:6.

7. Foy R, Eccles MP, Jamtvedt G, Young J, Grimshaw JM, Baker R. What do we know about how to do audit and feedback? Pitfalls in applying evidence from a systematic review. BMC Health Serv Res. 2005;5:7.

8. Burgess R. New principles of best practice in clinical audit. Oxford: Radcliffe Publishing; 2011

9. Grimshaw JM, Eccles MP, Lavis JN, Hill SJ, Squires JE. Knowledge translation of research findings. Implement Sci. 2012;7:50

10. Meld. St. 16 (2011-2015). Nasjonal helse- og omsorgsplan: 2011-2015 [National Health and care services plan: 2011-2015]. Oslo: Ministry of Health and Care Services; 2011. p. 124.

11. Turner T, Misso M, Harris C, Green S. Development of evidence-based clinical practice guidelines (CPGs): comparing approaches. Implement Sci. 2008:3:45

12. Metoder og verktøy [Methods and tools]. In: https://helsedirektoratet.no/ metoder-og-verktoy. Accessed 21 Mar 2017

13. Grant BF, Stinson FS, Dawson DA, Chou SP, Dufour MC, Compton W, Pickering RP, Kaplan K. Prevalence and co-occurrence of substance use disorders and independent mood and anxiety disorders: results from the
National Epidemiologic Survey on alcohol and related conditions. Arch Gen Psychiatry. 2004;61(8):807-16

14. Morisano D, Babor T, Robaina K. Co-occurrence of substance use disorders with other psychiatric disorders: implications for treatment services. Nordic Stud Alcohol Drugs. 2014;31(1):5-25

15. Landheim AS, Bakken K, Vaglum P. Gender differences in the prevalence of symptom disorders and personality disorders among poly-substance abusers and pure alcoholics. Substance abusers treated in two counties in Norway. Eur Addict Res. 2003:9(1):8-17.

16. Lai HM, Cleary M, Sitharthan T, Hunt GE. Prevalence of comorbid substance use, anxiety and mood disorders in epidemiological surveys, 1990-2014: a systematic review and meta-analysis. Drug Alcohol Depend. 2015;154:1-13.

17. Saban A, Flisher AJ. The association between psychopathology and substance use in young people: a review of the literature. J Psychoactive Drugs. 2010;42(1):37-47

18. Helsedirektoratet [The Norwegian Directorate of Health]. Nasjonal faglig retningslinje for utredning, behandling og oppfølging av personer med samtidig rus- og psykisk lidelse - ROP-lidelser [national guideline for assessment, treatment and social rehabilitation of persons with concurrent substance use disorders and mental disorders]. Oslo: The Norwegian Directorate of Health; 2012

19. Gap-undersøkelse for behandlere i psyksik helsevern [Audit-survey for health professionals in specialist mental health services]. Nasjonal kompetansetjeneste for samtidig rusmisbruk og psykisk lidelse [Norwegian National Advisory Unit on concurrent substance abuse and mental health] In: http://gap.rop.no/skjemamaler/for-behandlere-i-psykisk-helsevern.versjon-2.0. Accessed 09 Sept 2015

20. Sheldon TA, Cullum N, Dawson D, Lankshear A, Lowson K, Watt I, West P, Wright D, Wright J. What's the evidence that NICE guidance has been implemented? Results from a national evaluation using time series analysis, audit of patients' notes and interviews. BMJ. 2004;329(7473):999

21. Francke AL, Smit MC, de Veer AJ, Mistiaen P. Factors influencing the implementation of clinical guidelines for health care professionals: a systematic meta-review. BMC Med Inform Decis Mak. 2008;8:38,

22. Boaz A, Baeza J, Fraser A. Effective implementation of research into practice: an overview of systematic reviews of the health literature. BMC Res Notes. 2011;4:212

23. Grol R, Wensing M, Eccles M. Improving patient care: the implementation of change in clinical practice. Edinburgh: Elsevier; 2005.

24. Grimshaw J, Eccles M, Thomas R, MacLennan G, Ramsay C, Fraser C, Vale L. Toward evidence-based quality improvement - evidence (and its limitations) of the effectiveness of guideline dissemination and implementation strategies 1966-1998. J Gen Intern Med. 2006;21:S14-20.

25. Nilsen P. Making sense of implementation theories, models and frameworks. Implement Sci. 2015;10:53

26. Barbui C, Girlanda F, Ay E, Cipriani A, Becker T, Koesters M. Implementation of treatment guidelines for specialist mental health care. Cochrane Database Syst Rev. 2014;1:CD009780. doi:10.1002/14651858.CD009780.pub2

27. The Effective Practice and Organisation of Care (EPOC) Group. http://epoc. cochrane.org/. Accessed 20 Mar 2017

28. Foy R, Eccles M. Audit and feedback interventions. In: Straus SE, Tetroe J, Graham ID, editors. Knowledge translation in health care: moving from evidence to practice. Chichester: Blackwell; 2009. p. 126-31.

29. Ivers NM, Sales A, Colquhoun H, Michie S, Foy R, Francis Jل Jrimshaw JM. No more 'business as usual' with audit and feedback interventions: towards an agenda for a reinvigorated intervention. Implement Sci. 2014;9:14.

30. Ivers NM, Grimshaw JM, Jamtvedt G, Flottorp S, O'Brien MA, French SD, Young J, Odgaard-Jensen J. Growing literature, stagnant science? Systematic review, meta-regression and cumulative analysis of audit and feedback interventions in health care. J Gen Intern Med. 2014;29(11):1534-41.

31. Hysong SJ, Best RG, Pugh JA. Audit and feedback and clinical practice guideline adherence: making feedback actionable. Implement Sci. 2006:1:10.

32. van der Veer S, de Keizer N, Ravelli A, Tenkink S, Jager K. Improving quality of care. A systematic review on how medical registries provide information feedback to health care providers. Int J Med Inform. 2010;79(5):305-23.

33. Baxter P, Jack S. Qualitative case study methodology: study design and implementation for novice researchers. Qual Rep. 2008;13(4):544-59. In: http://nsuworks.nova.edu/tqr/vol13/iss4/2. Accessed 25 Jan 2016

34. Stake RE. The art of case study research. Thousand Oaks: Sage; 1995.

35. Graham ID, Straus SE, Tetroe J, editors. Knowledge translation in health care: moving from evidence to practice. Chichester: Wiley-Blackwell; 2009. 
36. Velkommen til GAP [Welcome to GAP]. In: http://gap.rop.no. Accessed 25 Jan 2018.

37. Braun V, Clarke V. Using thematic analysis in psychology. Qual Res Psychol. 2006;3(2):77-101.

38. Stake RE. Multiple case study analysis. New York: Guilford Press; 2006.

39. Yin RK. Case study research : design and methods. 5th ed. SAGE: Los Angeles; 2014

40. Kristensen $\mathrm{H}$, Hounsgaard L. Evaluating the impact of audits and feedback as methods for implementation of evidence in stroke rehabilitation. $\mathrm{Br} \mathrm{J}$ Occup Ther. 2014;77(5):251-9.

41. Sinuff T, Muscedere J, Rozmovits L, Dale CM, Scales DC. A qualitative study of the variable effects of audit and feedback in the ICU. BMJ Qual Saf. 2015; 24(6):393-9.

42. Taylor A, Neuburger J, Walker K, Cromwell D, Groene O. How is feedback from national clinical audits used? Views from English National Health Service trust audit leads. J Health Serv Res Policy. 2016; https://doi.org/10. $1177 / 1355819615612826$

43. Davis DA, Mazmanian PE, Fordis M, Van Harrison R, Thorpe KE, Perrier L. Accuracy of physician self-assessment compared with observed measures of competence - a systematic review. JAMA. 2006;296(9):1094-102.

44. Statens helstilsyn/Norwegian Board of Health Supervision. Tilsynsmelding 2016 [supervision report 2016]. In: https://www.helsetilsynet.no/no/ Publikasjoner/Tilsynsmelding/Tilsynsmelding-2016/. Accessed 16 Mar 2017.

45. Norsk pasientskadeerstatning/the Norwegian system of patient injury compensation. Årsrapport 2016 [annual report 2016]. In. https://www.npe. no/globalassets/dokumenter-pdf-og-presentasjoner/rapporter/npe_ arsrapport_2016_web.pdf. Accessed 17 Mar 2017.

46. Gagliardi AR, Brouwers MC, Finelli A, Campbell CM, Marlow BA, Silver IL. Physician self-audit: a scoping review. J Contin Educ Heal Prof. 2011; 31(4):258-64.

47. Broyles LM, Rodriguez KL, Kraemer KL, Sevick MA, Price PA, Gordon AJ. A qualitative study of anticipated barriers and facilitators to the implementation of nurse-delivered alcohol screening, brief intervention, and referral to treatment for hospitalized patients in a veterans affairs medical center. Addict Sci Clin Pract. 2012;7·7.

48. Forsner T, Hansson J, Brommels M, Wistedt AA, Forsell Y. Implementing clinical guidelines in psychiatry: a qualitative study of perceived facilitators and barriers. BMC Psychiatry. 2010:10:8

49. Cabana MD, Rand CS, Powe NR, Wu AW, Wilson MH, Abboud PA, Rubin HR. Why don't physicians follow clinical practice guidelines? A framework for improvement. JAMA. 1999:282(15):1458-65.

50. MacNaughton K, Chreim S, Bourgeault IL. Role construction and boundaries in interprofessional primary health care teams: a qualitative study. BMC Health Serv Res. 2013;13:486.

51. Versteeg M, Laurant M, Franx G, Jacobs A, Wensing M. Factors associated with the impact of quality improvement collaboratives in mental healthcare: an exploratory study. Implement Sci. 2012;7:1.

52. Michie S, Pilling S, Garety P, Whitty P, Eccles MP, Johnston M, Simmons J. Difficulties implementing a mental health guideline: an exploratory investigation using psychological theory. Implement Sci. 2007;2(1):1-8.

53. Del Fiol G, Workman TE, Gorman PN. Clinical questions raised by clinicians at the point of care: a systematic review. JAMA Intern Med. 2014;174(5):710-8.

54. Clarke MA, Belden JL, Koopman RJ, Steege LM, Moore JL, Canfield SM, Kim MS. Information needs and information-seeking behaviour analysis of primary care physicians and nurses: a literature review. Health Inf Libr J. 2013;30(3):178-90.

55. O'leary DF, Mhaolrúnaigh SN. Information-seeking behaviour of nurses: where is information sought and what processes are followed? J Adv Nurs. 2012;68(2):379-90.

56. Weng Y, Kuo KN, Cy Y, Lo H, Yh S, YW C. Information-searching behaviors of main and allied health professionals: a nationwide survey in Taiwan. J Eval Clin Pract. 2013:19(5):902-8.

57. Horsfall J, Cleary M, Hunt GE, Walter G. Psychosocial treatments for people with co-occurring severe mental illnesses and substance use disorders (dual diagnosis): a review of empirical evidence. Harv Rev Psychiatry. 2009;17(1):24-34.

58. Haggerty JL, Reid RJ, Freeman GK, Starfield BH, Adair CE, McKendry R. Continuity of care: a multidisciplinary review. BMJ. 2003:327(7425):1219-21.

59. Reid RJ, Wagner EH. Strengthening primary care with better transfer of information. CMAJ. 2008;179(10):987-8.

60. Danbolt LJ, Kjönsberg K, Lien L. Hjelp når du trenger det: en kvaliatativ studie av samhandling og gjensidifhetskunnskap i den psykiske helsetjenesten [help when you need it. A qualitative study of the interactions and mutual knowledge between primary and secondary level functions in psychiatric health care]. Tidsskrift for Psykisk Helsearbeid. 2010; 7(3):238-45.

61. Fredheim T, Danbolt L, Haavet OR, Kjonsberg K, Lien L. Collaboration between general practitioners and mental health care professionals: a qualitative study. Int J Ment Health Syst. 2011:5(1):13.

62. Fickel JJ, Parker LE, Yano EM, Kirchner JE. Primary care - mental health collaboration: an example of assessing usual practice and potential barriers. J Interprof Care. 2007;21(2):207-16.

63. Shiffman RN, Dixon J, Brandt C, Essaihi A, Hsiao A, Michel G, O'Connell R. The GuideLine Implementability appraisal (GLIA): development of an instrument to identify obstacles to guideline implementation. BMC Med Inform Decis Mak. 2005;5:23.

64. Creswell JW. Qualitative inquiry \& research design : choosing among five approaches. 3rd ed. Los Angeles: Sage; 2013.

\section{Submit your next manuscript to BioMed Central} and we will help you at every step:

- We accept pre-submission inquiries

- Our selector tool helps you to find the most relevant journal

- We provide round the clock customer support

- Convenient online submission

- Thorough peer review

- Inclusion in PubMed and all major indexing services

- Maximum visibility for your research

Submit your manuscript at www.biomedcentral.com/submit
C Biomed Central 



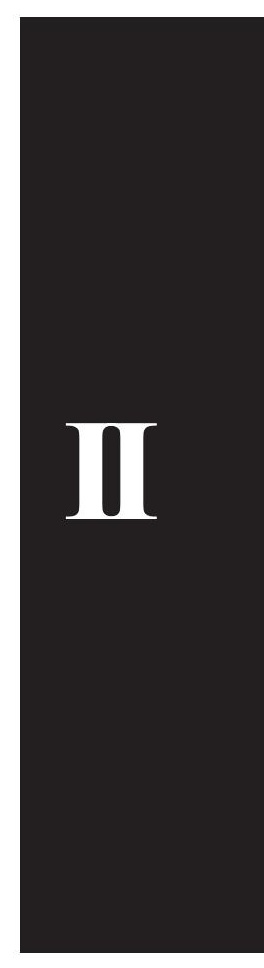



IJHCQA
31,7

822

Received 7 August 2017 Revised 18 December 2017 Accepted 4 January 2018

\title{
Audit and feedback in mental healthcare: staff experiences
}

\author{
Monica Stolt Pedersen \\ Norwegian National Advisory Unit on Concurrent Substance Abuse and \\ Mental Health Disorders, Innlandet Hospital Trust, Ottestad, Norway and \\ Faculty of Medicine, University of Oslo, Oslo, Norway \\ Anne Landheim \\ Norwegian National Advisory Unit on Concurrent Substance Abuse and \\ Mental Health Disorders, Innlandet Hospital Trust, Ottestad, Norway and \\ Innland University of Applied Sciences, Campus Elverum, Elverum, Norway \\ Merete Møller \\ Østfold Hospital Trust, Norway, and \\ Lars Lien \\ Norwegian National Advisory Unit on Concurrent Substance Abuse and \\ Mental Health Disorders, Innlandet Hospital Trust, Ottestad, Norway and \\ Innland University of Applied Sciences, Campus Elverum, Elverum, Norway
}

\begin{abstract}
Purpose - Audit and feedback (A\&F) often underlie implementation projects, described as a circular process; i.e. an $\mathrm{A} \& \mathrm{~F}$ cycle. They are widely used, but effect varies with no apparent explanation. We need to understand how A\&F work in real-life situations. The purpose of this paper, therefore, is to describe and explore mental healthcare full A\&F cycle experiences.

Design/methodology/approach - This is a naturalistic qualitative study that uses four focus groups and qualitative content analysis.

Findings - Staff accepted the initial A\&F stages, perceiving it to enhance awareness and reassure them about good practice. They were willing to participate in the full cycle and implement changes, but experienced poor follow-up and prioritization, not giving them a chance to own to the process. An important finding is the need for an A\&F cycle facilitator.

Practical implications - Research teams cannot be expected to be involved in implementing clinical care. Guidelines will keep being produced to improve service quality and will be expected to be practiced. This study gives insights into planning and tailoring A\&F cycles.

Originality/value - Tools to ease implementation are not enough, and the key seems to lie with facilitating a process using A\&F. This study underscores leadership, designated responsibility and facilitation throughout a full audit cycle.

Keywords Evidence-based practice, Quality improvement, Audit, Clinical guidelines, Self-assessment
\end{abstract} Paper type Research paper

\section{Introduction}

Evidence-based clinical practice guidelines aim to secure and improve care for clients, patients and service users, and are produced at a fast pace in mental health services (Shekelle et al., 2012; Barbui et al., 2014). They are, however, not easily translated into practice (Grol, 2008;

(C) Monica Stolt Pedersen, Anne Landheim, Merete Møller and Lars Lien. This article is published under the Creative Commons Attribution (CC BY 4.0) licence. Anyone may reproduce, distribute, translate and create derivative works of this article (for both commercial and non-commercial purposes), subject to full attribution to the original publication and authors. The full terms of this licence may be seen at http://creativecommons.org/licences/by/4.0/legalcode

The authors thank Kari Kjønsberg for moderating the focus group interviews and writing Care Quality Assurance Vol. 31 No. 7 , 2 pp. 822-833 merald Publishing Limited DOI 10.1108/JHCQA-08-2017-0142 
Girlanda et al., 2017) and a gap between evidence summarized in guidelines (what is known) and what is adopted in practice (what is done) exists (Sederer, 2009). In recent years, more research on how to close the gap has emerged (Grimshaw et al., 2012), but we still lack knowledge about how to choose the most appropriate strategies for guideline implementation (Gagliardi and Alhabib, 2015). One research field is the various implementation strategies believed to affect either practitioner behavior or patient outcome. One intervention is audit and feedback (A\&F), an implementation strategy targeting healthcare professionals (Grimshaw et al., 2012; Mazza et al., 2013; Effective Practice and Organisation of Care, 2015). $\mathrm{A} \& \mathrm{~F}$, a well-established intervention that aims to improve healthcare quality, used in different healthcare settings, may positively influence compliance with desired practice (Foy et al., 2005; Burgess, 2011; Hysong et al., 2006; Ivers et al., 2012; Ivers, Grimshaw, Jamtvedt, Flottorp, O'brien, French, Young and Odgaard-Jensen, 2014). A\&F are used for heterogeneous interventions and involve developing clinical performance summaries (audit) over a specific time, and subsequently providing a summary (feedback) to individual practitioners, teams, or healthcare organization managers (Brehaut and Eva, 2012). A\&F are often the basis for quality improvement (QI) or implementation projects, and can be described as a circular process, an audit cycle or A\&F cycle (Burgess, 2011; Potter et al., 2010; Dixon et al., 2011) (Figure 1).

$\mathrm{A} \& \mathrm{~F}$ are regularly designed to be a multifaceted improvement strategy (Grol et al., 2005) where reflecting on results, agreeing on where improvement is needed and producing an action plan are essential processes (Burgess, 2011). The idea is that when performance and care are measured against evidence-based standards, feeding back results can be expected to motivate service providers to improve (Hysong et al., 2017). A Cochrane review (140 trials) showed highly variable A\&F, ranging from substantial positive effects to null and even negative effects on provider behavior (Ivers $e t$ al., 2012). Variability may partly be caused by misunderstanding the causal mechanisms underlying A\&F (Brehaut and Eva, 2012) or feedback characteristics (Ivers, Grimshaw, Jamtvedt, Flottorp, O'brien, French, Young and

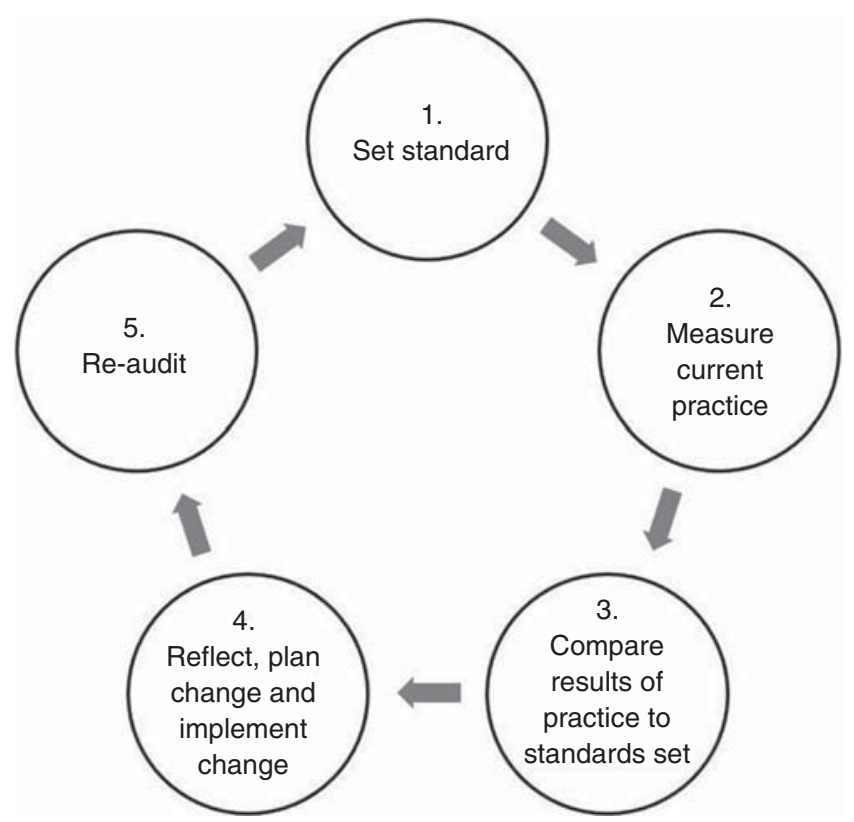

Sources: Burgess (2011) and Grol et al. (2005)
Audit and feedback in mental healthcare
Figure 1. A common, modified audit and feedback (A\&F) cycle 
IJHCQA Odgaard-Jensen, 2014). Other explanations and modifiers could be organizational culture 31,7 and feedback actionability (Hysong et al., 2006), or defined barriers like under resourcing, project design inexperience or lacking an overall audit plan (Johnston et al., 2000).

Foy et al. (2005) claimed that A\&F will continue to be an unreliable approach to QI until we learn how and when it works best. Over time, research has attempted to understand A\&F (Ivers, Grimshaw, Jamtvedt, Flottorp, O’brien, French, Young and Odgaard-Jensen, 2014), which is important, given the strategy's popularity, and effect studies are necessary to understand the A\&F cycle. There is, however, also a need to understand how an A\&F cycle is experienced and used by healthcare professionals to enhance A\&F understanding in real-life settings. Qualitative studies have inquired into how A\&F is perceived. The A\&F response is usually better when it was perceived relevant and the process fitted with provider preferences, local policies and values (Christina et al., 2016; Kristensen and Hounsgaard, 2014). In concordance with quantitative research, facilities with a successful guideline adherence tend to deliver more timely, individualized and non-punitive feedback (Hysong et al., 2006). Some authors (Ivers, Barnsley, Upshur, Tu, Shah, Grimshaw and Zwarenstein, 2014; Payne and Hysong, 2016; Kristensen and Hounsgaard, 2014) addressed the process and to have a process facilitator, which are amongst recommendations designed to accomplish a better A\&F cycle. Clinicians also feel that A\&F is fragmented and variable in its effectiveness, and they might feel disconnected (Sinuff et al., 2015). Payne and Hysong (2016) observe that the assessment process itself generates emotions within physicians, which has an impact on which actions they take. Competing goals either at the organization or patient level are a barrier (Ivers, Barnsley, Upshur, Tu, Shah, Grimshaw and Zwarenstein, 2014; Payne and Hysong, 2016; Meehan et al., 2006). In mental health services, Meehan et al. (2006) reports on topics related to A\&F as ambivalence, competing work demands, weak support from senior medical staff, questionable evidence to support outcome measures, and that at eight months post implementation, nurses remained ambivalent about the outcome measurement's benefits, and had not engaged in the process. To our knowledge, there are few in-vivo studies on how a full A\&F cycle in mental health services is undertaken and experienced. Implementation and QI projects are facilitated by researchers, and there is a need to explore these processes as naturally occurring in clinical settings undertaken by local groups (Dogherty et al., 2014). Our aim was to describe and explore how specialist mental health services staff experience working with an $\mathrm{A} \& \mathrm{~F}$ cycle as a basis for implementation to gain real-life process knowledge.

\section{Background}

Studies show a high comorbidity between substance use and mental health disorders, well documented through clinical and epidemiological studies (Grant et al., 2004; Saban and Flisher, 2010; Morisano et al., 2014; Landheim et al., 2003; Lai et al., 2015). Norwegian health authorities have over the last 30 years recognized and acknowledged dual disorder patients and the insufficient treatment they have been offered. Several reports have been published, and at last a national clinical guideline exists. The Norwegian National Guideline for Assessment, Treatment and Social Rehabilitation of Persons with Concurrent Substance Use Disorders and Mental Disorders (hereafter the "Guideline") was launched in 2012 (The Norwegian Directorate of Health, 2012). It contains 93 recommendations covering user involvement, families, assessment, treatment, follow-up care, roles and responsibilities, with a separate chapter on implementation. The Guideline was developed for healthcare providers in either primary or specialist services, which targeted people with severe and less severe mental illness concurrent with substance misuse when the two disorders are associated with significant impairment.

The Norwegian National Advisory Unit on Concurrent Substance Abuse and Mental Health Disorders (hereafter the "Advisory Unit") developed tools to assist Guideline implementation based on the Grol et al. (2005) change model, briefly describing an implementation process in stages. The Guideline was published in paper and electronic versions linked to recommended 
screening tools. A user panel chose the ten most important recommendations to be published as a pamphlet, poster and electronic versions. Other implementation initiatives were developed; e.g., website (www.snakkomrus.no) and national learning program. The main strategy was an audit survey mirroring the most important Guideline recommendations. The survey (designed to be applicable to audit practice in District Psychiatric Centres (DPCs)), included 46 questions about screening and diagnostic practices, assessing the target group, integrated treatment, collaboration, evidence-based methods and competence requirements. It was an electronic self-report questionnaire, which came with a standardized action form to be completed and a template for its use. The action form recommended improvements, goals, actions, progress plan, main responsibility, economic assessment and evaluation. The audit survey with templates was available to DPCs on the Advisory Units website (Norwegian National Advisory Unit on Concurrent Substance Abuse and Mental Health, 2013).

\section{Method}

Study design

The study was a naturalistic, not a research-driven process, which aimed to learn from an A\&F cycle decided and led by DPC unit leaders. The study had a descriptive and explorative design. A qualitative method with focus group interviews was chosen to understand A\&F experiences.

\section{Study site}

As a naturalistic study, we contacted DPC staff who might be about to initiate a QI process by using pre-existing A\&F with action forms to implement the Guideline. Staff in one South-Eastern Norway DPC were ready to start in 2014 and agreed to participate. The DPC was an independent unit within a hospital trust, with responsibility for providing specialist mental health services to adults in one geographical area. The DPC included one general outpatient unit, one crisis resolution team and two inpatient units, offering services to a 72,000 population.

\section{The local audit process}

A supervisor at the health trust with responsibility for information on services in concurrent substance abuse and mental health disorders held an introductory educational meeting at the DPC, spring, 2013. Later the same year, she was present at a management meeting at the hospital trust, on the Guideline, tools for implementation and audit survey. A decision was made to start the implementation process. Existing practice was audited in March 2014 with the supervisor's assistance. All four units were included. Feedback was given at unit level verbally and in writing about four weeks after the audit. Each unit held separate meetings where all staff were invited to sessions on evidence-based practice, recommendations in the Guideline and on how to conduct an implementation process informed by an A\&F cycle. The meetings were led by the supervisor with unit leaders present.

QI teams were formed, chosen by unit leaders, with one to three QI teams per unit. Seven teams with 6-21 members (53 participants) were included. The QI teams reflected unit staff; the two inpatient units included nurses, social educators or nursing assistants and one psychiatrist or psychologist. The QI crisis resolution team had similar education and roles, held more meetings and all staff were included. The general outpatient clinic team had more doctors, psychologists and specialist nurses, working regular hours with booked appointments. Only the crisis resolution team had the unit leader present at the QI team meetings.

The QI teams gathered three to four weeks after feedback to reflect on the results and to complete the action plans for the following year. A final decision on the improvement areas and the action plans was made in a DPC management meeting in June 2014, and the following areas were chosen: alcohol and drug use screening; concurrent substance
Audit and feedback in mental healthcare 
IJHCQA abuse and mental illness treatment; and improving collaboration between DPC, substance 31,7 abuse departments in the health authority and local authorities.

The actions (the implementation phase) were initiated the following year with unit leaders responsible for their completion. Amongst the actions were educational meetings aimed at all personnel, inter-professional meetings to enhance knowledge and possible role expansion. There were plans to enhance and improve communication and shared care between different service providers and making available educational materials. A re-audit led by the supervisor was conducted in June 2015; all units participated. Feedback was given to the DPC managers (DPC head and unit leaders) in June 2015 to be forwarded to the staff immediately afterwards by the unit leaders.

Recruitment, setting and description of the focus groups

Focus group participants were recruited from QI team members appointed at the outset a year earlier. Members were selected by the unit leaders at our request from QI team participants representing several occupational groups. All participants were health professionals working with patients daily. Each group included four to six participants from the same unit, with the aim to homogenize experience and context within the group. Consequently, the groups included participants with different educational and professional backgrounds, such as psychologists, specialist nurses and social educators, which provided rich data (Kitzinger, 1995), totaling 20 persons. No unit leader was present in the focus groups, which allowed staff to speak more freely.

\section{Ethical approval and consent to participate}

Participation in the audit and QI team creation were initiated and executed by the DPC. Information about the research project was given orally and in writing to all group members, and all participants signed a consent form. Since staff were asked by their leader to take part in the focus groups, we cannot be certain that participation was always consensual. The study was supported by the Innlandet Hospital Trust managers and approved by the Data Protection Officer for Research at Oslo University Hospital (Table I).

\section{Data collection}

We conducted one focus group interview in each unit when the full A\&F cycle was completed. An interview guide focusing on the complete A\&F cycle was created, drawing on QI team meeting observations in 2014, and on A\&F cycle literature (Potter et al., 2010; Ivers, Sales, Colquhoun, Michie, Foy, Francis, and Grimshaw, 2014). The interview guide was created by the first author around A\&F usefulness, action schema, actions taken to implement the National Guideline. We ensured the groups were asked similar questions to

Table I.

Quality improvement teams (QI teams) and focus groups

\begin{tabular}{|c|c|c|c|}
\hline & $\begin{array}{l}\text { QI teams } \\
\text { (members) }^{\mathrm{a}}\end{array}$ & $\begin{array}{l}\text { Focus group members (number participated } \\
\text { in a QI team meeting } 1 \text { year earlier) }\end{array}$ & $\begin{array}{l}\text { Educational background: focus } \\
\text { groups members }^{\mathrm{c}}\end{array}$ \\
\hline $\begin{array}{l}\text { General } \\
\text { outpatient clinic }\end{array}$ & $2(14)$ & $6(5)$ & $\begin{array}{l}\text { Psychologist specialists, } \\
\text { psychologists, special nurses }\end{array}$ \\
\hline Inpatient unit 1 & $3(21)$ & $5(5)$ & $\begin{array}{l}\text { Psychologist, nurses, assistant } \\
\text { nurse, social worker }\end{array}$ \\
\hline Inpatient unit 2 & $1(6)$ & $4(3)$ & $\begin{array}{l}\text { Psychologist, special nurse, } \\
\text { social educator, assistant nurse }\end{array}$ \\
\hline $\begin{array}{l}\text { Crisis resolution } \\
\text { team }\end{array}$ & $7(12)$ & $5(4)$ & Nurses and special nurses \\
\hline \multicolumn{4}{|c|}{$\begin{array}{l}\text { Notes: }{ }^{\text {a }} \mathrm{QI} \text { teams and total members from each unit; }{ }^{\mathrm{b}} \text { focus groups members and how many participated in } \\
\text { the QI teams one year later; ceducational background }\end{array}$} \\
\hline
\end{tabular}


avoid inconsistency. Areas open enough to ensure that we got insight into the phenomenon (Graneheim and Lundman, 2004). Two focus groups interviews took place in June 2015 and two in September 2015. Interviews lasted approximately one hour and were led by the first author, helped by an experienced moderator whose role was to ensure that every group member was heard. The conversation focused on the study aim. Main points summarized to ensure validation. Summarizing was done by the moderator. Participants were given the opportunity to make changes or add additional comments. Follow-up questions ascertained whether information was understood. Interviews were audio recorded and summarized immediately after each interview, including reflections.

\section{Analysis}

Our qualitative content analysis used several steps, following Graneheim and Lundman (2004) - a method suitable for analyzing communication systematically; it focuses on context and subject matter and emphasizes both similarities and differences. The aim is to condense and describe the phenomenon and to establish categories sharing the same meaning (Elo and Kyngäs, 2008). Since our purpose was to learn more about how an A\&F cycle is experienced by mental health service staff, we decided on an inductive content analysis with no pre-existing analytical framework, which is recommended when there is insufficient or fragmented knowledge about the phenomenon (Elo and Kyngäs, 2008), but had the main areas from the interview guide as an outset for the analysis. The audio-recorded interviews were transcribed verbatim and NVivo 10 qualitative data analysis software was used to facilitate analysis. Materials were read several times to sense the whole, and to gather ideas for further analysis. Text was divided into meaning units, which were examined and condensed with the key content preserved and coded. The codes were sorted into categories grounded in the data, representing a manifest content in the text (Graneheim and Lundman, 2004). The categories were discussed and revised by the research team to enhance credibility.

\section{Findings}

Themes evolved around three areas in the interview guide. The first was A\&F usefulness and how staff experienced A\&F, which was experienced as meaningful and reassuring. The second area was experience around the actions schema and the actions taken to implement Guideline recommendations; staff experienced poor follow-up on actions and poor prioritization. The last area was broader experience; staff felt they did not own the full A\&F cycle.

\section{Audit was experienced as meaningful and reassuring}

Staff valued being audited in two ways. Despite initial uncertainty, especially amongst outpatient unit and crisis resolution team participants, there was no resistance to participate in the survey. All participants found it meaningful to have their practice audited. Some pointed out that it probably had more value as a management tool to understand what training courses were needed, who needed to be supported to achieve goals and so on. When they talked about A\&F in less direct ways, they often revealed that the value was obvious and helped to ensure service quality. Most groups said A\&F was a way to increase awareness about practice and about patients with dual diagnosis, their rights, and the treatment methods recommended in the Guideline. One group also talked about increased awareness leading to a stronger responsibility sense. Patients with a dual diagnosis were commonly passed from one unit to another, often from mental health services to drug treatment services. The Guideline clarifies who is responsible for integrated treatment in mental health services:

Well, I think the fact that this $[\mathrm{A} \& \mathrm{~F}]$ comes from outside the unit leads to awareness and so a change of attitude. The fact that these patients have been passed around in the systems is a proof of our individual responsibility.
Audit and feedback in mental healthcare 
IJHCQA 31,7

\section{8}

One focus groups (an inpatient unit) found A\&F particularly useful, especially in providing reassurance about current practice and reinforcing what they already knew. It was a way to boost informal or hidden competencies and make them visible and useful. This was viewed as adding value to the whole unit, and brought forth pride in the staff, and competencies from which everyone could benefit:

When I started here two years ago, I thought several of the staff here had great knowledge of substance abuse. They had never been acknowledged for the expertise they had and that it was good enough. In that way, this A\&F was terrific. We got it in writing that there is competence! Yes, we have potential for improvement, but there was actually a lot that was of good quality and I think that was great!

All groups agreed that for an A\&F to have any value, it must be followed by something more. It must be a process, followed by discussions on where to improve practice and action plans to achieve goals. In this process, QI teams discussed feedback and drew up action plans, and thus the A\&F cycle was experienced as meaningful:

It's supposed to be an audit, and then some actions and then a re-audit. There's no help in just auditing and auditing and just waiting and seeing.

\section{Follow-up actions}

Planned actions tended to fizzle out. Participants from three groups reported having started enthusiastically. They drew up action plans, but after a while, they felt that planned actions became just that: planned. As an example, one inpatient unit group described an action to become familiar by reading the Guideline. Lists were made to be signed after reading. After a few weeks, about half the staff had signed, but then nothing happened. Participants missed having a person with the responsibility to follow-up actions they planned and there was no one to ensure that everyone mutually understood the implementation:

Can they just tell us [that] we should read the National Guideline and then everybody does that? It's not like that. I think the leader had a list in his office, and when you'd read the National Guideline you ticked off your name. It just came to nothing.

When asked about what they as staff members missed or would suggest as A\&F cycle improvements, the groups primarily requested a reminder function, meaning someone with the function and the responsibility to execute the actions, to systematize what needed to be done, and to ensure that actions were implemented. No group member stated that unit leaders kept a firm hand on the process, or that DPC practice and development nurses had a significant role. In other words, staff experienced that no one facilitated the full A\&F cycle. A halfway stage evaluation was a suggestion that could have made the implementation process better, which was considered a possible and necessary way to complete the A\&F cycle, where the improvement areas chosen would have been implemented. Staff in three focus groups reflected on the time that passed between actions being set out and anyone asking for results or reminding them of the process. Their proposed solution was a much more forceful follow-up, or a supervisor or facilitator throughout the A\&F cycle:

We need a reminder, someone to be in charge. That could be a practice and development nurse who can be in charge throughout the year, not just set up meetings.

When asked specifically about unit leader role, all groups experienced poor follow-up. Staff in two groups understood the leader's time commitments and heavy workload, and sometimes seemed even to excuse the unit leader:

But the unit leader has tried in a way [...] as far as she could in our everyday situation. 


\section{Non-prioritization}

Participants found that new focus areas constantly appeared, needing to be addressed and implemented. There was a flow of new national guidelines, local procedures and projects. It was considered overwhelming and fragmented and as continuously coming from "above." They felt that they did not have the opportunity to learn anything well enough or incorporate it into practice. Since there was insufficient time for the changes to be practiced, recommendations easily disappeared; they were forgotten and not used in everyday treatment:

Audit and

feedback in

mental

healthcare

Yes, we're talking about it, that now there's yet another thing coming. We lose one and get another. We don't have time to immerse ourselves. Something new comes along that we also have to deal with. And then it easily disappears along the way. So, we don't forget the dual diagnosis patients, but we may not have the increased focus that we should have.

\section{$A \& F$ cycle ownership}

Regarding the full A\&F cycle process, there was no ownership among any focus group. They recalled certain courses, meetings and common interest in the beginning, but little sense of it as a process. They agreed that they had been invited to participate by filling out action plans and suggesting activities to achieve goals and admitted that they had subsequently been able to participate in occasional actions, but the implementation process or the A\&F cycle as a whole was not owned. Some also questioned whether managers had a genuine interest and ownership in the process, stating that leaders needed to own the process and transfer it to staff. Outpatient clinic staff said that they did what they were asked to do, and that A\&F was one among several things implemented without being part of something bigger. A\&F was seen by some groups as imposed on them without the opportunity to discuss or reflect on its purpose, or how it best can form a basis for QI:

Well, I think if we, the ones doing the practical work, are to get ownership [...] we should be involved. We should have a say.

Re-audit feedback is supposed to be given immediately after its completion, but when asked, it turned out that no staff, only managers, had received feedback from the re-audit, one to three months after completion.

\section{Discussion}

We found that staff felt accepting and were mainly positive in the initial A\&F cycle stages, were willing to participate in the audit survey, and implementation, but everyday life in the DPC units interfered with completion. Plans were often not fulfilled owing to organizational deficiencies and poor follow-up, and thus lacking A\&F cycle ownership. Auditing raised practice awareness about dual diagnosis patients, in line with A\&F intentions (Ivers, Sales, Colquhoun, Michie, Foy, Francis, and Grimshaw, 2014; Jamtvedt et al., 2006) - an important recognition by mental health staff.

Participants felt the need for someone to facilitate the implementation process, a common recommendation for an A\&F cycle (Burgess, 2011), shown to be important in earlier qualitative studies (Kristensen and Hounsgaard, 2014). Difficulties focusing on QI, when organizational resources are not established or available are a known barrier (Ivers, Barnsley, Upshur, Tu, Shah, Grimshaw and Zwarenstein, 2014). A systematic review examined the facilitator in the implementation process (Dogherty et al., 2014), which showed that in most studies, there is an external researcher or research team responsible for implementation processes. They questioned how results are transferable to a clinical context without external researchers present. The study showed that it was probably hard to hold on to a full A\&F cycle without designated facilitators. 
IJHCQA 31,7

830
Advisory Unit staff produced the audit survey and associated action schemas to ease Guideline implementation, but as it seems, it was not enough. We know from other studies that during the implementation phase, support from a local leader and at department level is crucial for guideline success in mental healthcare (Forsner et al., 2010).

Unit leaders and department managers seemed to have failed to sell A\&F as a useful improvement tool; its purpose and goal were not clear to staff, resulting in non-ownership. On the other hand, focus group participants were the same as those in the QI teams one year earlier, at the outset. We expected this to have given some ownership; one mental health service study, found multidisciplinary team participation to result in implementation phase ownership, and was seen to facilitate success (Forsner et al., 2010). It seems that unit leaders were not able to follow-up all the way through a full A\&F cycle, and staff felt overwhelmed by non-prioritization, and did not grab the chance given by QI teams to be an active part in the process.

When interviews were conducted, participants had been using the A\&F cycle for one year to implement Guideline recommendations. Outpatient clinic staff had implemented several other important changes, like getting a new unit leader and moving to a new location that integrated with the DPC. A large reorganization in the health authority also led to additional work for the DPC along with restrictions on the educational budgets, which might have restrained the full A\&F cycle.

We cannot expect research teams to be involved in clinical project implementation and must expect specialist mental health service staff to take autonomous responsibility for implementing national guidelines. Guidelines will, with great probability, keep being produced by national authorities to improve care quality, who expect them to be practiced. Tools to ease implementation are not enough. The key seems to lie with facilitating an implementation process.

\section{Strengths and limitations}

The study's strength is the inductive and naturalistic study design, which provided insight into how the A\&F cycle is used in clinical practice to implement the Guideline, and how this is experienced by staff in Norway's mental health services. Given the study's naturalistic approach, a limitation is the difficulty replicating the study design, involving the entire process. We sought to strengthen validity by describing thoroughly the local A\&F cycle and methods used. The material's richness might be limited to one site, but we included all units to increase heterogeneity and richness. The interviews were not piloted since ours was a naturalistic study.

Interviews were conducted a year after the initial A\&F, after actions were taken to implement Guideline recommendations and after a re-audit. This was to get the full A\&F cycle experience. Nevertheless, recall bias is a possibility when reflecting on a process over an entire year. We accounted for this by going through the process at each interview.

Focus groups allow interactions, relationships and discussions among the participants (Kitzinger, 1995). There are, however, also limitations regarding stronger and weaker voices in the group when group members come from the same unit and are colleagues; i.e., professional hierarchies or group norms not accepted by everyone. We sought to compensate by having an experienced moderator who focused on this potential problem. The first author and interviewer is an information scientist with a speciality in health service organizations and evidence-based practice.

\section{Conclusion and recommendations}

Exploring staff experiences provides valuable information regarding A\&F cycles. This information may be used when planning and tailoring further implementation projects. We found a process that was formally decided at high management levels in the organization, taken on by local managers and given support in the initial phase. The A\&F cycle was well 
planned and set out. Our main findings are that staff felt enthusiastic in the A\&F cycle's initial stages, but that everyday life in the DPC units interfered with the process and good intentions were often not fulfilled owing to organizational deficiencies and poor follow-up. This study shows that it is probably hard to hold on to a full A\&F cycle without designated facilitators even when tools for implementation are ready at hand. For healthcare organizations, this gives valuable insight into staff needs and facilitation. Our study is relevant for leaders and managers in specialist mental health services using A\&F as tool to implement guidelines and promote evidence-based practice. We suggest exploring how unit leaders in mental health services experience the process and complete an A\&F cycle. We recommend more naturalistic studies in specialist mental health services to understand A\&F processes in real life.

\section{References}

Barbui, C., Girlanda, F., Ay, E., Cipriani, A., Becker, T. and Koesters, M. (2014), "Implementation of treatment guidelines for specialist mental health care", Cochrane Database of Systematic Reviews, Vol. 1 No. CD009780, pp. 1-43.

Brehaut, J.C. and Eva, K.W. (2012), "Building theories of knowledge translation interventions: use the entire menu of constructs", Implementation Science, Vol. 7 No. 114, pp. 1-10, doi: 10.1186/1748-5908-7-114.

Burgess, R. (2011), New Principles of Best Practice in Clinical Audit, Radcliffe Publishing, Oxford.

Christina, V., Baldwin, K., Biron, A., Emed, J. and Lepage, K. (2016), "Factors influencing the effectiveness of audit and feedback: nurses' perceptions", Journal of Nursing Management, Vol. 24 No. 8, pp. 1080-1087.

Dixon, N., Pearce, M. and Quest, H.Q. (2011), Guide to Using Quality Improvement Tools to Drive Clinical Audits, HQIP, London, available at: www.hqip.org.uk/resources/hqip-guide-to-using-qualityimprovement-tools-to-drive-clinical-audit/ (accessed July 2017).

Dogherty, E.J., Harrison, M., Graham, I. and Keeping-Burke, L. (2014), "Examining the use of facilitation within guideline dissemination and implementation studies in nursing", International Journal of Evidence-Based Healthcare, Vol. 12 No. 2, pp. 105-127.

Effective Practice and Organisation of Care (2015), "EPOC taxonomy", available at: https:/epoc. cochrane.org/epoc-taxonomy (accessed July 6, 2017).

Elo, S. and Kyngäs, H. (2008), "The qualitative content analysis process", Journal of Advanced Nursing, Vol. 62 No. 1, pp. 107-115.

Forsner, T., Hansson, J., Brommels, M., Wistedt, A.A. and Forsell, Y. (2010), "Implementing clinical guidelines in psychiatry: a qualitative study of perceived facilitators and barriers", BMC Psychiatry, Vol. 10 No. 8, pp. 1-10, doi: 10.1186/1471-244X-10-8.

Foy, R., Eccles, M.P., Jamtvedt, G., Young, J., Grimshaw, J.M. and Baker, R. (2005), "What do we know about how to do audit and feedback? Pitfalls in applying evidence from a systematic review", BMC Health Services Research, Vol. 5 No. 50, pp. 1-7, doi: 10.1186/1472-6963-5-50.

Gagliardi, A.R. and Alhabib, S. (2015), "Trends in guideline implementation: a scoping systematic review", Implementation Science, Vol. 10 No. 54, pp. 1-11, doi: 10.1186/s13012-015-0247-8.

Girlanda, F., Fiedler, I., Becker, T., Barbui, C. and Koesters, M. (2017), "The evidence-practice gap in specialist mental healthcare: systematic review and meta-analysis of guideline implementation studies", The British Journal of Psychiatry, Vol. 210 No. 1, pp. 24-30.

Graneheim, U.H. and Lundman, B. (2004), "Qualitative content analysis in nursing research: concepts, procedures and measures to achieve trustworthiness", Nurse Education Today, Vol. 24 No. 2, pp. 105-112.

Grant, B.F., Stinson, F.S., Dawson, D.A., Chou, S.P., Dufour, M.C., Compton, W., Pickering, R.P. and Kaplan, K. (2004), "Prevalence and co-occurrence of substance use disorders and independent mood and anxiety disorders: results from the national epidemiologic survey on alcohol and related conditions", Archives of General Psychiatry, Vol. 61 No. 8, pp. 807-816.
Audit and

feedback in

mental

healthcare

831 
IJHCQA 31,7

832

Grimshaw, J.M., Eccles, M.P., Lavis, J.N., Hill, S.J. and Squires, J.E. (2012), "Knowledge translation of research findings", Implementation Science, Vol. 7 No. 50, pp. 1-17, doi: 10.1186/1748-5908-7-50.

Grol, R. (2008), "Knowledge transfer in mental health care: how do we bring evidence into day-to-day practice?", Canadian Journal of Psychiatry, Vol. 53 No. 5, pp. 275-276.

Grol, R., Wensing, M. and Eccles, M. (2005), Improving Patient Care: The Implementation of Change in Clinical Practice, 1st ed., Elsevier, Edinburgh.

Hysong, S.J., Best, R.G. and Pugh, J.A. (2006), "Audit and feedback and clinical practice guideline adherence: making feedback actionable", Implementation Science, Vol. 1 No. 9, pp. 1-10, doi: 10.1186/1748-5908-1-9.

Hysong, S.J., Kell, H.J., Petersen, L.A., Campbell, B.A. and Trautner, B.W. (2017), “Theory-based and evidence-based design of audit and feedback programmes: examples from two clinical intervention studies”, BMJ Quality \& Safety, Vol. 26 No. 4, pp. 323-334.

Ivers, N., Barnsley, J., Upshur, R., Tu, K., Shah, B., Grimshaw, J. and Zwarenstein, M. (2014), "My approach to this job is ... one person at a time': perceived discordance between population-level quality targets and patient-centred care", Canadian Family Physician, Vol. 60 No. 3, pp. 258-266.

Ivers, N.M., Sales, A., Colquhoun, H., Michie, S., Foy, R., Francis, J.J. and Grimshaw, J.M. (2014), "No more 'business as usual' with audit and feedback interventions: towards an agenda for a reinvigorated intervention", Implementation Science, Vol. 9 No. 14, pp. 1-8, doi: 10.1186/17485908-9-14.

Ivers, N.M., Grimshaw, J.M., Jamtvedt, G., Flottorp, S., O'brien, M.A., French, S.D., Young, J. and Odgaard-Jensen, J. (2014), "Growing literature, stagnant science? Systematic review, meta-regression and cumulative analysis of audit and feedback interventions in health care", Journal of General Internal Medicine, Vol. 29 No. 11, pp. 1534-1541.

Ivers, N.M., Jamtvedt, G., Flottorp, S., Young, J.M., Odgaard-Jensen, J., French, S.D., O’brien, M.A., Johansen, M., Grimshaw, J. and Oxman, A.D. (2012), "Audit and feedback: effects on professional practice and healthcare outcomes”, Cochrane Database of Systematic Reviews, Vol. 6, p. 229.

Jamtvedt, G., Young, J.M., Kristoffersen, D.T., O’brien, M.A. and Oxman, A.D. (2006), "Does telling people what they have been doing change what they do? A systematic review of the effects of audit and feedback", Quality \& Safety in Health Care, Vol. 15 No. 6, pp. 433-436.

Johnston, G., Crombie, I.K., Davies, H.T., Alder, E.M. and Millard, A. (2000), "Reviewing audit: barriers and facilitating factors for effective clinical audit”, Quality in Health Care, Vol. 9 No. 1, pp. 23-36.

Kitzinger, J. (1995), “Qualitative research: introducing focus groups”, British Medical Journal, Vol. 311 No. 7000, pp. 299-302.

Kristensen, H. and Hounsgaard, L. (2014), "Evaluating the impact of audits and feedback as methods for implementation of evidence in stroke rehabilitation", British Journal of Occupational Therapy, Vol. 77 No. 5, pp. 251-259.

Lai, H.M., Cleary, M., Sitharthan, T. and Hunt, G.E. (2015), "Prevalence of comorbid substance use, anxiety and mood disorders in epidemiological surveys, 1990-2014: a systematic review and meta-analysis”, Drug and Alcohol Dependence, Vol. 154, September, pp. 1-13.

Landheim, A.S., Bakken, K. and Vaglum, P. (2003), "Gender differences in the prevalence of symptom disorders and personality disorders among poly-substance abusers and pure alcoholics. Substance abusers treated in two counties in Norway", European Addiction Research, Vol. 9 No. 1, pp. 8-17.

Mazza, D., Bairstow, P., Buchan, H., Chakraborty, S.P., Van Hecke, O., Grech, C. and Kunnamo, I. (2013), "Refining a taxonomy for guideline implementation: results of an exercise in abstract classification”, Implementation Science, Vol. 8 No. 32, pp. 1-10, doi: 10.1186/1748-5908-8-32.

Meehan, T., Mccombes, S., Hatzipetrou, L. and Catchpoole, R. (2006), "Introduction of routine outcome measures: staff reactions and issues for consideration", Journal of Psychiatric and Mental Health Nursing, Vol. 13 No. 5, pp. 581-587. 
Morisano, D., Babor, T. and Robaina, K. (2014), "Co-occurrence of substance use disorders with other psychiatric disorders: implications for treatment services", Nordic Studies on Alcohol and Drugs, Vol. 31 No. 1, pp. 5-25.

Norwegian National Advisory Unit on Concurrent Substance Abuse and Mental Health (2013), "Gap-undersøkelse for behandlere i psyksik helsevern (audit-survey for health professionals in specialist mental health services)", Norwegian National Advisory Unit on Concurrent Substance Abuse and Mental Health, Ottestad, available at: http://gap.rop.no/skjemamaler/for-behandlerei-psykisk-helsevern.-versjon-2.0 (accessed July 6, 2017).

Audit and

feedback in

mental

healthcare

Payne, V.L. and Hysong, S.J. (2016), "Model depicting aspects of audit and feedback that impact physicians' acceptance of clinical performance feedback", BMC Health Services Research, Vol. 16 No. 260, pp. 1-12, doi: 10.1186/s12913-016-1486-3.

Potter, J., Fuller, C. and Ferris, M. (2010), Local Clinical Audit: Handbook for PHYSICIANS, HQIP, London, available at: www.hqip.org.uk/assets/Guidance/Local-clinical-audit-handbook-forphysicians-August-2010-FINAL.pdf (accessed October 2, 2015)

Saban, A. and Flisher, A.J. (2010), "The association between psychopathology and substance use in young people: a review of the literature", Journal of Psychoactive Drugs, Vol. 42 No. 1, pp. 37-47.

Sederer, L.I. (2009), "Science to practice: making what we know what we actually do", Schizophrenia Bulletin, Vol. 35 No. 4, pp. 714-718.

Shekelle, P., Woolf, S., Grimshaw Jeremy, M., Schünemann Holger, J. and Eccles Martin, P. (2012), "Developing clinical practice guidelines: reviewing, reporting, and publishing guidelines; updating guidelines; and the emerging issues of enhancing guideline implementability and accounting for comorbid conditions in guideline development", Implementation Science, Vol. 7 No. 62, pp. 1-7, doi: 10.1186/1748-5908-7-62.

Sinuff, T., Muscedere, J., Rozmovits, L., Dale, C.M. and Scales, D.C. (2015), “A qualitative study of the variable effects of audit and feedback in the ICU”, BMJ Quality \& Safety, Vol. 24 No. 6, pp. 393-399.

The Norwegian Directorate of Health (2012), "National guideline for assessment, treatment and social rehabilitation of persons with concurrent substance use disorders and mental disorders", The Norwegian Directorate of Health, Oslo, Norwegian National Guidelines, IS-1948, available at: https:/helsedirektoratet.no/Lists/Publikasjoner/Attachments/188/Nasjonal-faglig-retningslinjepersoner-med-rop-lidelser-IS-1948.pdf (accessed July 6, 2017).

\section{Corresponding author}

Monica Stolt Pedersen can be contacted at: monica.stolt.pedersen@sykehuset-innlandet.no

For instructions on how to order reprints of this article, please visit our website: www.emeraldgrouppublishing.com/licensing/reprints.htm

Or contact us for further details: permissions@emeraldinsight.com 


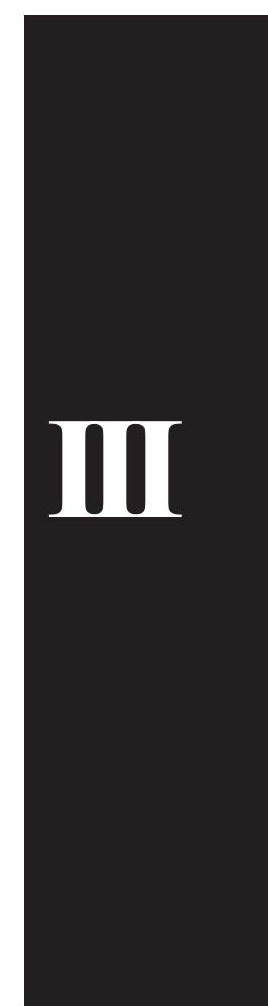





\title{
First-line managers' experience of the use of audit and feedback cycle in specialist mental health care: A qualitative case study
}

\author{
Monica Stolt Pedersen ${ }^{\mathrm{a}, \mathrm{b}, *}$, Anne Landheim ${ }^{\mathrm{a}}$, Merete Møller ${ }^{\mathrm{c}}$, Lars Lien ${ }^{\mathrm{a}}$ \\ ${ }^{a}$ Norwegian National Advisory Unit on Concurrent Substance Abuse and Mental Health Disorders, Innlandet Hospital Trust, Norway \\ ${ }^{\mathrm{b}}$ Faculty of Medicine, University of Oslo, Norway \\ ${ }^{\mathrm{c}}$ Division of Mental Health, Østfold Hospital Trust, Norway
}

\section{A R T I C L E IN F O}

\section{Keywords:}

Audit and feedback

Health services research

Evidence-based practice

Clinical practice guidelines

Quality improvement

Qualitative research

\begin{abstract}
A B S T R A C T
Background: Audit and feedback was the main strategy to facilitate implementation of The National Guideline for Persons with Concurrent Substance Use Disorders and Mental Disorders in specialist mental health services. Studies have shown that leadership support contributes to implementation success. The aim of the study was to explore how first-line managers in a District Psychiatric Centre experienced using audit and feedback cycle. Method: The study had a qualitative case study design with individual interviews with five first-line managers from a District Psychiatric Centre in Norway. Qualitative content analysis was conducted.

Results: First-line managers were positive to contribute to better practice for the patient group and apply available tools. Four themes emerged: 1) Lack of endurance, where first-line managers saw their role as being process leaders, but failed to persist, 2) Lack of support in the process, where first-line managers called for a stronger organisational focus 3) Lack of ownership, where first-line managers felt the process was imposed on them, and 4) Lack of leader autonomy, where first-line managers seemed insecure about their role between professional leadership and own management.

Conclusion: First-line managers were not sufficiently experienced or equipped to solve the implementation process satisfactorily. They were torn between different commitments, without the autonomy to act as process drivers or facilitators, and without taking the necessary leadership role. The potential impact of the use of audit and feedback may thus not be fully realized, in part, because of limited organisational support and capacity to respond effectively.
\end{abstract}

\section{Introduction}

Clinical practice guidelines (CPG) are important foundations for evidence-based practice (EBP), produced to guide clinicians and managers in planning and delivery of health care and quality improvement (Barbui et al., 2014; Shekelle, Woolf, Grimshaw, Schünemann, \& Eccles, 2012). There is a well-known knowledge-practice gap between what CPGs recommend as best practice and the actual treatment and care patients are offered by mental health care (Bet et al., 2013; Sederer, 2009; van Minnen, Hendriks, \& Olff, 2010; von Ranson, Wallace, \& Stevenson, 2013). The critical research-practice gap in mental health services necessitates implementation research to provide better services for patients (Proctor et al., 2009). Implementation research may help to close this gap (Foy et al., 2015). The research field is rapidly growing, with a number of models and interventions to choose from to promote the use of CPGs, but there are still not one established strategy for guideline implementation in mental health care (Gagliardi \& Alhabib, 2015), although promising strategies exists (Bighelli et al., 2016).

One widely used intervention to facilitate implementation is audit and feedback (A\&F). An A\&F cycle is commonly used in different health care settings and may have a positive effect on health professionals' compliance with desired practice (Burgess, 2011; Foy et al., 2005; Hysong, Best, \& Pugh, 2006; Ivers et al., 2012, 2014). The term is used for a heterogeneous group of interventions to improve the process and outcome of care (Colquhoun et al., 2016). A\&F interventions involve the development of a summary of some aspect of clinical performance

\footnotetext{
Abbreviations: CPG, Clinical practice guidelines; EBP, Evidence-based practice; A\&F, Audit and feedback; The National Guideline, The Norwegian national guideline for assessment, treatment and social rehabilitation of persons with concurrent substance use disorders and mental disorders; DPC, District psychiatric centres; R\&D nurses, Research and development nurses (practice development personnel); CRT, Crisis resolution team; QI team, Quality improvement team

* Corresponding author at: Norwegian National Advisory Unit on Concurrent Substance Abuse and Mental Health Disorders, Innlandet Hospital Trust, P.b. 104, 2381 Brumunddal, Norway.

E-mail address: monica.stolt.pedersen@sykehuset-innlandet.no (M.S. Pedersen).
} 
(audit) over a specific period of time, and subsequent provision of that summary (feedback) to individual practitioners, teams, or health care organisations (Brehaut \& Eva, 2012). The purpose is to prompt health care providers to modify their practice if practice is not in line with e.g. a CPG (Ivers et al., 2012). It can be described as a circular process, an audit cycle, targeting health care professionals (Burgess, 2011; Mazza et al., 2013; Potter, Fuller, \& Ferris, 2010). The Norwegian National Guideline for Assessment, Treatment and Social Rehabilitation of Persons with Concurrent Substance Use Disorders and Mental Disorders (hereafter the National Guideline) was launched in 2012 (Helsedirektoratet [The Norwegian Directorate of Health], 2012). It contains 93 recommendations in areas of user involvement, families, assessment, treatment, follow-up care, roles and responsibilities and was developed for health care providers in either primary or specialist services. In conjunction with launching the National Guideline, implementation strategies based on the model of Grol, Wensing and Eccles (2005) were developed. A main strategy was an audit, an evidencebased strategy itself (Ivers et al., 2012), designed for implementing the National Guideline to District Psychiatric Centres (DPC). One additional purpose of CPGs is to use them as benchmarks against clinical practice (Burgers, Smolders, Weijden, Davis, \& Grol, 2013; Turner, Misso, Harris, \& Green, 2008).

Leadership is considered an important contextual factor, and leadership support is presumed to contribute to implementation success (Aarons, Ehrhart, Farahnak, \& Sklar, 2014; Damschroder et al., 2009; Guerrero et al., 2016; Reichenpfader, Carlfjord, \& Nilsen, 2015; Saeed, Bloch, \& Silver, 2015; Sandström, Borglin, Nilsson, \& Willman, 2011; Taylor et al., 2011). Both transformational leadership focusing on inspiring and motivating followers for a particular course of action, and transactional leadership, focusing on managing incentives and rewards and meeting quality standards are important for managing and supporting organisational change (Aarons, Ehrhart, Farahnak, \& Hurlburt, 2015). In general we know little about first-line managers' actions in improvement processes (Øvretveit, 2010). Although we know that senior or upper-level management often makes the strategic decisions about implementing EBP, it is the first-line personnel who drive effective implementation, thus better facilitated if led by first-line managers (Aarons et al., 2015; Aarons, Ehrhart, Farahnak, \& Sklar, 2014). A large proportion of implementation and quality improvement projects are facilitated or entirely carried out by researchers, and there is therefore a need to explore these processes as naturally occurring in clinical settings, undertaken by local groups (Dogherty, Harrison, Graham, \& Keeping-Burke, 2014). To our knowledge, there are few studies on how first-line managers' experiences conducting a full A\&F cycle in specialist mental health services. The aim of this study was to describe and explore how first-line managers in a DPC experience using A\&F cycle as basis for quality improvement in specialist mental health care.

\section{Methods}

\section{Study design}

The study was an instrumental case study, used to facilitate our understanding of A\&F (Stake, 1995). The case itself is a natural process using A\&F to implement the National Guideline. This article leans on two other articles describing various phases of the same A\&F process (Pedersen, Landheim, Møller, \& Lien, 2018a, 2018b).

A qualitative method with individual interviews was chosen to understand the roles and experiences of first-line managers in an A\&F process.

\section{Study site}

We looked for a natural occurring process and contacted DPCs about to implement the National Guideline by using a pre-existing audit strategy. One DPC was ready in 2014 and agreed to participate, and the study thus took place in this DPC in southeastern Norway. The DPC is an independent department within a hospital trust, with responsibility to provide specialist mental health care in a given geographical area. The DPC was situated in an urban setting and consisted of two outpatient and two inpatient units, offering adult specialist mental health services to a population of about 72,000 . The two inpatient units had similar staff in terms of numbers and type and length of education, where nurses and social educators (both of whom have at least a threeyear bachelor's degree) and assistant nurses are commonly referred to as "milieu personnel", while psychologists and psychiatrists are often referred to as therapists. The staff of both inpatient units consisted mainly of milieu personnel and 1-2 therapists. One inpatient unit had patients with psychosis-related disorders and the other had more patients within general psychiatry or personality disorders. One outpatient unit was a crisis resolution team (CRT), mainly consisting of nurses, social educators or others with similar relevant qualifications, and had a psychologist and psychiatrist attached to the unit. They reached out from the hospital setting to patients mostly referred from GPs or other hospital departments. The second outpatient unit was operating as a general psychiatric outpatient clinic with regular hours and booked appointments, mainly staffed by therapists such as psychiatrists, psychologists or specialist nurses. All four units had patient with concurrent mental and substance use disorders and the National Guideline was therefore highly relevant to implement in this setting. The total number of staffs at the DPC was 63 (between 12 and 18 in each unit), not counting administrative or temporary personnel.

DPCs are often organised into three management levels: senior (executive) management led by Director of Division Mental Health Services at the Health Authority, middle management responsible for the DPC as a total, led by DPC manager and first-line (unit) management. Each unit had a first-line manager. First-line managers had the frontline staff reporting to them with personnel responsibility, HSE responsibility, shift plans, procedures and guidelines, budgeting, training plans for staff etc. Since 2001, there has been unitary management in Norwegian hospitals, replacing the traditional dual management structure based on a head nurse and a head doctor. The Health Personnel Act however, makes it clear that when cooperating with other health care professionals, the physician should make medical decisions on examination and treatment of patient (Lov av 2. juli 1999 nr. 64 om helsepersonell m.v. (helsepersonelloven), 1999).

\section{The process}

The main implementation strategy developed was an audit for DPCs mirroring the recommendations in the National Guideline, consisting of 46 questions about screening and diagnostic practices, assessment of the target group, integrated treatment, collaboration, use of evidencebased methods and competence requirements for e.g. the process of care. The electronic self-report questionnaire came with a standardised action form to be completed and a template for its use describing an A\& F cycle: 1 . Conduct the audit, 2 . Identify improvement areas based on feedback, 3. Select improvement areas and define objectives related to the selected areas, 4. Choose measures to be implemented to achieve the individual goal, 5. Describe the progress of the various measures, 6 . Describe who are main responsibility for the measures, 7. Make an economic assessment, 8. Implement the improvement work, 9. Evaluate whether the goals and measures are met in relation to the progress plan, 10. Perform a new audit. The audit with templates was available for the DPC at the website of the National Advisory Unit on Concurrent Substance Abuse and Mental Health Disorders ([Audit-survey for health professionals in specialist mental health services] [Internet], 2013). There were no audit data nationally to benchmark against.

The senior management group wished to implement the National Guideline using the facilitated tools. The DPC manager made a common decision with the first-line managers in a DPC-management meeting (DPC manager, four first-line managers, R\&D nurses and administration 
manager) to implement the National Guideline with the use of the A\&F cycle. The first audit of existing practice was conducted in 2014. A supervisor, not employed at the DPC, with responsibility for concurrent mental and substance use disorders, assisted in the practical execution of the audit. Each eligible (all staff excluding administrative personnel, short-term temporary staff etc.) employee conducted the audit. Each unit held separate meetings led by the supervisor, where feedback of the results was given at a unit level verbally and in writing to the whole staff group present. The meetings included information on EBP, on recommendations in the National Guideline and on how to conduct an implementation process informed by the A\&F cycle. The first-line managers were present at all the meetings. The first-line managers selected members for multidisciplinary quality improvement (QI) teams for each unit. The teams reflected on the feedback from the audits and worked to complete action plans for the following year. A final decision on the areas for improvement and action plans was made in a management meeting for the entire DPC in 2014 and the following common areas were chosen: 1) Screening of alcohol and drug use, 2) Enhanced knowledge of the treatment of concurrent substance abuse and mental illness, and 3) Improved collaboration between the DPC, substance abuse departments in the health authority and local authorities (Pedersen et al., 2018a). The actions were initiated the following year with the first-line managers responsible for their implementation. Some of the actions, such as training courses, were planned and organised by practice development personnel (R\&D nurses). A re-audit led by the same supervisor was conducted in June 2015. Feedback of the results was given to the management in 2015 and was planned forwarded by the unit managers to the staff immediately afterwards.

\section{Participants}

Participants $(n=5)$ for the interview were all of the first-line managers, all with a background as registered nurses and several years of experience as managers. One unit manager was new to the organisation. There were four women and one man. One unit had a vacancy for the post of first-line manager at the commencement of the A\&F process and was led by the DPC manager who then had a double role for a few months. A new first-line manager was in place a after a few months, taking over the responsibility for the process. Both the DPC manager (in the role as first-line manager) and the first-line managers were interviewed to obtain as rich and accurate data as possible.

\section{Data collection}

The interviews were conducted when the full A\&F cycle had been completed, one year after commencement of the process, shortly after the final re-audit. An open interview guide focusing on the complete A\& $\mathrm{F}$ cycle was created, drawing on observations of the QI team meetings in 2014 (Pedersen et al., 2018a) and on literature on A\&F cycles and in the field of implementation leadership. It covered broader areas like usefulness, what is done, experience of the whole process, A\&F as leadership tool, what could be done differently (barriers), what would you do again (facilitators), have you changed the way you work because an A\& F-process, are your more conscious of own/staffs practice etc. The interviews took place in 2015, lasted for about $1 \mathrm{~h}$ and were conducted by the first author (MSP). Summary of the main points and follow-up questions ensured validation and ascertained that the information was understood. The interviews were audio recorded and notes of reflections were made immediately after each interview. All interviews were held at the site of the DPC, in the managers' own offices.

\section{Analysis}

We used qualitative content analysis as described by Graneheim and Lundeman (Graneheim \& Lundman, 2004), a method suitable for the systematic analysis of communication. It enabled a focus on both context and subject matter and emphasised both similarities and differences. The aim was to condense and describe the phenomenon and the outcome of the analysis in categories sharing the same meaning (Elo \& Kyngäs, 2008). Since the purpose of this study was to learn more about how first-line managers describe and experience the use of A\&F as an implementation strategy in specialist mental health care, we decided on a mostly inductive content analysis. No pre-existing analytical framework was used, as recommended when there is insufficient or fragmented knowledge of the phenomenon (Elo \& Kyngäs, 2008), but we used the interview guide as a guiding framework in the beginning of the analysis.

The audio-recorded interviews were transcribed verbatim and the NVivo 10 software was used to facilitate the analysis (QSR International, 2012). The material was read several times to gain a sense of the whole, and to gather ideas for further analysis. The text was divided into meaning units, which were examined and condensed with the key content preserved and coded. The codes were then sorted into categories grounded in the data and representing the manifest content of the text (Graneheim \& Lundman, 2004).

\section{Results}

All the first-line managers with no exception expressed a positive attitude towards A\&F as a strategy for implementation. They saw the A $\& \mathrm{~F}$ as an important management tool to show needs regarding staff skills and gaps between an actual practice and a practice more in line with the National Guideline where it helped to focus on important improvement areas. They would like to use A\&F more and in other areas as well.

All four units experienced being in another, and qualitative better professional place than before the process, and the results of the second audit showed that improvements had been accomplished for all units in all the areas they decided to improve on in the chosen areas. Still, some of the participants did not necessarily believe in great improvements. One of the leaders expressed scepticism about whether the process actually resulted in improvement of practice, questioning whether the A $\& F$ process was worth the effort.

"But whether we've actually got that much better at treating substance abuse..."

In the following results we present the themes most prominent when the first-line managers elaborated on the A\&F process.

Four themes emerged: 1) Lack of endurance, where the first-line managers saw their role as being process leaders, but they failed to persist, 2) Lack of support in the process, where first-line managers called for a stronger organisational focus 3) Lack of ownership, where the first-line managers felt the process was imposed on them, and 4) Lack of leader autonomy, where the first-line managers seemed insecure about their role between professional leadership from therapists and own management of the unit.

\section{Lack of endurance}

The first-line managers saw themselves as the ones who had to keep a grip on to the A\&F cycle and make sure it was completed. That included having task focus, reminding staff of their tasks and responsibilities, and following up on the action forms completed in the initial phases, i.e. facilitating the process and leading it forward. One of them delegated parts of this work to dedicated members of staff, who organised training courses for the unit. Some expressed a wish to delegate, but most of them saw the work as a first-line manager's responsibility and an important part of their role.

"And I can see that I have to be the one who promotes this, to a great extent. Like keeping it warm, you know."

Most reported difficulties in persisting and keeping focus 
throughout the whole year. Their schedule was always tight, and there were many things to distract them from decisions made on areas for improvement. They felt trapped in a hectic clinic, managing and administering their units and staff. The first-line managers were clearly more eager at the beginning of the A\&F cycle than in the completion phase. Therefore, although the first-line managers saw their role as the ones to keep a grip on the process, it was also here they strayed off the path. They lacked the endurance to follow up on the decisions made at the outset.

"But we're also affected by what happened last week and the process we're in the middle of, and so on."

\section{Lack of support}

All of the first-line managers reported lacking support from the management level above. Some said the A\&F process had been totally absent from the DPC management meetings, and requested a stronger organisational focus in the DPC as a whole and a forum for discussing the process. In particular, they asked for reminders, "someone" to remind them of the implementation process they were involved in, asking for a status report from time to time.

"There hasn't been enough leadership support. You might say I think I've done what I could with it, but if you think about our management meetings, there's not been much focus on it. But I suppose it's been because everything else has been taking away the focus. So I can't say there's been much focus on that [the A\&F cycle], really."

Q: "Do you think you've been given the leadership support you need to help your staff to ..." Manager: "In this thing? In the audit process?" Q: "Yes" Manager: "No, not at all!"

There was no doubt that the lack of support the first-line managers experienced gave the implementation process less attention, less power and less leadership than they felt it probably should have had. The A\&F cycle fell into oblivion, the first-line managers forgot their self-proclaimed role to support staff on the decisions they made at the beginning of the process and to remind them and inquire about the development of the implementation.

"Yes, well, a bit shocked that, well, are we forgetting all about it or what, what's happening to us. So it was good to be reminded about it the day we got the results from the audit and I started to think now I've got to do something."

The first-line managers were pleased with the practical support they received in the execution of the audit and the preparation and facilitation of the feedback reports by the supervisor, and with the administration of training courses by the R\&D nurses. One of the first-line managers expressed some disappointment with the R\&D nurses, pointing at the need for closer follow up in the ward and more process responsibility. They all appointed members to QI teams at the beginning of the process, which was necessary as part of the implementation strategy, but none of the managers seem to have used or involved these groups further in the process to any great extent.

\section{Lack of ownership}

This implementation process with the use of an A\&F cycle was decided at a hospital and DPC level. The first-line managers were invited to decide whether they wanted their unit to be part of the process, and they all decided to participate. Nevertheless, some of the first-line managers claimed that the A\&F process with all its actions was imposed on them.

"You could say we really don't have any choice about it, but in saying that, I do actually think it's a good thing."
Although mainly viewed as positive, there were statements indicating a feeling of being run over, and not being understood. They stated that various areas of hospital and government priorities, and particularly clinical guidelines, were always top-down initiatives from higher authoratives that expected them to be implemented in the clinic. These clinical guidelines were not necessarily seen as an aid to enhance clinical practice or improve quality, but more as directives from "above".

"I think it's a problem in the health care system. That so much is initiated from the top. And they think we're just sitting here and looking at each other and having a nice time. And they don't realise that just one more thing, in fact that can be the straw that breaks the camel's back."

The first-line managers felt loyal to the A\&F process and basically went along with what they were required or expected to do, but lacked ownership and did not necessarily find it satisfying. A few of the firstline managers definitely wanted more of a say in the matter in their own unit. But when asked specifically about this, they sometimes referred more to the lack of time than the question of increased autonomy as a first-line manager.

"I'd like to be able to decide more, I'd like more autonomy in terms of what I think we can really manage to do something about. Because nothing happens properly when we carry on like we've been doing this past year. There's an awful lot to do, we get all these directives raining down on our heads and then you just have to make what you want out of it. And I'm not happy with that."

\section{Lack of leader autonomy}

The first-line managers, except the one from the general outpatient clinic, said that completion of an A\&F cycle had led to increased discussion of practice in general in the units. Mainly, but with the exception of the general outpatient clinic, they had faith in an A\&F cycle creating increased awareness of best practice and of clinical guidelines as a standard for EBP. Nevertheless, many practice decisions were still made by the therapists alone. One of the participants felt that the A\&F had led to more and better discussion with a more confident staff, but decisions, even small ones concerning practice, were still easier to make when a therapist was present because someone (e.g. the therapist) could take responsibility for making the final decision. She also said that the decisions were never written down and not necessarily related to clinical guidelines or local procedures, but were based on experience and the therapist's opinion and putative knowledge.

"Oh, definitely, yes, the rest of the staff has enough knowledge to take part in treatment discussions with therapists. I've found that it gives all the staff more expertise, you know. Incredibly useful discussions and assessments. And then when we end the discussion, we've finished it and we've achieved a result. While before we could sit discussing and discussing and we never agreed and finished, it just remained there. But now we wrap up the discussions; okay then, we'll do that then, that's fine."

Therapists play a key role in the treatment of patients as they are professionally and legally responsible for medication and the course of treatment. Some of the units had experienced unstable situations with new doctors coming and going at a fast pace, never allowing for the development of stable relationships with the rest of the staff. An otherwise competent staff with considerable knowledge and experience leaned back and waited when a new therapist arrived. The staff had no tradition of taking a lead and telling the therapist, "in this unit we're working on these principles of treatment and EBP".

"While we, the staff, have the feeling that here comes a new consultant, how is he going to want things to be? Will he want things 


\section{like they are here now or will we have to change again?"}

The first-line managers did not take a leadership role either, to explain the principles the unit was run by. Instead, they defined themselves as part of the staff in terms of these decisions. This was particularly present in the in-patient units. Further, the firs-line managers largely ignored the leadership role in the choice of treatment profiles and strategies in the unit. In this area they also seemed to lean back and leave the decisions almost entirely to the therapists alone. They did not intervene or profile their unit with the treatment strategies they followed, and made no effort to promote the use of clinical guidelines or EBP. This was left to the therapists alone. Some, however, had a desire to contribute to these decisions without necessarily seeing solution.

"So I'd like to create a ward with much more of the treatment based on milieu therapy, where the consultants obviously have some influence, but they must also realise that this is actually how we want to run things in this ward."

\section{Discussion}

All four units had important improvements according to the reaudit, most of the planned actions were fulfilled, but although positive attitudes towards A\&F as a strategy, the process as such was still not seen as a completely successful process. This brought up four main themes of the experience of the process: 1) Lack of endurance, 2) Lack of support in the process, 3) Lack of ownership, and 4) Lack of leader autonomy.

This study told a story of first-line managers who were willing to contribute to better practice for a group of patients with concurrent mental and substance use disorder traditionally not receiving best practice in specialist mental health care. They also applied available A\& F tools, but we found managers who relinquished responsibility both to their staff and to the managerial level above, thus not fulfilling their responsibility, which was more easily taken in the initial stages of the process than in its completion phase. First-line managers do not seem to be sufficiently experienced or equipped for solving this task regarding implementation processes using $\mathrm{A} \& \mathrm{~F}$ or to have an adequate understanding of their role.

The first-line managers saw their role as the ones to lead the process, but this was also where they strayed off and lost focus. They reflected on pitfalls they came across in attempting to complete a full A\&F cycle throughout a whole year; many other tasks were always claiming their attention. An important dimension of the Consolidated Framework for Implementation Research (CFIR) is to allow time for the implementation to take place (Damschroder et al., 2009), also emphasised elsewhere (Fixsen, 2005). This is also called perseverant leadership, and is one of the domains in the Implementation Leadership Scale (ILS) (Aarons, Ehrhart, \& Farahnak, 2014). They were not able to preserve through vicissitudes of implementing recommendations from the National Guideline or carry on through the challenges, as described in the ILS, according to themselves.

It is not possible to see the lack of endurance as a stand-alone-failure on behalf of the first-line managers. Their role was claimed to be that of process leaders, but they found they were alone with the task, without the necessary organisational support, and they felt a lack of leader autonomy in attempting to fulfil the A\&F cycle. We interpreted this partly as a time barrier, releasing less time for leadership than needed, also shown in studies on barriers (Cabana et al., 1999). This is also described in qualitative studies where a growing administrative workload sets little time aside for working on improvements, despite an initially positive attitude by the management (Andreasson, Eriksson, \& Dellve, 2016). A Swedish study in mental health care found that the time barrier was only present in the clinics who had only received a guideline, whereas the clinics with an active implementation strategy did not report a time barrier (Forsner, Hansson, Brommels, Wistedt, \&
Forsell, 2010). They assumed this to be due to the organised approach of intervention clinics trying to change and develop practice. This would support an explanation of lacking organisational support for the A\&F process initiated a year earlier. Lack of supportive conditions, e.g. lack of leader support and focus in management meetings emerged to prevent optimal fulfilment of the A\&F cycle and thus may also have hindered an optimal implementation of the National Guideline. Organisational commitment, involvement and support are crucial when initiating an improvement process. There is a risk of impeding the implementation process if executive managers don't involve lower levels of management or pay attention to how the process leadership is utilised (Aarons, Ehrhart, Farahnak, \& Sklar, 2014). The need for implementation competence and support for mangers has also been described in other studies (Øvretveit, 2010; Sandström et al., 2011; van der Zijpp et al., 2016). Some qualitative studies addresses the importance of the work process, and to have a process facilitator is amongst the recommendations to accomplish a A\&F cycle, (Ivers et al., 2014; Kristensen \& Hounsgaard, 2014; Payne \& Hysong, 2016).

It is possible that the managers are disclaiming their responsibility when they discovered in the end of the A\&F cycle that they had lost focus and strayed off the planned path. The process was well organised with management commitment at several levels and baseline A\&F, combined with instructions on how to run an implementation process and the use of QI teams from the clinic to engage in the process, all important constructs within the CFIR framework of planning and engaging that are believed to enhance success (Damschroder et al., 2009).

It is vital for managers to have knowledge of EBP and reasons for the use of clinical guidelines in order to ensure high-quality patient outcomes (Guerrero, Padwa, Fenwick, Harris, \& Aarons, 2016). This study indicates that first-line managers sometimes view national clinical guidelines more as a never-ending load of instructions coming from the authorities than as help to ensure good practice and best possible patient outcomes. This attitude could well act as hindrance to leading the implementation of national clinical guidelines by the use of A\&F. It is thus vital to teach first-line managers about EBP in general and the importance of the use of national clinical guidelines to enhance practice. This may also, in addition to lack of supportive climate in the organisation, suggest a lack of knowledge of EBP and CPG as a source of EBP. Knowledgeable leadership is one of four domains in the Implementation Leadership Scale (Aarons, Ehrhart, \& Farahnak, 2014) and an important feature of an effective implementation leader. The use of evidence-based clinical guidelines is one way of making available and ensuring evidence-based mental health services (Shekelle et al., 2012). Leaders play a key role in supporting EBP (Aarons, 2006; Aarons, Ehrhart, Farahnak, \& Sklar, 2014).

Instead of talking about cooperation and teamwork, the first-line managers mostly talked about stakeholders in the decision-making processes, who were not always easy to deal with. They seemed to have a vague perception of their role as first-line managers, caught between everyday administration and management of staff, their own leadership and consultants' formal and informal leadership, and the management level above. Staff in mental health care has previously reported ambivalence and lack of support from senior medical staff in relation to A\& $\mathrm{F}$; at eight months post-implementation, a significant number of nurses remained ambivalent about the benefits of the outcome measurement and had not engaged in the process (Meehan, McCombes, Hatzipetrou, \& Catchpoole, 2006). There are reasons to believe that first-line managers have the same kind of experience.

This tells a story of complexity in organisations, and the difficulty of separating the interwoven actions between managers and the context, which has also been found elsewhere in a search for leadership actions associated with successful improvement ( $\emptyset_{\text {vretveit, 2010). Managers }}$ cannot, or should not, dictate consultants how to work with patients, but they can facilitate the use of evidence-based clinical guidelines as a source of summarised evidence on best practice adapted to the national context. When this process was decided upon in 2013, it was an 
administrative management decision. All the managers at first- and middle-management levels were nurses, and to our knowledge the "medical management" was not involved in the decisions. This might have caused some of the lack of autonomy experienced by first-line managers. Consultants play an important and unique role in bearing the final responsibility for the patient and are thus a key element of the team around the care process (Grol, Ouwens, \& Wollersheim, 2013). The process of implementing the National Guideline using the A\&F strategy could possibly have gained from involving the medical leaders into the formal process to a larger degree.

\section{Strengths and limitations of this study}

A major strength of this study is the natural setting of the study, reflected a real world setting without a researcher being part of the project. Given the naturalistic approach, a limitation is the possibility to replicate the exact study design, involving the entire process, although the study is based on a DPC that used the toolkit made nationally available for DPC in Norway to ease implementation of the National Guideline, and the study site may be considered an average DPC in Norway. Further limitations could be the relatively small number of study participants and the lack of pilot interviews because the case boundaries was set and excluded the inclusion of more participants as this was all the first-line managers available in the case. Qualitative research is however, not aimed to be generalisable, but to provide rich description of findings within the context of the study setting. This might allow determining the transferability of the findings to other contexts. There will be a possibility of recall bias when reflecting on a process over a whole year. This was taken care of at the beginning of each interviews, where the interviewer summarised the formal process in the DPC from initiation and first audit throughout the actions taken and results of the re-audit. We decided to include only the first-line managers' perspective to be as close to the actual process as possible. This might have led to loss of some overarching perspectives, but we do think it led to a deeper understanding of this particular level of management.

\section{Implications}

Qualitative case studies in a natural clinical environment are important to understand how implementation strategies are absorbed in real life. This study may contribute to development of better A\&F processes and to a better understanding of organisational challenges that must be taken into account when planning an implementation process. Particularly the challenges first-line managers in daily operation meet, suggesting stronger organisational assumption of responsibility to equip them better for the task.

\section{Conclusion}

This study told a story of first-line managers who were willing to contribute to better practice for a group of patients with concurrent mental and substance use disorder traditionally not receiving best practice in specialist mental health care. They also applied available A\& F tools, but we found managers who relinquished responsibility both to their staff and to the managerial level above, thus not fulfilling their responsibility, which was more easily taken in the initial stages of the process than in its completion phase. First-line managers do not seem to be sufficiently experienced or equipped for solving this task regarding implementation processes using $\mathrm{A} \& \mathrm{~F}$ or to have an adequate understanding of their role. This A\&F process seems to be set out properly according to known best practice of quality improvement and implementation processes. Still, the first-line managers seemed to have a vague perception of their role, caught between everyday administration and management of staff, their own leadership and the consultants' formal and informal leadership, and the management level above. The potential impact of the use of A\&F may not be fully realized, in part, because of limited organisational structures and capacity to respond effectively.

There is still a need for more research in this area in the form of effect studies and testing of theories, and also for qualitative studies in a natural clinical environment.

\section{Ethics approval and consent to participate}

The study was supported by Innlandet Hospital Trust, Norway and approved by the Data Protection Officer for Research at Oslo University Hospital. All of the participants signed a declaration of consent. Data are presented in a way that anonymises individual participants and all are addressed as "she" in the text for anonymity reasons.

\section{Consent for publication}

The final version was prepared and revised by all authors and all authors approved for submission.

\section{Funding}

This work was supported by Innlandet Hospital Trust, Norway, Grant number E13240.

\section{Authors' contributions}

AL and LL participated in the design of the study and formulation of the research question and contributed in the analysis and drafting of the manuscript. MM participated in the coordination of the study and drafting of the manuscript. MSP conceived the study, and participated in its design and formulation of the research question, performed the interviews and drafted the manuscript.

\section{Authors' information}

MSP is an information scientist specialising in organisations and EBP. The remaining authors have experience from clinical work in mental health services.

\section{Availability of data material}

The datasets will not be shared. In recordings or transcripts, individuals are easily identified by their statements and views. None of the datasets are translated to any other language than Norwegian.

\section{Declaration of competing interest}

AL has been a member of the working group at The Norwegian Directorate of Health who produced the National guideline for assessment, treatment and social rehabilitation of persons with concurrent substance use and mental health disorders, launched in 2012. None of the other authors have competing interests.

\section{References}

[Audit-survey for health professionals in specialist mental health services] [Internet]. Norwegian National Advisory Unit on Concurrent Substance Abuse and Mental Health. ([cited June 2019]. Available from) http://gap.rop.no/skjemamaler/forbehandlere-i-psykisk-helsevern-versjon-2.0.

Aarons, G. A. (2006). Transformational and transactional leadership: Association with attitudes toward evidence-based practice. Psychiatr Serv. 57(8), 1162-1169.

Aarons, G. A., Ehrhart, M. G., \& Farahnak, L. R. (2014). The implementation leadership scale (ILS): Development of a brief measure of unit level implementation leadership. Implement Sci. 9(1), 45. https://doi.org/10.1186/1748-5908-9-45.

Aarons, G. A., Ehrhart, M. G., Farahnak, L. R., \& Hurlburt, M. S. (2015). Leadership and organizational change for implementation (LOCI): A randomized mixed method pilot study of a leadership and organization development intervention for evidence-based 
practice implementation. Implement Sci. 10(1), 11. https://doi.org/10.1186/s13012 014-0192-y.

Aarons, G. A., Ehrhart, M. G., Farahnak, L. R., \& Sklar, M. (2014). Aligning leadership across systems and organizations to develop a strategic climate for evidence-based practice implementation. Annu Rev Public Health. 35, 255-274. https://doi.org/10. 1146/annurev-publhealth-032013-182447.

Andreasson, J., Eriksson, A., \& Dellve, L. (2016). Health care managers' views on and approaches to implementing models for improving care processes. J Nurs Manag. 24(2), 219-227. https://doi.org/10.1111/jonm.12303.

Barbui, C., Girlanda, F., Ay, E., Cipriani, A., Becker, T., \& Koesters, M. (2014). Implementation of treatment guidelines for specialist mental health care. Cochrane Database Syst Rev. 1, CD009780. https://doi.org/10.1002/14651858.CD009780. pub2.

Bet, P. M., Hugtenburg, J. G., Penninx, B. W., Balkom, A., Nolen, W. A., \& Hoogendijk, W. J. (2013). Treatment inadequacy in primary and specialized care patients with depressive and/or anxiety disorders. Psychiatry Res. 210(2), 594-600. https://doi.org/ 10.1016/j.psychres.2013.06.023.

Bighelli, I., Ostuzzi, G., Girlanda, F., Cipriani, A., Becker, T., Koesters, M., et al. (2016) Implementation of treatment guidelines for specialist mental health care. Cochrane Database Syst Rev. 12, Cd009780. https://doi.org/10.1002/14651858.CD009780. pub3.

Brehaut, J. C. \& Eva, K. W. (2012). Building theories of knowledge translation interventions: Use the entire menu of constructs. Implement Sci. 7(114), https://doi.org/ 10.1186/1748-5908-7-114

Burgers, J. S., Smolders, M., Van der Weijden, T., Davis, D., \& Grol, R. (2013). Clinical practice guidelines as a tool for improving patient care. In R. Grol, M. Wensing, M. P. Eccles, \& D. Davis (Eds.). Improving patien care: The implementation of change in healt care(2nd ed.). Chichester, UK: Wiley.

Burgess, R. (2011). New principles of best practice in clinical audit. XVIOxford: Radcliffe Publishing (214 s. : ill. p).

Cabana, M. D., Rand, C. S., Powe, N. R., Wu, A. W., Wilson, M. H., Abboud, P. A., et al. (1999). Why don't physicians follow clinical practice guidelines? A framework for improvement. JAMA. 282(15), 1458-1465.

Colquhoun, H., Michie, S., Sales, A., Ivers, N. M., Grimshaw, J. M., Carroll, K., et al. (2016). Reporting and design elements of audit and feedback interventions: A secondary review. BMJ Qual Saf.. https://doi.org/10.1136/bmjqs-2015-005004.

Damschroder, L. J., Aron, D. C., Keith, R. E., Kirsh, S. R., Alexander, J. A., \& Lowery, J. C. (2009). Fostering implementation of health services research findings into practice: A consolidated framework for advancing implementation science. Implement Sci. 4, 50. https://doi.org/10.1186/1748-5908-4-50.

Dogherty, E. J., Harrison, M., Graham, I., \& Keeping-Burke, L. (2014). Examining the use of facilitation within guideline dissemination and implementation studies in nursing. International journal of evidence-based healthcare. 12(2), 105-127. https://doi.org/10 1097/xeb.0000000000000008.

Elo, S., \& Kyngäs, H. (2008). The qualitative content analysis process. J Adv Nurs. 62(1), 107-115. https://doi.org/10.1111/j.1365-2648.2007.04569.x.

Fixsen, D. L. (2005). Implementation research : A synthesis of the literature. Tampa, Florida: University of South FloridaLouis de la Parte Florida Mental Health Institute Publication.

Forsner, T., Hansson, J., Brommels, M., Wistedt, A. A., \& Forsell, Y. (2010). Implementing clinical guidelines in psychiatry: A qualitative study of perceived facilitators and barriers. BMC Psychiatry. 10(8), https://doi.org/10.1186/1471-244x-10-8.

Foy, R., Eccles, M. P., Jamtvedt, G., Young, J., Grimshaw, J. M., \& Baker, R. (2005). What do we know about how to do audit and feedback? Pitfalls in applying evidence from a systematic review. BMC Health Serv Res. 5(50), https://doi.org/10.1186/1472-69635-50.

Foy, R., Sales, A., Wensing, M., Aarons, G. A., Flottorp, S., Kent, B., et al. (2015). Implementation science: A reappraisal of our journal mission and scope. Implement Sci. 10, 51. https://doi.org/10.1186/s13012-015-0240-2.

Gagliardi, A. R., \& Alhabib, S. (2015). Trends in guideline implementation: A scoping systematic review. Implement Sci. 10(54), https://doi.org/10.1186/s13012-0150247-8.

Graneheim, U. H., \& Lundman, B. (2004). Qualitative content analysis in nursing research: Concepts, procedures and measures to achieve trustworthiness. Nurse Educ Today. 24(2), 105-112. https://doi.org/10.1016/j.nedt.2003.10.001.

Grol, R., Ouwens, M., \& Wollersheim, H. (2013). Planning and organizing the change process. In R. Grol, M. Wensing, M. Eccles, \& D. Davis (Eds.). Improving patient care (pp. 374). (2nd ed.). Chichester: Wiley.

Grol, R., Wensing, M., \& Eccles, M. (2005). Improving patient care: The implementation of change in clinical practice. Edinburgh: Elsevier (290 p).

Guerrero, E. G., Aarons, G. A., Grella, C. E., Garner, B. R., Cook, B., \& Vega, W. A. (2016) Program capacity to eliminate outcome disparities in addiction health services. Adm Policy Ment Health. 43(1), 23-35. https://doi.org/10.1007/s10488-014-0617-6.

Guerrero, E. G., Padwa, H., Fenwick, K., Harris, L. M., \& Aarons, G. A. (2016). Identifying and ranking implicit leadership strategies to promote evidence-based practice implementation in addiction health services. Implement Sci. 11, 69. https://doi.org/10. 1186/s13012-016-0438-y.

Helsedirektoratet [The Norwegian Directorate of Health] (2012). Nasjonal faglig retningslinje for utredning, behandling og oppfølging av personer med samtidig ruslidelse og psykisk lidelse - ROP-lidelser [National guideline for assessment, treatment and social rehabilitation of persons with concurrent substance use disorders and mental disorders]. Oslo: The Directorate.

Hysong, S. J., Best, R. G., \& Pugh, J. A. (2006). Audit and feedback and clinical practice guideline adherence: Making feedback actionable. Implement Sci. 1(9), https://doi. org /10.1186/1748-5908-1-9.

Ivers, N. M., Barnsley, J., Upshur, R., Tu, K., Shah, B., Grimshaw, J., et al. (2014). "My approach to this job is...one person at a time": perceived discordance between population-level quality targets and patient-centred care. Can Fam Physician. 60(3), 258-266.

Ivers, N. M., Grimshaw, J. M., Jamtvedt, G., Flottorp, S., O'Brien, M. A., French, S. D., et al. (2014). Growing literature, stagnant science? Systematic review, meta-regression and cumulative analysis of audit and feedback interventions in health care. $J$ Gen Intern Med. 29(11), 1534-1541. https://doi.org/10.1007/s11606-014-2913-y.

Ivers, N. M., Jamtvedt, G., Flottorp, S., Young, J. M., Odgaard-Jensen, J., French, S. D., et al. (2012). Audit and feedback: Effects on professional practice and healthcare outcomes. Cochrane Database Syst Rev. 6(CD000259), 229. https://doi.org/10.1002/ 14651858.CD000259.pub3.

Kristensen, H., \& Hounsgaard, L. (2014). Evaluating the impact of audits and feedback as methods for implementation of evidence in stroke rehabilitation. Br J Occup Ther. 77(5), 251-259. https://doi.org/10.4276/030802214x13990455043520.

LOV-1999-07-02-64 (Ed.). (1999). Lov av 2. juli $1999 \mathrm{nr} .64$ om helsepersonell m.v. (helsepersonelloven).

Mazza, D., Bairstow, P., Buchan, H., Chakraborty, S. P., Van Hecke, O., Grech, C., et al. (2013). Refining a taxonomy for guideline implementation: Results of an exercise in abstract classification. Implement Sci. 8(32), https://doi.org/10.1186/1748-59088-32.

Meehan, T., McCombes, S., Hatzipetrou, L., \& Catchpoole, R. (2006). Introduction of routine outcome measures: Staff reactions and issues for consideration. $J$ Psychiat Ment Health Nurs. 13(5), 581-587. https://doi.org/10.1111/j.1365-2850.2006. 00985.x.

Øvretveit, J. (2010). Improvement leaders: What do they and should they do? A summary of a review of research. Qual Saf Health Care. 19(6), 490-492. https://doi.org/10. 1136/qshc.2010.041772.

Payne, V. L., \& Hysong, S. J. (2016). Model depicting aspects of audit and feedback that impact physicians' acceptance of clinical performance feedback. BMC Health Serv Res. 16(260), https://doi.org/10.1186/s12913-016-1486-3

Pedersen, M. S., Landheim, A., Møller, M., \& Lien, L. (2018a). Acting on audit \& feedback: A qualitative instrumental case study in mental health services in Norway. BMC Health Serv Res. 18(1), 71. https://doi.org/10.1186/s12913-018-2862-y.

Pedersen, M. S., Landheim, A., Møller, M., \& Lien, L. (2018b). Audit and feedback in mental healthcare: Staff experiences. Int J Health Care Qual Assur. 31(7), 822-833. https://doi.org/10.1108/IJHCQA-08-2017-0142.

Potter, J., Fuller, C., \& Ferris, M. (2010). Local clinical audit: Handbook for physician London: HQIP. ([cited 2019 June]. Available from:) https://www.hqip.org.uk/ resource/hqip-local-clinical-audit-handbook-for-physicians/.

Proctor, E. K., Landsverk, J., Aarons, G. A., Chambers, D., Glisson, C., \& Mittman, B. (2009). Implementation research in mental health services: An emerging science with conceptual, methodological, and training challenges. Adm Policy Ment Health. 36(1), 24-34. https://doi.org/10.1007/s10488-008-0197-4.

OSR International (Ed.). (2012). NVivo qualitative data analysis software, version 10(10 ed.). QSR International Pty Ltd..

Reichenpfader, U., Carlfjord, S., \& Nilsen, P. (2015). Leadership in evidence-based practice: A systematic review. Leadership in health services (Bradford, England). 28(4), 298-316. https://doi.org/10.1108/lhs-08-2014-0061.

Saeed, S. A., Bloch, R. M., \& Silver, S. (2015). Role of leadership in narrowing the gap between science and practice: Improving treatment outcomes at the systems level. Psychiatr Q. 86(3), 311-323. https://doi.org/10.1007/s11126-015-9372-4.

Sandström, B., Borglin, G., Nilsson, R., \& Willman, A. (2011). Promoting the implementation of evidence-based practice: A literature review focusing on the role of nursing leadership. Worldviews on Evidence-Based Nursing. 8(4), 212-223. https://doi. org $/ 10.1111 / \mathrm{j} .1741-6787.2011 .00216 . x$

Sederer, L. I. (2009). Science to practice: Making what we know what we actually do. Schizophr Bull. 35(4), 714-718. https://doi.org/10.1093/schbul/sbp040.

Shekelle, P., Woolf, S., Grimshaw, J. M., Schünemann, H. J., \& Eccles, M. P. (2012) Developing clinical practice guidelines: Reviewing, reporting, and publishing guidelines; updating guidelines; and the emerging issues of enhancing guideline implementability and accounting for comorbid conditions in guideline development. Implement Sci. 7(62), https://doi.org/10.1186/1748-5908-7-62.

Stake, R. E. (1995). The art of case study research. Thousand Oaks, Calif: Sage.

Taylor, S. L., Dy, S., Foy, R., Hempel, S., McDonald, K. M., Øvretveit, J., et al. (2011) What context features might be important determinants of the effectiveness of patient safety practice interventions? BMJ Qual Saf. 20(7), 611-617. https://doi.org/10. 1136/bmjqs.2010.049379.

Turner, T., Misso, M., Harris, C., \& Green, S. (2008). Development of evidence-based clinical practice guidelines (CPGs): Comparing approaches. Implement Sci. 3, 45. https://doi.org/10.1186/1748-5908-3-45

van der Zijpp, T. J., Niessen, T., Eldh, A. C., Hawkes, C., McMullan, C., Mockford, C., et al. (2016). A bridge over turbulent waters: Illustrating the interaction between managerial leaders and facilitators when implementing research evidence. Worldviews Evid Based Nurs. 13(1), 25-31. https://doi.org/10.1111/wvn.12138.

van Minnen, A., Hendriks, L., \& Olff, M. (2010). When do trauma experts choose exposure therapy for PTSD patients? A controlled study of therapist and patient factors. Behav Res Ther. 48(4), 312-320. https://doi.org/10.1016/j.brat.2009.12.003.

von Ranson, K. M., Wallace, L. M., \& Stevenson, A. (2013). Psychotherapies provided for eating disorders by community clinicians: Infrequent use of evidence-based treatment. Psychotherapy research : journal of the Society for Psychotherapy Research. 23(3), 333-343. https://doi.org/10.1080/10503307.2012.735377. 

Appendix 



\section{Forespørsel om deltakelse i forskningsprosjektet "Bridging the gap between current practice and recommendations in national guidelines: a qualitative study of mental health services"}

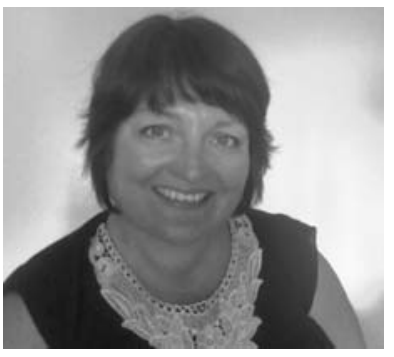

Dette er Monica Stolt Pedersen. Hun er forsker og PhD-stipendiat ved Sykehuset Innlandet HF, Nasjonal kompetansetjeneste for samtidig rusmisbruk og psykisk lidelse (ROP).

Dette er et spørsmål til deg om å delta i en forskningsstudie for å finne ut mer om strategiske beslutninger som følger av utylling og analyse av gap-undersøkelse. Du er valgt ut til å delta i studien fordi du er ansatt i en enhet som skal i gang med en implementeringsprosess. Nasjonal faglig retningslinje for utredning, behandling og oppfølgning av personer med samtidig ruslidelse og psykisk lidelse - ROP-lidelser ble lansert i 2012. Den inneholder et eget implementeringskapittel, samt at Nasjonal kompetansetjeneste ROP har blitt gitt et ansvar for å implementere retningslinja. Hensikten med denne studien er å beskrive og undersøke implementeringsprosessen fra bruken av lokal gap-undersøkelse til praksisendring. Lokal gap-unders $\varnothing$ kelse er startpunkt for implementeringsarbeidet. Studien skal se på hva hvilke strategiske valg som tas for å endre praksis, hvordan bruk av lokal gapunders $\varnothing$ kelse oppleves av ledere og ansatte i enheten, samt om arbeidet endrer praksis i henhold til Nasjonal retningslinje.

\section{Hva innebærer studien?}

Første del av studien er deltakende observasjon. Det betyr at forskeren vil være tilstede ved interne møter $\mathrm{i}$ avdelingen. Det vil bli tatt lydopptak av møtet, samt at forskeren vil ta notater underveis $\mathrm{i}$ møtet. Du vil i tillegg bli spurt om navn, alder, stilling og ansvarsområder. Ca et år etter oppstart vil enhetsledere bli intervjuet individuelt. Samtidig vil det bli foretatt et fokusgruppeintervju med ansatte ved enheten/seksjonen. Informasjonen som kommer frem vil bli oppbevart i en forskningsserver i Sykehuset Innlandet HF, kun tilgjengelig for forskeren og veiledere. Forskeren vil analysere materialet og skrive artikler om funnene. Alle data vil bli anonymisert.

\section{Hva skjer med informasjonen om deg?}

Du vil ikke ha noen spesielle fordeler av studien, men erfaringen fra studien kan komme andre til gode senere. Informasjonen som registreres om deg skal kun brukes slik som beskrevet i hensikten med studien. Det er kun personell knyttet til prosjektet som har adgang til forskningsmaterialet. Det vil ikke være mulig å identifisere deg i resultatene av studien når disse publiseres. Opplysningene blir senest slettet i 2021.

\section{Frivillig deltakelse}

Det er frivillig å delta i studien. Dersom du ikke ønsker å delta, trenger du ikke å oppgi noen grunn, og det får ingen konsekvenser. Dersom du ønsker å delta, undertegner du samtykkeerklæringen på neste side.

Ved spørsmål kan du kontakte Monica Stolt Pedersen: telefon 45447050 eller e-post monica.stolt.pedersen@sykehuset-innlandet.no. 


\section{Samtykke til deltakelse i studien}

"Bridging the gap between current practice and recommendations in national guidelines: a qualitative study of mental health services"

Jeg er villig til å delta i studien

(Signert av prosjektdeltaker, dato)

Jeg bekrefter å ha gitt informasjon om studien

(Signert, forsker, dato) 


\section{Intervjuguide fokusgruppeintervjuer}

Formålet med intervjuene er å undersøke erfaringer og opplevelser med bruk av gap-unders $\emptyset$ kelse i en forbedringsprosess.

Forskningsspørsmål:

1. Hvordan opplever ansatte i et DPS å jobbe med gap-undersøkelser som grunnlag for egen endring i praksis?

Velkommen, takk og «smal-talk». Presentasjoner: Kari og meg, rundt bordet + prosjektet mitt (=innledning/fokus). Hva ble gjort i fjor.

\section{Nytte Hva er gjort $\quad$ Opplevelse}

\section{Tema: Erfaringer/Nytte}

- Tror dere at gap-undersøkelsen har ført noen endringer i posten/enheten? (usikker på om de har fått presentert resultatene sine)

o Hvorfor/hvorfor ikke

o Hvilke endringer

- Er gap-undersøkelser et egnet lederverktøy?

- Kunne dere tenke dere å bruke gap-undersøkelser igjen på ulike områder av praksis?

\section{Tema: Forbedringsprosess/Hva er gjort}

- Hva har dere opplevd som har ført til endringer og har det sammenheng med gap-analyser?

- Hva tenker dere om at praksis blir målt mot anbefalinger i nasjonale retningslinjer?

- Hva tenker dere om hvordan dere fikk resultatene presentert i fjor? Merete kom og viste det frem for hele enheten og dere fikk en kopi av det skriftlig.

(De fleste postene hadde en viss motstand)

\section{Tema: Opplevelse}

- Kan dere si noe om hvordan dere opplevde å få et slikt fokus på egen praksis som resultater fra en gap-undersøkelse er? (Bra, godt, ugreit, unødvendig, nyttig....)

- Synes dere at dere ble delaktige i forbedringsprosessen på en OK måte?

o Hvorfor/hvorfor ikke?

- Har dere blitt mer beviste på egen praksis etter gap-undersøkelser?

- Hva med andre ting, er det $\emptyset \mathrm{kt}$ bevissthet/diskusjon/stadfesting omkring andre områder? (hvem gjør hva, ansvar, etc)

- Er det noe mer dere vil ta opp før vi avslutter? 


\section{Intervjuguide lederintervjuer}

Formålet med intervjuene er å unders $\varnothing$ ke erfaringer og opplevelser med bruk av gap-undersøkelse i en forbedringsprosess.

Forskningsspørsmål:

1. Hvordan opplever ledere i et DPS å jobbe med gap-undersøkelser som grunnlag for egen endring i praksis?

Velkommen, takk og «smal-talk». Presentasjoner: meg (hvis nødv) + prosjektet mitt (=innledning/fokus). Hva ble gjort i fjor.

\section{Nytte Hva er gjort $\quad$ Opplevelse}

- Er gap-undersøkelser et godt/nyttig verktøy i forhold til forbedringsarbeid for deg som leder?

o Hva er bra

o Hva er mindre bra

o Hvordan fungerer gap-undersøkelser for deg som leder?

- Hvordan har du brukt / bruker du resultatene fra gap-undersøkelsen?

- Kan du si noe om hvordan du som leder opplevde å få et slikt fokus på enhetens praksis som resultater fra en gap-undersøkelse er?

- Hva tenker du om at deres praksis blir målt mot anbefalinger i nasjonale retningslinjer?

- Tror du at gap-undersøkelsen har bidratt til noen endringer i posten/enheten?

o På hva slags måte? (nytte)

- Opplever du at gjennomføring av gap-undersøkelser har medført mer diskusjon omkring praksis blant personalet?

o Engasjerende?

- Har du blitt mer beviste på egen praksis/postens praksis etter gap-undersøkelser?

- Hva tenker du er de viktigste tiltakene du som leder har satt i gang i løpet av dette året?

- Hvilken rolle tenker du at fagutviklingssykepleierne har hatt?

o De hadde en del ansvar for gjennomføring av tiltakene, har dette vært godt for deg som leder, eller ført til fragmentering av ansvar?

- Er det noe mer dere vil ta opp før vi avslutter? 


\title{
PERSONVERNOMBUDETS TILRÅDING
}

\author{
Til: \\ Lars Lien \\ Kopi: \\ Fra: $\quad$ Personvernombudet for forskning og kvalitetssikring \\ Saksbehandler: $\quad$ Stein Vetland \\ Dato: $\quad$ 15. november 2013 \\ Offentlighet: $\quad$ Ikke unntatt offentlighet \\ Sak: $\quad$ Personvernombudets tilråding til innsamling og \\ behandling av personopplysninger \\ Saksnummerl 2013/16177 \\ Personvernnummer:
}

\section{Personvernombudets tilråding til innsamling og behandling av personopplysninger for prosjektet "Bridging the gap between current practice and recommendations in national guidelines: a qualitative study of mental health services"}

Viser til innsendt melding om behandling av personopplysninger / helseopplysninger. Det følgende er personvernombudets tilråding av prosjektet.

Med hjemmel i Personopplysningsforskriftens § 7-12 jf. Helseregisterlovens § 36 har Datatilsynet, ved oppnevning av personvernombud, fritatt sykehuset fra meldeplikten til Datatilsynet. Behandling og utlevering av person-/helseopplysninger meldes derfor til sykehusets personvernombud.

Databehandlingen tilfredsstiller forutsetningene for melding gitt $\mathrm{i}$ personopplysningsforskriften § 7-27 og er derfor unntatt konsesjon.

Personvernombudet tilrår at prosjektet gjennomføres under forutsetning av følgende:

1. Databehandlingsansvarlig er Sykehuset Innland HF ved adm. dir.

2. Behandling av personopplysningene / helseopplysninger i prosjektet skjer i samsvar med og innenfor det formål som er oppgitt i meldingen.

3. Data lagres som oppgitt i meldingen. Annen lagringsform forutsetter gjennomføring av en risikovurdering som må godkjennes av Personvernombudet. 
4. Innsendte samtykke benyttes. Eventuelle fremtidige endringer som berører formålet, utvalget inkluderte eller databehandlingen må forevises personvernombudet før de tas i bruk.

5. Kryssliste som kobler avidentifiserte data med personopplysninger lagres som angitt i meldingen og oppbevares separat på prosjektleders avlåste kontor.

6. Dersom formålet eller databehandlingen endres må personvernombudet informeres om dette.

7. Kontaktperson for prosjektet skal hvert tredje år sende personvernombudet ny melding som bekrefter at databehandlingen skjer i overensstemmelse med opprinnelig formål og helseregisterlovens regler.

8. Data slettes eller anonymiseres ved prosjektslutt 2021 ved at krysslisten slettes og eventuelle andre identifikasjonsmuligheter i databasen fjernes. Når formålet med registeret er oppfylt sendes melding om bekreftet sletting til personvernombudet.

Prosjektet er registrert i oversikten over tilrådinger og uttalelser til forskning som Personvernombudet fører for sykehuset. Oversikten er offentlig tilgjengelig.

Lykke til med prosjektet!

Med vennlig hilsen

for Personvernombudet for forskning og kvalitetssikring

Stein Vetland, personvernrådgiver

Kompetansesenter for personvern og informasjonssikkerhet

Stab pasientsikkerhet og kvalitet

Oslo universitetssykehus HF

Epost: personvern@oslo-universitetssykehus.no

Web: www.oslo-universitetssykehus.no/personvern 


\section{Errata}

Navn på kandidat: Monica Stolt Pedersen

Avhandlingstittel: The use and experience of an audit $\&$ feedback cycle when implementing a clinical practice guideline in specialist mental health care in Norway. A qualitative case study

\begin{tabular}{|c|c|c|c|c|}
\hline Side & Linje & Originaltekst & Type & Korrigert tekst \\
\hline iii & $\begin{array}{l}25- \\
26\end{array}$ & Overskrift mangler innført & & $\begin{array}{l}\text { 5.4.3.3 Individual interviews of the } \\
\text { first-line managers... } 47\end{array}$ \\
\hline 1 & 29 & $\begin{array}{l}\text { (the researcher's translation from } \\
\text { Norwegian Directorate of Health, } \\
\underline{2012)}\end{array}$ & Celtf & $\begin{array}{l}\text { (the researcher's translation from } \\
\text { Norwegian Directorate of Health, } \\
\text { 2012) }\end{array}$ \\
\hline 7 & 7 & (2013)estimated & Celtf & (2013) estimated \\
\hline 12 & 6 & , such as EBP & Cor & , such as CPG \\
\hline 17 & 14 & $\begin{array}{l}\text { 3.1 Searching for qualitative studies } \\
\text { on audit andfeedback }\end{array}$ & Celtf & $\begin{array}{l}\text { 3.1 Searching for qualitative studies } \\
\text { on audit and feedback }\end{array}$ \\
\hline 18 & 28 & ...in any order with four words & Cor & ...in any order with three words \\
\hline 20 & 17 & ...change drivers. $A \& F, \ldots$ & Celtf & ...change drivers. $\mathrm{A} \& \mathrm{~F}, \ldots$ \\
\hline 22 & 23 & 2019); there is a ... & Celtf & 2019); there is a ... \\
\hline 23 & 18 & ... records, but lackQI & Celtf & ... records, but lack QI \\
\hline 29 & 4 & $(\mathrm{REF})$ & Cor & (Lincol \& Guba, 2013) \\
\hline 32 & 33 & (Norwegian Directorate of Health) & Celtf & (Norwegian Directorate of Health). \\
\hline 38 & 8 & made by the MSP, 2019) & Cor & made by MSP, 2019) \\
\hline 39 & 19 & $\begin{array}{l}\text {... observation was } \\
\text { chosen(Creswell, ... }\end{array}$ & Celtf & $\begin{array}{l}\text {... observation was chosen } \\
\text { (Creswell, ... }\end{array}$ \\
\hline 41 & 15 & $\begin{array}{l}\text { computer software NVivo } 10 \text { by } \\
\text { QSR International was used to assist } \\
\ldots\end{array}$ & Cor & $\begin{array}{l}\text { computer software NVivo } 10 \text { (QSR } \\
\text { International, 2012) was used to } \\
\text { assist ... }\end{array}$ \\
\hline 45 & 2 & $\begin{array}{l}\text { To analyse substudies } 2 \text { and } 3 \text {, the } \\
\ldots\end{array}$ & Cor & To analyse substudy 2 , the $\ldots$ \\
\hline 45 & 10 & The purpose of these studies ... & Cor & The purpose of this study ... \\
\hline 45 & 11 & $\begin{array}{l}\text { by staff and first-line managers in a } \\
\ldots\end{array}$ & Cor & by staff in a ... \\
\hline 45 & $\begin{array}{l}19 \\
20\end{array}$ & $\begin{array}{l}\ldots \text { transcripts of the individual } \\
\text { interviews with the first-line } \\
\text { managers and the focus group } \\
\text { interviews .... }\end{array}$ & Cor & $\begin{array}{l}\ldots \text { transcripts of the focus group } \\
\text { interviews .... }\end{array}$ \\
\hline 46 & 15 & $\ldots$ generate data for paper $3 \ldots$ & Cor & ... generate data for substudy $3 \ldots$ \\
\hline
\end{tabular}




\begin{tabular}{|c|c|c|c|c|}
\hline 47 & $3-5$ & $\begin{array}{l}\text { Individual interviews of the first- } \\
\text { line managers } \\
\text { The purpose of the interviews ... }\end{array}$ & $\begin{array}{l}\text { Celtf } \\
\text { og } \\
\text { Cor }\end{array}$ & $\begin{array}{l}\text { Individual interviews of the first- } \\
\text { line managers. } \\
\text { 5.4.3.3 Individual interviews of the } \\
\text { first-line managers } \\
\text { The purpose of the interviews ... }\end{array}$ \\
\hline 47 & 9 & 2).Each ... & Celtf & 2). Each ... \\
\hline 54 & 30 & Background and aim & Cor & Slett linje \\
\hline 59 & 15 & $\begin{array}{l}\text { (Kristensen \& Hounsdgaard, 2014) } \\
\text { found ... }\end{array}$ & Cor & (2014) found ... \\
\hline 67 & 19 & $\begin{array}{l}\ldots \text { (Nowell, Norris, White, } \& \\
\text { Moules, 2017)and ... }\end{array}$ & Celtf & $\begin{array}{l}\ldots \text { (Nowell, Norris, White, \& } \\
\text { Moules, 2017) and ... }\end{array}$ \\
\hline 74 & 23 & $\begin{array}{l}\ldots \text { the full A\&F cycle. e of } \\
\text { interdisciplinary ... }\end{array}$ & Cor & $\begin{array}{l}\ldots \text { the full A\&F cycle. } \\
\text { Interdisciplinary ... }\end{array}$ \\
\hline 74 & 26 & To be able to hold on maintain, & Cor & To be able to maintain, \\
\hline 77 & 19 & ... review (Vol. 35, pp.3-23). & Cor & $\begin{array}{l}\text {... review. Health Information \& } \\
\text { Libraries Journal, 35(1), 3-23. }\end{array}$ \\
\hline 77 & 21 & $\begin{array}{l}\text { Angrosino, M., V. . (2016). } \\
\text { Naturalistic Observation Taylor and } \\
\text { Francis. }\end{array}$ & Cor & $\begin{array}{l}\text { Angrosino, M. V. (2016). } \\
\text { Naturalistic Observation. New } \\
\text { York: Taylor and Francis. }\end{array}$ \\
\hline 79 & $\begin{array}{l}18- \\
21\end{array}$ & $\begin{array}{l}\ldots \text { (2nd ed.). Retrieved from } \\
\text { http://search. } \\
\text { ebscohost.com/login.aspx? } \\
\text { direct=true \&db= nlebk\&AN= } \\
1881274 \& \text { site=e host-live }\end{array}$ & Cor & $\begin{array}{l}\text {... (2nd ed.). New York, NY: } \\
\text { Oxford University Press. }\end{array}$ \\
\hline 80 & 30 & $\begin{array}{l}\text { Cochrane Collaboration, t. (2013, } \\
\text { 12.05.2013). Archie Cochrane: the } \\
\text { name behind Cochrane. } \\
\text { Retrieved } 11.27 \text { 2014, from The } \\
\text { Cochrane Colloboration } \\
\text { www.cochrane.org/aboutus/history/ } \\
\text { archie-cochrane\#REF2... }\end{array}$ & Cor & $\begin{array}{l}\text { Cochrane Collaboration. (2013). } \\
\text { Archie Cochrane: the name behind } \\
\text { Cochrane. Retrieved from the } \\
\text { Cochrane Colloboration } \\
\text { https://community.cochrane.org/arc } \\
\text { hie-cochrane-name-behind-cochrane }\end{array}$ \\
\hline 81 & 21 & $\begin{array}{l}\text { (Fifth edition ed.). Los Angeles: } \\
\text { Los Angeles: SAGE. }\end{array}$ & Cor & (5th ed.). Los Angeles: SAGE. \\
\hline 83 & 32 & $\begin{array}{l}\text { Worldviews on Evidence } \square \text { Based } \\
\text { Nursing }\end{array}$ & Celtf & $\begin{array}{l}\text { Worldviews on Evidence-Based } \\
\text { Nursing }\end{array}$ \\
\hline 90 & 28 & $\begin{array}{l}\text {... a guide to best practice (3rd ed. } \\
\text { ed.). Philadelphia: ... }\end{array}$ & Celtf & $\begin{array}{l}\text {... a guide to best practice (3rd ed.). } \\
\text { Philadelphia: ... }\end{array}$ \\
\hline 92 & 7 & $\begin{array}{l}\text {... med kommentarer. 2021, from } \\
\text { Norwegian Directorate ... }\end{array}$ & Cor & $\begin{array}{l}\text {... med kommentarer. Retrieved } \\
\text { 2021, from Norwegian Directorate } \\
\ldots\end{array}$ \\
\hline 94 & $\begin{array}{l}26- \\
27\end{array}$ & $\begin{array}{l}\ldots \text { of evidence } \square \text { based practice: A } \\
\text { literature review focusing on the }\end{array}$ & Celtf & $\begin{array}{l}\text {... of evidence-based practice: A } \\
\text { literature review focusing on the }\end{array}$ \\
\hline
\end{tabular}




\begin{tabular}{|c|c|c|c|c|}
\hline & & $\begin{array}{l}\text { role of nursing leadership. } \\
\text { Worldviews on Evidence } \square \text { Based } \\
\text { Nursing, ... }\end{array}$ & & $\begin{array}{l}\text { role of nursing leadership. } \\
\text { Worldviews on Evidence-Based } \\
\text { Nursing, ... }\end{array}$ \\
\hline 94 & 31 & $\begin{array}{l}\text {... content } \\
\text { analysis.(Research)(Report). } \\
\text { Implementation Science, 10, } 43 .\end{array}$ & Cor & $\begin{array}{l}\text {... content analysis. Implementation } \\
\text { Science, } 10(43), 1-13 \text {. } \\
\text { doi:10.1186/s13012-015-0234-0 }\end{array}$ \\
\hline 96 & 4 & ...Journal. & Cor & ... Journal, 11(2), 63-75. \\
\hline
\end{tabular}

